\title{
Interventions for providers to promote a patient-centred approach in clinical consultations (Review)
}

\author{
Lewin S, Skea Z, Entwistle VA, Zwarenstein M, Dick J
}
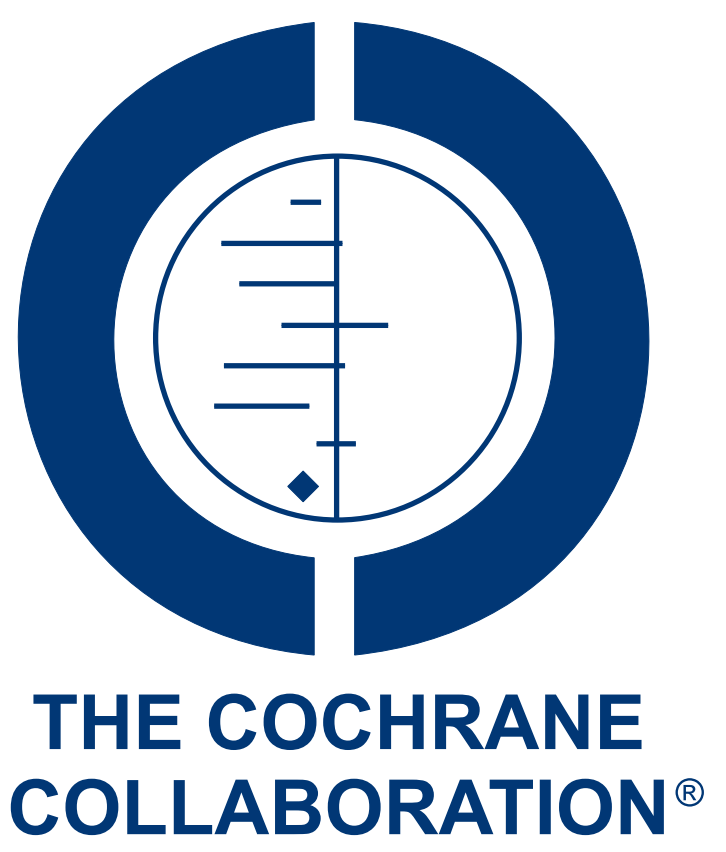

This is a reprint of a Cochrane review, prepared and maintained by The Cochrane Collaboration and published in The Cochrane Library 2001, Issue 4

http://www.thecochranelibrary.com

\section{WILEY}

Interventions for providers to promote a patient-centred approach in clinical consultations (Review)

Copyright $\odot 2012$ The Cochrane Collaboration. Published by John Wiley \& Sons, Ltd. 
TABLE OF CONTENTS

HEADER . . . . . . . . . . . . . . . . . . . . . . . . . . . . . . . . . . . . 1

ABSTRACT . . . . . . . . . . . . . . . . . . . . . . . . . . . . . . . . . . . . . . . . . . . . . . .

PLAIN LANGUAGE SUMMARY . . . . . . . . . . . . . . . . . . . . . . . . . . . . . . . . . . . 2

BACKGROUND . . . . . . . . . . . . . . . . . . . . . . . . . . . . . . . . . . . . . . . . .

OBJECTIVES . . . . . . . . . . . . . . . . . . . . . . . . . . . . . . . . . . . . . .

METHODS . . . . . . . . . . . . . . . . . . . . . . . . . . . . . . . . . . . . . .

RESULTS . . . . . . . . . . . . . . . . . . . . . . . . . . . . . . . . . . . . . . . 6

DISCUSSION . . . . . . . . . . . . . . . . . . . . . . . . . . . . . . . . . . . . . . 14

AUTHORS' CONCLUSIONS . . . . . . . . . . . . . . . . . . . . . . . . . . . . . . . . . . 15

ACKNOWLEDGEMENTS . . . . . . . . . . . . . . . . . . . . . . . . . . . . . . . . . . . . . . . . . .

REFERENCES . . . . . . . . . . . . . . . . . . . . . . . . . . . . . . . . . . . . . . 16

CHARACTERISTICS OF STUDIES . . . . . . . . . . . . . . . . . . . . . . . . . . . . . . . . . . . . . . .

DATA AND ANALYSES . . . . . . . . . . . . . . . . . . . . . . . . . . . . . . . . . . . . . . . . . . . . . . . . .

ADDITIONAL TABLES . . . . . . . . . . . . . . . . . . . . . . . . . . . . . . . . . . . . . . . 53

APPENDICES . . . . . . . . . . . . . . . . . . . . . . . . . . . . . . . . . . . . . 61

WHAT'S NEW . . . . . . . . . . . . . . . . . . . . . . . . . . . . . . . . . . . 62

HISTORY . . . . . . . . . . . . . . . . . . . . . . . . . . . . . . . . . . . . . . . . 63

CONTRIBUTIONS OF AUTHORS . . . . . . . . . . . . . . . . . . . . . . . . . . . . . . . . . .

DECLARATIONS OF INTEREST . . . . . . . . . . . . . . . . . . . . . . . . . . . . . . . . . . . . . . $\quad 63$

SOURCES OF SUPPORT . . . . . . . . . . . . . . . . . . . . . . . . . . . . . . . . . . . . . . . . . . .

INDEX TERMS . . . . . . . . . . . . . . . . . . . . . . . . . . . . . . . . . . . . . . . . . . . . . . 63

Interventions for providers to promote a patient-centred approach in clinical consultations (Review)

Copyright $\odot 2012$ The Cochrane Collaboration. Published by John Wiley \& Sons, Ltd. 


\title{
[Intervention Review] \\ Interventions for providers to promote a patient-centred approach in clinical consultations
}

\author{
Simon Lewin ${ }^{1}$, Zoe Skea $^{2}$, Vikki A Entwistle ${ }^{3}$, Merrick Zwarenstein ${ }^{4}$, Judy Dick ${ }^{5}$ \\ ${ }^{1}$ Preventive and International Health Care Unit, Norwegian Knowledge Centre for the Health Services, Oslo, Norway. ${ }^{2}$ Academic \\ Urology Unit \& Health Services Research Unit, University of Aberdeen, Aberdeen, UK. ${ }^{3}$ Social Dimensions of Health Institute, \\ University of Dundee, Dundee, UK. ${ }^{4}$ Combined Health Services Sciences, Sunnybrook Health Sciences Centre, Toronto, Canada. \\ ${ }^{5}$ Health Systems Research Unit, Medical Research Council of South Africa, Tygerberg, South Africa \\ Contact address: Simon Lewin, Preventive and International Health Care Unit, Norwegian Knowledge Centre for the Health Services, \\ Box 7004 St Olavsplass, Oslo, N-0130, Norway. simon.lewin@nokc.no. \\ Editorial group: Cochrane Consumers and Communication Group. \\ Publication status and date: Edited (no change to conclusions), published in Issue 4, 2012. \\ Review content assessed as up-to-date: 29 December 1999.
}

Citation: Lewin S, Skea Z, Entwistle VA, Zwarenstein M, Dick J. Interventions for providers to promote a patient-centred approach in clinical consultations. Cochrane Database of Systematic Reviews 2001, Issue 4. Art. No.: CD003267. DOI: 10.1002/14651858.CD003267.

Copyright (C) 2012 The Cochrane Collaboration. Published by John Wiley \& Sons, Ltd.

\begin{abstract}
A B S T R A C T
Background

Communication problems in health care may arise as a result of healthcare providers focusing on diseases and their management, rather than people, their lives and their health problems. Patient-centred approaches to care are increasingly advocated by consumers and clinicians and incorporated into training for healthcare providers. The effects of interventions that aim to promote patient-centred care need to be evaluated.
\end{abstract}

\section{Objectives}

To assess the effects of interventions for healthcare providers that aim to promote patient-centred approaches in clinical consultations.

Search methods

We searched: MEDLINE (1966 to December 1999); HEALTH STAR (1975 to December 1999); PsycLIT (1987 to December 1999$)$; CINAHL (1982 to December 1999); EMBASE (1985 to December 1999) and the bibliographies of studies assessed for inclusion.

\section{Selection criteria}

Randomised controlled trials, controlled clinical trials, controlled before and after studies, and interrupted time series studies of interventions for healthcare providers that promote patient-centred care in clinical consultations. Patient-centred care was defined as a philosophy of care that encourages: (a) shared control of the consultation, decisions about interventions or management of the health problems with the patient, and/or (b) a focus in the consultation on the patient as a whole person who has individual preferences situated within social contexts (in contrast to a focus in the consultation on a body part or disease). The participants were healthcare providers, including those in training.

\section{Data collection and analysis}

Two review authors independently extracted data onto a standard form and assessed study quality for each study. We extracted all outcomes other than healthcare providers' knowledge, attitudes and intentions.

Interventions for providers to promote a patient-centred approach in clinical consultations (Review)

Copyright @ 2012 The Cochrane Collaboration. Published by John Wiley \& Sons, Ltd. 


\section{Main results}

Seventeen studies met the inclusion criteria. These studies display considerable heterogeneity in terms of the interventions themselves, the health problems or health concerns on which the interventions focused, the comparisons made and the outcomes assessed. All included studies used training for healthcare providers as an element of the intervention. Ten studies evaluated training for providers only, while the remaining studies utilised multi-faceted interventions where training for providers was one of several components. The healthcare providers were mainly primary care physicians (general practitioners or family doctors) practising in community or hospital outpatient settings. In two studies, the providers also included nurses.

There is fairly strong evidence to suggest that some interventions to promote patient-centred care in clinical consultations may lead to significant increases in the patient centredness of consultation processes. Twelve of the fourteen studies that assessed consultation processes showed improvements in some of these outcomes. There is also some evidence that training healthcare providers in patientcentred approaches may impact positively on patient satisfaction with care. Of the eleven studies that assessed patient satisfaction, six demonstrated significant differences in favour of the intervention group on one or more measures. Few studies examined healthcare behaviour or health status outcomes.

\section{Authors' conclusions}

Interventions to promote patient-centred care within clinical consultations may significantly increase the patient centredness of care. However, there is limited and mixed evidence on the effects of such interventions on patient healthcare behaviours or health status; or on whether these interventions might be applicable to providers other than physicians. Further research is needed in these areas.

\section{PLAIN LANGUAGE SUMMARY}

\section{Training healthcare providers to be more 'patient centred' in clinical consultations}

Problems in health care may arise from healthcare providers focusing on managing diseases rather than on people and their health problems. Patient-centred approaches are increasingly incorporated into training for providers, although 'patient-centredness' is hard to define or measure. Interventions focus on issues like consultation style, developing empathy, and identifying and handling emotional problems. This review of trials found that training in patient-centredness for healthcare providers may improve communication with patients, enable clarification of patients' concerns in consultations and improve satisfaction with care. It is not clear whether this training makes a difference to healthcare use or outcomes.

\section{B A C K G R U N D}

Communication problems between healthcare providers and patients are common. Various studies have found that many patients are dissatisfied with the information that healthcare providers give them (Coulter 1998; Ong 1995; Stewart 1995a; Stewart 1995b). Some communication problems have been attributed to the fact that many healthcare providers focus on diseases and their management, rather than on the people, their lives and their health issues.

The concept of 'patient-centred medicine' was introduced into the medical literature in the mid 1950s by Balint (Balint 1955; Balint 1956), who contrasted it with 'illness-centred medicine' (Brown 1999b). It has its roots within the paradigm of holism, which suggests that people need to be seen in their biopsychosocial entirety (Henbest 1989), and draws medical attention to patients' individual identities (Armstrong 1982).

Despite wide discussion, there is little consensus regarding the meaning of patient-centred medicine. A range of definitions have been developed in the academic and clinical literature (Byrne 1976; McWhinney 1989; Laine 1976; Stewart 1995b; Mead 2000). For example, Byrne 1976 describes patient-centred medicine as an approach whereby the healthcare provider uses the patient's knowledge and experience to guide the interaction within the consultation. For McWhinney 1989, the patient-centred approach is one where 'the physician tries to enter the patient's world, to see the illness through the patient's eyes.' Stewart 1995 provides a more detailed description of the approach, identifying six related components: (1) exploring both the disease and the illness expe- 
rience; (2) understanding the whole person; (3) finding common ground regarding management; (4) incorporating prevention and health promotion; (5) enhancing the doctor-patient relationship, and (6) 'being realistic' about personal limitations and issues such as the availability of time and resources. In a recent narrative review of the ways in which patient-centred care has been defined in the literature, Mead 2000 identified five dimensions: (1) biopsychosocial perspective - the extension of the scope of medicine from the purely biological to the psychological and social levels; (2) the 'patient-as-person' - understanding the individual's experience of illness; (3) sharing power and responsibility; (4) the therapeutic alliance - developing a professional-patient relationship based on care, sensitivity and empathy; (5) the 'doctor-as-person' - selfawareness and attention to emotional cues in the profession-patient relationship.

Different elements of patient-centred care may be differently constructed and valued by different stakeholders, and for different reasons. Some people regard patient-centred care as desirable in its own right, while others see it as a means to particular (and varied) ends. Healthcare providers and healthcare consumers may have varied opinions about which components and which outcomes of patient-centred care are most important. For example, consumers may be more concerned with the extent to which healthcare providers assess consumers' level of knowledge and adjust the consultation accordingly, than with outcomes such as adherence to care plans.

Patient centredness, however defined, is increasingly being advocated and incorporated into the training of healthcare providers. It is now extensively taught to medical practitioners specialising in primary care or family practice care (Kinmonth 1996) and clinical nurse practitioners (Brown 1999a) and is being included in the delivery of care in a range of other settings (Ockene 1995; Ford 1996). The growth of interest in training healthcare providers in patient-centred care has occurred despite a relatively poor empirical understanding of the effects of different interventions to promote it.

Provider-patient communication, an element of patient-centred care, has been examined in more detail. For example, a review to ascertain whether the quality of provider-patient communication impacts on patient health outcomes identified 21 randomized controlled trials (RCTs) and analytic studies. Most of the included studies demonstrated a correlation between effective providerpatient communication and improved patient health outcomes (Stewart 1995a).

Even if the processes of patient-centred care are regarded as desirable in their own right, reliable reassurance that they result in more good than harm should be sought. As with many other complex interventions in health care (Campbell 2000), evidence of the effectiveness, or lack thereof, of interventions to promote patientcentred care is still needed (Toop 1998). Interventions to promote patient-centred care may have varying acceptability and impact across different healthcare settings and cultures, may involve different components from training to organisational restructuring and may impact on both consumer and provider satisfaction with care.

This review examines the effects of interventions directed at healthcare providers that are intended to promote patient-centred care within clinical consultations. It explores the extent to which these interventions succeed in making consultations patient centred. It also examines the effects of the interventions on healthcare behaviours, health status and wellbeing and patient satisfaction with care. For the purposes of this review, we have adopted a broad definition of patient-centred care as including the following two main features:

1. healthcare providers share control of consultations, decisions about interventions or the management of the health problems with patients, and/or

2. healthcare providers focus on the patient as a person, rather than solely on the disease, in consultations.

Within our definition, shared treatment decision making is effectively a sufficient indicator of patient-centred care.

\section{O B J E C T I V E S}

To assess the effects of interventions for healthcare providers that aim to promote patient-centred approaches in clinical consultations. We considered effects on provider-patient interactions, healthcare behaviours (including health service utilisation), patients' health and wellbeing, and patients' satisfaction with care.

\section{METHODS}

\section{Criteria for considering studies for this review}

\section{Types of studies}

Randomised controlled trials (RCTs), controlled clinical trials (CCTs), controlled before and after studies (CBAs), and interrupted time series (with at least 3 data points before and after the intervention).

\section{Types of participants}

Types of healthcare providers: Any, including those training to qualify as healthcare providers.

This review focuses primarily on interventions directed at healthcare providers. Some studies, however, combined interventions 
given directly to patients with interventions for healthcare providers. Most assessed some patient outcomes. We extracted data about the health care that patients received, their health outcomes and their subjective assessments of their consultation experience. There were no restrictions on the types of patients for whom outcome data was extracted.

\section{Types of interventions}

Any intervention directed at healthcare providers and intended to promote patient-centred care within clinical consultations. The review focused on clinical consultations firstly because these are the most usual type of encounters between patients and healthcare providers. Secondly, we wanted to differentiate interventions to promote patient-centred care in the context of clinical healthcare consultations from related interventions that may be intended to promote patient-centred approaches in social support or social care. These interventions are likely to be quite different in terms of their target groups; their outcomes; and their policy implications. An intervention was included if the description of the intervention was adequate to allow review authors to establish that it aimed to increase the patient-centredness of the clinical consultation. By patient-centred care we mean a philosophy of care that encourages: a) shared control of the consultation, decisions about interventions or management of the health problems with the patient, and/or b) a focus in the consultation on the patient as a whole person who has individual preferences situated within social contexts. This is in contrast to a focus in the consultation on a body part or disease. Review authors determined the eligibility of the intervention by examining the introduction to the study report and the description of the intervention. If necessary, additional papers describing the intervention were retrieved to help determine the eligibility of the study.

\section{Exclusions}

- Studies that considered cultural, disability, sexuality or other sensitivity training only for healthcare providers. Although sensitivity to these issues may be necessary for patient-centred care, it is not sufficient in itself to constitute patient-centred care according to our definition.

- Studies that evaluated training in psychotherapy or counselling for healthcare providers. Although much training in psychotherapy and counselling would meet our inclusion criteria, in psychotherapy and counselling (in contrast to most other healthcare situations), communication between healthcare provider and patient is itself the primary treatment. We therefore excluded studies that evaluated training in psychotherapy or counselling unless they specifically indicated that the training aimed to encourage a more patient-centred approach to psychotherapy or counselling than is usually used.

- Studies that trained healthcare providers to deliver a specific, secondary intervention initiated by the health provider (e.g. advice on a healthy diet or smoking cessation) in a patientcentred manner in clinical consultations, regardless of whether the intervention was related to the primary purpose of the consultation as indicated by the patient or their carer. We only classified interventions as patient centred if they promoted a patient-centred approach to care that was integrated with the primary purpose of the consultation rather than being a secondary, 'bolt-on' component of it initiated by the healthcare provider.

\section{Types of outcome measures}

A number of processes and outcomes might be affected by interventions that aim to promote patient-centred care in the clinical consultation. We extracted all outcomes and grouped these in the following categories:

1. Consultation processes, including the extent to which patient-centred care was judged to be achieved in practice;

2. Other healthcare behaviours, including types of care plans agreed; providers' provision of interventions; patients' adoption of lifestyle behaviours; and patients' use of interventions and services;

3. Health status and wellbeing, including physiological measures (for example of blood pressure); clinical assessments (for example of wound healing); patient self-reports of symptom resolution or quality of life; and patient self-esteem;

4. Patient and/or carers' satisfaction with care.

\section{Exclusions}

- Studies that did not include any of the outcomes listed above.

- Studies which measured only healthcare providers' knowledge, attitudes or intentions, for example by assessing their responses to written vignettes describing patient cases. However, studies using simulated patients to assess practice were included.

\section{Search methods for identification of studies}

We searched the following electronic databases:

- MEDLINE (1966 to December1999)

- HEALTH STAR (1975 to December 1999)

- PsycLIT (1987 to December 1999)

- CINAHL (1982 to December 1999)

- EMBASE (1985 to December 1999)

We retrieved documents that included both one or more terms relating to patient-centred care and one or more terms suggesting an evaluative study design. Search strategies were tailored to each database. The strategy for MEDLINE is presented at Appendix 1 as an example.

Bibliographies of studies assessed for inclusion were also searched. Any authors who were contacted for further information on their 
studies were also asked if they were aware of any other published or ongoing studies that would meet our inclusion criteria.

\section{Data collection and analysis}

One review author assessed the potential relevance of all titles and abstracts identified from the electronic searches. Full text copies of all articles that were judged to be potentially relevant from the titles and abstracts were retrieved. Two review authors then independently assessed these retrieved articles for inclusion. Disagreements were resolved by discussion. In several papers, the description of the intervention was not sufficiently detailed to allow the review authors to judge whether it met the review's inclusion criteria. In these cases, the authors were contacted and, where possible, more detailed descriptions and/or materials were then assessed. Data relating to the following was extracted from all included studies using a standard form:

1. participants (healthcare providers and patients), including the problem/s for which patients attended the health service;

2. clinical setting or level of care (e.g. primary, secondary, tertiary etc.) and country;

3. study design and the key features of the study (e.g. whether allocation to groups was at the level of individual healthcare provider or practice/clinic);

4. intervention (full description; stated theoretical/conceptual basis; aims; training strategies used; how delivered/who delivered by; duration and timing; whether patient-centred care was seen as an end in itself or a means to an end). When extracting information on the theoretical/conceptual basis for each intervention, we were interested in which aspects of patientcentred care (according to our initial definition) were addressed by the study. Each intervention was therefore assessed as to whether it encouraged the following: sharing control of the consultation with the patient; sharing the management of the health problems with the patient; a focus in the consultation on the patient as a whole person who has individual preferences situated within social contexts; other.

5. methodological quality (allocation procedure; protection against contamination; whether baseline measurements made; whether outcome assessors were blinded; whether an intention to treat analysis was used; whether there was potential for unit of analysis error for some outcomes and, if so, whether this was acknowledged and/or adjustments made);

6. the number of healthcare providers that were approached, trained and followed up; the number of patients at baseline and the number and proportion followed up;

7. outcomes assessed and timing of outcome assessment;

8. results (effects), organised into four areas: provider and/or patient consultation processes, healthcare behaviours, health status and well being, patient satisfaction with care.

Full descriptions of the interventions were extracted by one review author onto a standard form. The standard forms were then sent to one of the other review authors who checked this descriptive data and then independently extracted the rest of the data, including outcome data. Any discrepancies between the two review authors' data extraction sheets were discussed by the data extractors and resolved by consensus. Where necessary, other members of the review team were asked to consider and discuss problems. Where data were missing, attempts were made to contact the authors of the studies to obtain the information.

Following data extraction, all review authors independently assessed the intensity of patient centredness and teaching/training tactics for each intervention in the included studies using the rubrics presented below. We intended to create subgroups of interventions, based on intensity of patient centredness and teaching tactics, which could then be related to outcomes.

1) patient centredness:

- weak (0): The main focus of the intervention is on encouraging healthcare providers to adopt specific strategies for dealing with certain conditions (e.g. asthma, diabetes), although training in patient-centred care is part of it. The intervention aims to promote only one of the following three 'behaviours' (or more than one, but only weakly): encourage sharing control of the consultation; sharing the management of the health problems with the patient; a focus in the consultation on the patient as a whole person who has individual preferences situated within social contexts.

- medium (1): The intervention is primarily about encouraging healthcare providers to adopt patient-centred behaviours, as well as use specific strategies for dealing with certain conditions (e.g. asthma, diabetes). The intervention usually aims to promote two of the three 'behaviours' listed above.

- strong (2): The main focus of the intervention is on encouraging healthcare providers to adopt patient-centred behaviours in the clinical consultation. The intervention usually aims to promote all three of the 'behaviours' listed above.

2) teaching tactics:

- weak (0): Usually one session only; less than a half day of training in total, with a high proportion of didactic content.

- medium (1): Usually more than one session and more than a half day of training in total, with some interactive components.

- strong (2): Usually three or more sessions and more than one day of training in total. Includes opportunity to practice skills within sessions and/or between sessions; follow up support/ encouragement throughout the study period; additional patientcentred educational reading material; training in the use of a patient-centred tool to facilitate the patient centredness of the consultation.

Each review author's scores for each parameter on each intervention were then added up, to give an overall score for the intensity of 
patient centredness and of teaching tactics for each intervention. The agreement between raters was assessed by calculating a Kappa statistic. These Kappa scores were low (see Description of studies), indicating poor agreement among the raters. We therefore decided not to conduct the planned sub-group analyses based on intensity of patient centredness and teaching tactics.

\section{Methodological quality}

Two review authors independently assessed the quality of each eligible study using the criteria listed below:

1. Procedure for allocation to intervention and control groups blind and secure?

2. Protection against contamination from intervention group to control group?

3. Outcome assessors blind?

4. Intention to treat analysis used?

5. Baseline measurements made?

6. Potential for unit of analysis error for some outcomes? If yes, was the problem acknowledged and were any adjustments/ corrections made?

For each criterion, the review authors indicated whether it was 'done', 'not done' or 'unclear'. Any discrepancies were resolved by discussion. We excluded studies that were so compromised by flaws in their design or execution as to be unlikely to provide reliable data. The reasons for such exclusions are listed in the table Characteristics of excluded studies.

\section{Consumer participation}

Several consumer advocates commented on the protocol and gave input into the interpretation of the findings. This was organised as part of the refereeing process used by the Cochrane Consumers and Communication Review Group.

\section{Analysis}

The heterogeneity of the aims, format and content of the interventions; the healthcare providers and patients involved in the studies; the clinical settings in which the studies were conducted; and the outcomes assessed was substantial. We judged it inappropriate to combine the results of included studies quantitatively, as an overall estimate of effect would have little practical meaning in these circumstances. A descriptive review of the included studies was therefore performed. We grouped together studies that compared broadly similar types of interventions:

1. Patient-centred training for healthcare providers compared with no intervention;

2. Patient-centred training for providers plus patient-centred training or materials for patients compared with no intervention;

3. Patient-centred training for providers plus condition or behaviour-specific training or materials (e.g. focusing on the management of asthma or diabetes mellitus) for both providers and patients compared with no intervention or with behaviourspecific materials for providers only;

4. Patient-centred training for providers, patient-centred materials for patients plus condition- or behaviour-specific materials for both providers and patients compared with condition- or behaviour-specific materials for both providers and patients.

We prepared tables that summarise:

1. The Characteristics of included studies. This summarises and describes the interventions delivered; the methods used; the outcomes assessed and how these were measured;

2. The results of all the outcomes assessed, including all numerical data (see Additional tables).

\section{R E S U L T S}

\section{Description of studies}

See: Characteristics of included studies; Characteristics of excluded studies.

\section{Results of the search}

In this section we describe the studies included in the review, examining the types of comparisons made; the characteristics of the interventions, including the intensity of patient centredness and teaching tactics; the characteristics of the participants, including providers and patients; and the types of outcomes measured.

Electronic searching identified 5260 titles and abstracts. 135 of these were judged to potentially meet the entry criteria and the full articles were retrieved for further detailed assessment. Seventeen studies met the review inclusion criteria: fifteen randomised controlled trials (Clark 1998; Howe 1996; Joos 1996; Kinmonth 1998; Langewitz 1998; Levinson 1993; Lewis 1991; Meland 1997; Pill 1998; Putnam 1988; Robbins 1979; Roter 1995; Smith 1995; Smith 1998; Thom 1999), and two controlled clinical trials (Cope 1986; Roter 1998), the latter being a controlled before and after study.

\section{Included studies}

All of the included studies were published in English. One study reported in Hebrew is still to be assessed for inclusion (Oleinik 1990). Ten randomised controlled trials and one controlled clinical trial were conducted in North America; three randomised controlled trials took place in the United Kingdom; one in Switzerland; and one in Norway. One controlled clinical trial was set in Trinidad and Tobago.

Considerable heterogeneity is evident between the included studies in terms of the aims, format and content of interventions; the 
clinical condition(s) on which they focused; the types of participating health professionals and patients; the outcomes measured; and the comparisons made. All included studies used training for healthcare providers as an element of the intervention. Ten studies used training for providers only, while the remaining studies utilised multi-faceted interventions where training for providers was one of several components.

In three randomised controlled trials the unit of randomisation was the practice (Meland 1997; Kinmonth 1998; Pill 1998) and for the remaining studies the unit of randomisation or allocation was the individual healthcare provider.

As outlined above, studies which involved broadly similar interventions were grouped together, giving four comparison groups:

(a) Patient-centred training for providers was compared with no training intervention in eleven studies (Cope 1986; Howe 1996; Langewitz 1998; Levinson 1993; Putnam 1988; Robbins 1979; Roter 1995; Roter 1998; Smith 1995; Smith 1998; Thom 1999). One study evaluated patient-centred training for providers using a controlled before and after design (Roter 1998). Roter 1995 was a three-armed trial comparing two different patient-centred training programmes for providers with no training intervention for the control group.

(b) Patient-centred training for providers plus patient-centred training or materials for patients was evaluated in three studies. In two studies the comparison was with no training intervention (Joos 1996; Lewis 1991), while in the other the comparison was with condition-specific materials for both providers and patients (Pill 1998).

(c) Patient-centred training for providers plus condition- or behaviour-specific training or materials for both providers and patients was evaluated in two randomised controlled trials. In one the comparison was with no training intervention (Clark 1998), while in the other the comparison was with behaviour-specific materials only for providers (Meland 1997).

(d) Patient-centred training for providers, patient-centred materials for patients plus condition-or behaviour-specific materials for both providers and patients was compared with condition- or behaviour-specific materials for both providers and patients in one study (Kinmonth 1998).

\section{Characteristics of the interventions}

Detailed descriptions of the interventions appear in the table Characteristics of included studies.

1) Aims and conceptual basis of the interventions:

The aims and conceptual bases of the studies varied widely. In particular, there was a gradation from interventions in which improving the patient centredness of care was the primary goal to others in which patient-centred care was seen primarily as a method of changing patient behaviour or improving a particular healthcare outcome. In this second group of interventions, improving the patient centredness of care can be seen as 'instrumental' in that it was used as a means to improve another health behaviour or healthcare outcome.

Studies in which improving the patient centredness of care was the primary goal tended to focus on communication skills or interpersonal skills as important in their own right. Some of these studies also explicitly recognised that such skills could be important in promoting patient participation; patient satisfaction; improving health outcomes etc. All studies, except for Meland 1997, Pill 1998 and Howe 1996 could be included in this group. Some interventions recognised the improvement of communication skills as a means of improving patient participation or partnership in healthcare discussions and treatment decisions (Cope 1986; Joos 1996; Langewitz 1998; Levinson 1993; Lewis 1991; Smith 1995; Thom 1999). Some recognised the improvement of communication skills as a means to improving particular healthcare behaviours or outcomes (Clark 1998; Kinmonth 1998; Putnam 1988; Robbins 1979; Roter 1995; Roter 1998; Smith 1998).

In two studies (Meland 1997; Pill 1998), the intervention seemed to aim to improve communication skills as a means to achieving the primary objective of improving particular healthcare behaviours or outcomes. For example, Meland 1997 aimed to change specific lifestyle behaviours in men at risk of coronary heart disease. In these studies, the focus was primarily on encouraging patient behaviour change through negotiating individual care plans and behaviour change targets, based on the patient's readiness to change, and then supporting patients in their choices.

One study, which focused on improving the detection of psychological problems, did not fit into either of the two groups described above (Howe 1996). This study aimed to determine whether general practitioners could improve their ability to detect psychological distress in their patients following an educational intervention which included feedback on patient consultations.

2) Intensity of patient centredness:

There was a wide range of intensity of patient centredness among the interventions. Four interventions achieved an overall patient centredness score of 7 or above out of 10 (Joos 1996; Langewitz 1998; Lewis 1991; and one of the two training interventions evaluated in Roter 1995). Eight interventions achieved an overall patient centredness score of 4 to 6Healthcare (Clark 1998; Cope 1986; Howe 1996; Kinmonth 1998 (for the nurse training component); Pill 1998; Putnam 1988; Roter 1998; Thom 1999). Six interventions achieved an overall patient centredness score of less than 4 (Kinmonth 1998 (for the GP training component); Meland 1997; Robbins 1979; Roter 1995 (for the second intervention); Smith 1995; Smith 1998). The Kappa statistic for ratings of intensity of patient centredness was 0.388 (range: $0.021-0.817$ ), indicating low levels of agreement across review authors.

3) Intensity of teaching tactics:

The intensity of teaching tactics also varied widely. Seven interventions achieved an overall teaching tactics intensity score of 7 or above out of 10 (Joos 1996; Kinmonth 1998 (for the nurse training component); Langewitz 1998; Pill 1998; Robbins 1979; Smith 
1995; Smith 1998). Six interventions achieved an overall teaching tactics intensity score of 4 to 6 (Lewis 1991; Putnam 1988; Roter 1995 (for both interventions); Roter 1998; Thom 1999). Six interventions achieved an overall teaching tactics intensity score of less than 4 (Clark 1998; Cope 1986; Howe 1996; Kinmonth 1998 (for the GP training component); Levinson 1993; Meland 1997). The Kappa statistic for ratings of intensity of teaching tactics was 0.547 (range: $0.228-0.835$ ), indicating moderate levels of agreement across review authors.

4) Characteristics of the persons delivering the intervention:

Various kinds of healthcare providers delivered the interventions in six studies (Cope 1986; Langewitz 1998; Pill 1998; Putnam 1988; Robbins 1979; Smith 1995) and one study used a mixture of healthcare providers and academics (Roter 1995). In one study, university teaching staff delivered the intervention (Smith 1998) and two studies stated that they used experienced facilitators to deliver the intervention (Kinmonth 1998; Levinson 1993). The interventions were self-directed in two studies (Howe 1996; Lewis 1991). The remaining five studies did not state by whom the interventions were delivered (Clark 1998; Joos 1996; Meland 1997; Roter 1998; Thom 1999).

Only three studies stated that the educators were experienced in teaching communication skills (Levinson 1993; Kinmonth 1998; Roter 1995).

5) Involvement of consumers in the design, development and delivery of the intervention:

Only one study (Kinmonth 1998) appeared to have involved consumers in the development of the intervention. None of the studies appeared to have involved consumers in the delivery of the intervention.

\section{Participants}

1) Healthcare providers:

The providers were mainly primary care physicians (general practitioners or family doctors) practising in community or hospital outpatient settings. In two studies, the providers also included nurses (Kinmonth 1998; Pill 1998). The clinical experience of providers varied both within and across studies, ranging from providers who were in their first or second postgraduate year to providers with more than 20 years of clinical experience. The study sample sizes also varied. In the three studies randomised by practice, the numbers of practices included ranged from 22-41. For the remaining studies, the total number of individual providers ranged from 1878.

The process through which providers were selected to participate in the studies varied. In two studies, participation in the training programmes appeared to be compulsory (as part of postgraduate training) with voluntary but paid participation in the evaluation component (Smith 1995; Smith 1998). All residents who took part in the training were invited to be evaluated in one of the studies (Smith 1998) whereas the other study invited only two classes to participate in the voluntary evaluation component (Smith 1995). Cope 1986 assessed and gave feedback to 18 of 68 internal medicine residents in one hospital (those residents with the lowest satisfaction scores), although it was unclear whether participation was compulsory or not.

In the remaining studies, participation appeared to be voluntary, with three studies reporting that they approached all residents or physicians in specific hospitals, clinics or practices (Joos 1996; Lewis 1991; Robbins 1979). One study approached only residents with contracts longer than 18 months (Langewitz 1998) and another approached only residents who had rotations within a certain specified period (Putnam 1988).

Two studies reported that they approached all practising physicians in their study area (Levinson 1993; Roter 1998). One study identified physicians from a 1992 survey of community-based family physicians in their local area (Thom 1999), another identified local paediatricians from various directories (Clark 1998), while a third study identified physicians from the mailing lists of local medical societies and by telephone solicitation (Roter 1995). One study approached all GPs who were part-time faculty teachers in one county of Norway (Meland 1997), and another approached all those that responded to a postal survey sent to a random sample of GP principals (Howe 1996).

Two studies approached practices with at least four GPs and a registered diabetes service (Kinmonth 1998) or practices that had been committed for at least two years to an annual peer review based clinical audit of diabetic care (Pill 1998).

In 14 of the 17 studies, the percentage of invited providers who agreed to participate ranged from 13 per cent to 100 per cent. In three studies this percentage was unclear (Clark 1998; Levinson 1993; Thom 1999).

2) Patients:

Patients were the direct recipients of interventions in six studies (Clark 1998; Joos 1996; Kinmonth 1998; Lewis 1991; Meland 1997; Pill 1998). In eleven studies, patients participated only in assessing the outcomes of the interventions (all studies except those listed above).

All but one of the studies (Langewitz 1998) used 'real' rather than simulated patients, while one study used both real and simulated patients (Smith 1995). In nine studies, the patients were adults presenting in primary care with various problems (Cope 1986; Howe 1996; Levinson 1993; Putnam 1988; Robbins 1979; Roter 1995; Smith 1995; Smith 1998; Thom 1999). The other studies were more narrowly focused on patients with particular medical conditions: adults with type 2 diabetes (Kinmonth 1998; Pill 1998); adults with a chronic condition (Joos 1996; Roter 1998); and adult males with high coronary heart disease risk (Meland 1997). In the study that used simulated patients only, these presented with a common medical and psychosocial problem (Langewitz 1998). In two studies the patients were children accompanied by their parents: in one the children had asthma (Clark 1998) and in the other the children presented with a range of different problems 
(Lewis 1991). The numbers of patients included in the studies ranged from four to 2764 . The study which included only four patients (Langewitz 1998) was organised such that each of the 42 medical students enrolled in the trial interviewed two simulated patients before and two simulated patients after the intervention (i.e. four simulated patients were used in total). This is equivalent to 84 patients before and 84 patients following the intervention.

\section{Outcomes}

The studies varied in terms of the outcome categories they used. There was wide variation in the types of behaviours/aspects measured within each outcome category.

1) Consultation processes: Fourteen studies assessed a range of consultation features, including provider behaviours relating to helping clarify patients' concerns/beliefs; provider behaviours relating to finding relevant information; providers' ability to convey information about results, communicate about treatment options and/or detect emotions; provider behaviours relating to involving patients in discussions/treatment decision making; the extent to which open-ended questions were used by providers; the extent of provider-patient psychosocial talk; provider levels of empathy/ humaneness; levels of provider-patient rapport; provider ability to motivate or to be reassuring and encouraging to the patient; agreements between provider and patient on main concerns; and provider ability to detect psychological distress.

These features of consultations were assessed by third party coding in five studies (Joos 1996; Lewis 1991; Putnam 1988; Roter 1995; Roter 1998), third party rating in four studies (Langewitz 1998; Robbins 1979; Pill 1998; Smith 1998) and by third party coding and rating in one study (Levinson 1993). Two studies used patient self-report (Kinmonth 1998; Thom 1999) and one study used parent self-report (Clark 1998). One study measured providers' psychological detection rate using a six point scale indicating the degree of psychological disturbance in the patient (Howe 1996).

2) Patient satisfaction: Eleven studies assessed various aspects of patient satisfaction including: satisfaction with 'art of care' and 'technical quality of care'; proportion of patients who would recommend their doctor to a friend; satisfaction with opportunities to disclose/provider empathy/comparison of provider with others; confidence in provider's abilities; satisfaction with the visit overall; satisfaction with the provider's communication skills/personal manner; and satisfaction with treatment received.

3) Healthcare behaviours: Eight studies assessed other healthcare behaviours including patients' use of medication; appointment adherence; and lifestyle behaviours such as smoking, diet and exercise.

4) Health status and wellbeing: Eight studies assessed health status indicators such as body mass index; weight; blood pressure; cholesterol levels; clinical complications; psychosocial well being/ distress levels; and symptom status.

\section{Risk of bias in included studies}

\section{Study design}

Of the 17 studies included in the review, 15 were RCTs and two were CCTs (Cope 1986; Roter 1998), the latter being a CBA. For several trials the results of certain outcomes measures were presented as within-group differences, measured before and after the intervention (Putnam 1988; Robbins 1979; Roter 1998). These results are subject to the same problems of interpretation as those from uncontrolled before and after studies. Apart from Robbins 1979 , insufficient data were reported to calculate post-intervention between group differences for these studies.

\section{Method of allocation}

Of the 15 RCTs, one study reported a blind and secure allocation procedure in which allocation was made by computer (Kinmonth 1998). The remaining studies did not provide clear descriptions of the randomisation process (Clark 1998; Howe 1996; Joos 1996; Langewitz 1998; Levinson 1993; Lewis 1991; Meland 1997; Pill 1998; Putnam 1988; Robbins 1979; Roter 1995; Smith 1995; Smith 1998; Thom 1999). One CCT used an allocation procedure which did not appear to be blind and secure in that the participants were assigned in an alternating fashion to intervention or control groups (Cope 1986). In the other CCT (Roter 1998), physicians volunteered to be part of the intervention group. The remaining physicians were allocated to the control group.

\section{Protection against contamination}

Attempts to ensure protection from contamination from the intervention to the control group were reported in one study only (Putnam 1988) in which intervention group physicians were asked not to discuss the intervention with control group physicians. In two studies there appeared to be potential for contamination that was not addressed. One of these recruited doctors from the same clinic into both the intervention and control groups (Roter 1998) while another recruited intervention and control physicians from the same training class (Smith 1995). In the remaining studies, it was unclear whether protection against contamination was adequate (Clark 1998; Cope 1986; Howe 1996; Joos 1996; Kinmonth 1998; Langewitz 1998; Levinson 1993; Lewis 1991; Meland 1997; Pill 1998; Robbins 1979; Roter 1995; Smith 1998; Thom 1999).

\section{Blinding of outcome assessors}

Blinding of outcome assessors was reported or clear in 11 studies (Kinmonth 1998; Langewitz 1998; Levinson 1993; Lewis 1991; Pill 1998; Putnam 1988; Robbins 1979; Roter 1995; Roter 1998; Smith 1995; Smith 1998). For six studies it was unclear whether 
blinding of outcome assessors had been ensured (Clark 1998; Cope 1986; Howe 1996; Joos 1996; Meland 1997; Thom 1999).

\section{Use of intention to treat analysis}

In one study no loss to follow-up was reported (Langewitz 1998). Five studies explicitly adopted an intention to treat approach to statistical analysis (Cope 1986; Kinmonth 1998; Meland 1997; Robbins 1979; Smith 1995). Two studies stated that an intention to treat approach was not used (Roter 1995; Roter 1998). In the remaining nine studies, it was unclear whether this approach had been used (Clark 1998; Howe 1996; Joos 1996; Levinson 1993; Lewis 1991; Pill 1998; Putnam 1988; Smith 1998; Thom 1999).

\section{Baseline measurement}

Baseline measures of health provider performance or patient outcomes were conducted in 15 studies (Clark 1998; Cope 1986; Howe 1996; Joos 1996; Kinmonth 1998; Langewitz 1998; Levinson 1993; Meland 1997; Pill 1998 [for certain measures only]; Putnam 1988; Robbins 1979; Roter 1998; Smith 1995; Smith 1998; Thom 1999), while two RCTs did not collect such data at baseline (Lewis 1991; Roter 1995). In twelve studies, no significant differences were found across study groups prior to intervention (Cope 1986; Howe 1996; Joos 1996; Kinmonth 1998; Langewitz 1998; Meland 1997; Pill 1998 [except for two measures]; Putnam 1988; Robbins 1979; Roter 1998; Smith 1998; Thom 1999). One study reported differences between the intervention and control groups at baseline, but these were not significance tested (Smith 1995). No data was provided on baselines differences between the intervention and control groups in two studies (Clark 1998; Levinson 1993).

\section{Potential for unit of analysis error for some outcomes}

Fifteen of the studies included in this review (Clark 1998; Cope 1986; Howe 1996; Joos 1996; Kinmonth 1998; Levinson 1993; Lewis 1991; Meland 1997; Pill 1998; Putnam 1988; Roter 1995; Roter 1998; Smith 1995; Smith 1998; Thom 1999) randomised health providers or practices / clinics to intervention or control groups and then collected some data at the level of the individual patient. Standard statistical methods that do not account for the cluster effects that may arise in such data will result in the overestimation of the significance of the intervention. The remaining two studies (Langewitz 1998 in which each physician was assessed on two simulated patients pre- and post-intervention and Robbins 1979 in which each physician was assessed on one patient pre- and post-intervention) did not include patient clusters.

The potential for a unit of analysis error for some outcomes was acknowledged in five of the 15 RCTs in which it might have occurred (Clark 1998; Joos 1996; Kinmonth 1998; Roter 1995; Thom 1999). The other 10 studies did not explicitly acknowledge this problem (Cope 1986; Howe 1996; Levinson 1993; Lewis 1991;
Meland 1997; Pill 1998; Putnam 1988; Roter 1998; Smith 1995; Smith 1998). Twelve studies made adjustments for clustering in the analysis (Clark 1998; Howe 1996; Joos 1996; Kinmonth 1998; Levinson 1993; Lewis 1991; Putnam 1988; Roter 1995 [ANOVA: patients nested within physicians and physicians within study groups]; Roter 1998; Smith 1995; Smith 1998; Thom 1999), while three studies made no such adjustments (Cope 1986; Pill 1998; Meland 1997).

\section{Effects of interventions}

In this section we report on the results by outcome category for each of the four comparison groups. The types of outcome assessed varied partly in accordance with the aim and nature of the intervention(s) evaluated. Where large numbers of outcomes were measured (generally for consultation processes), we present here only selected key results, including those judged to be the most relevant as indicators of patient-centred care. For all studies, full details of all reported outcomes are provided in the additional tables section. Unless otherwise stated, all statistically significant differences are in favour of the intervention group/s.

\section{Comparison I}

Patient-centred training for providers compared with no intervention.

Nine RCTs (Howe 1996; Langewitz 1998; Levinson 1993; Putnam 1988; Robbins 1979; Roter 1995; Smith 1995; Smith 1998; Thom 1999), and two CCTs (Cope 1986; Roter 1998) were included in the first comparison group.

(a) Consultation processes (Table 1)

The nine studies that examined consultation processes reported between one and 30 outcomes each within this category. The outcomes assessed included providers' humanistic and empathic behaviours and a range of provider and patient verbal behaviours in the consultation.

Two studies measured outcomes relating to provider detection and/or management of emotional distress (Howe 1996; Roter 1995). Howe 1986 reported that providers in the intervention group were able to detect a statistically significantly greater amount of psychological distress in patients who had previously been identified as having high emotional distress scores, within three months post intervention.

Roter 1995 compared two types of patient-centred training for providers (emotion handling and problem defining skills training) with no intervention (Roter 1995). The study reported 22 outcomes relating to consultation process, of which six were statistically significant for the emotion handling skills group compared to control. For the problem defining skills group, eight outcomes were statistically significant compared to control. The providers trained in problem defining skills only recognised a significantly greater amount of emotional problems and distress than 
the control group of providers in patients previously identified as having high emotional distress scores (post intervention duration not stated). The difference was not significant for the providers trained in emotion handling skills only compared with the control group. The providers trained in problem defining skills only used significantly more strategies overall for managing emotional problems than the control group and providers trained in emotion handling skills only, and gave significantly more counselling to their patients than the control group (a full list of behaviours measured including all numerical data is provided in the additional tables section). For clinical proficiency in dealing with simulated patients with emotional distress, providers trained in problem defining skills achieved a significantly better overall score than the control group, although this difference was not significant for the providers trained in emotion handling skills only compared with the control group (a full list of behaviours measured is provided in the additional tables section). In their performance with actual patients (post intervention duration not stated), providers trained in both the emotion handling skills and problem defining skills groups used significantly more targeted emotion handling behaviours and problem defining behaviours overall than those in the control group (Roter 1995). In their performance with simulated patients, providers trained in emotion handling skills only used significantly more targeted emotion handling behaviours and problem defining behaviours overall than providers in the control group. The difference was not significant for providers trained in problem defining skills compared with the control group.

Two studies assessed providers' humanistic and empathic behaviours (Robbins 1979; Thom 1999). Robbins 1979 assessed ten outcomes related to consultation processes. Five of these (provider levels of empathy; number of empathic responses; medical, psychosocial, and affective responses) were statistically significantly different in the intervention group compared with the control group, with immediate post-intervention results being better than pre-intervention results. There were no significant findings for other types of responses, such as exploratory, listening, honest labelling, yes/no, and semi-exploratory responses. Thom 1999 measured one consultation process outcome: patients' perceptions of their providers' humaneness during a consultation visit approximately six months post intervention. No statistically significant differences between the intervention and control groups were reported (Thom 1999).

Other studies measured a range of provider and patient verbal behaviours in the consultation. Langewitz 1998 assessed 30 consultation processes, of which 14 were reported as showing statistically significant differences between groups. The study reported that, at approximately ten months post intervention, providers in the intervention group were significantly more likely than those in the control group to have structured the consultation well, used a more patient-centred communication style, and been willing to involve patients in decision making.

Putnam 1988 examined 15 consultation processes, of which seven were reported as showing statistically significant differences. Immediately after the intervention, there was a significant increase in the mean frequency of patient exposition (defined as patient statements including objective information or thoughts, feelings, perceptions and intentions) in the intervention group, although there was not a significant increase in percentage of provider explanation. There were no significant before and after results reported for either the intervention or control group for the mean total number of patient and provider utterances.

Roter 1998 assessed 29 outcomes relating to doctor and patient verbal behaviours during consultations, of which nine were reported as showing statistically significant differences. Providers in the intervention group were significantly more likely than the control group to use open questions, and patients of providers in the intervention group gave significantly more medical information to the doctor than patients in the control group (post intervention duration not stated). In addition, patients of providers in the intervention group talked more in general than patients in the control group. There were no significant differences between the intervention and control group for the following: doctor emotional talk; doctor counsels (medical); doctor counsels (lifestyle); ratio of doctor:patient talk; patient emotional talk; patient questions; and patient information giving (lifestyle).

Smith 1998 measured 15 interviewer behaviours which were applied to consultations with actual and simulated patients approximately one month post intervention. There were statistically significant differences between intervention and control group for four of these behaviours in real patient interviews and for 13 in simulated patient interviews. The overall quality of the interviews in terms of the three skill areas was assessed. Ratings were significantly higher for providers in the intervention group for overall interview quality with real patients; in data gathering with simulated patients; in informing and motivating simulated patients; and in managing somatization in simulated patients.

Levinson 1993 assessed 11 consultation process outcomes. The provider behaviours assessed included: positive talk; biomedical information giving; closed-ended questions; open-ended questions; and psychosocial talk. The patient behaviours assessed included biomedical information giving and psychosocial talk. No significant differences between the intervention and control groups were reported.

(b) Patient satisfaction (Table 2)

The seven studies that assessed patients' satisfaction with aspects of the provider's manner and/or abilities, or with the visit in general, reported between one and five outcomes each within this category. Cope 1986 examined three patient satisfaction measures, and all three showed statistically significant differences. Immediately after their post intervention medical visit, patients in the intervention group were significantly more satisfied overall with their provider's manner and abilities than patients in the control group.

Smith 1995 reported five patient satisfaction measures of which two showed statistically significant differences. Immediately after 
their post intervention medical visit, patients in the intervention group had significantly more confidence in their providers and were generally more satisfied with their medical visits than patients in the control group, although no significant differences between the groups were reported for patients' satisfaction with opportunities to disclose, provider empathy and comparison of provider with others.

The five remaining studies reported no statistically significant differences between the intervention and control groups for either general satisfaction scores or for specific aspects of patient satisfaction with their provider's manner and/or abilities (Langewitz 1998; Putnam 1988; Roter 1998; Smith 1998; Thom 1999). Langewitz 1998 reported that the proportion of patients who stated that they would recommend their doctor to a friend significantly increased in the intervention group following the intervention.

(c) Healthcare behaviours (Table 3)

The three studies that assessed aspects such as behavioural, medication, and/or appointment adherence reported between three and four outcomes each within this category. Putnam 1988 reported on behavioural, medication and appointment adherence, none of which showed any statistically significant changes from before to after the intervention in either the intervention or control group. Thom 1999 measured continuity with the study provider, self-reported adherence to advice or treatment, number of referrals and number of diagnostic tests ordered. None of these showed any significant differences between the two groups approximately six months after post intervention medical visit. Roter 1995 found no significant difference between either of two intervention groups (providers trained in problem defining skills only or providers trained in emotion handling skills only) and the control group for the proportion of emotional distressed patients revisiting providers at two weeks, three months and six months after the post intervention medical visit.

(d) Health status and well being (Table 4)

Two studies assessed one outcome each that fell into the health status and well being category. Roter 1995 measured levels of emotional distress in patients previously identified as having high distress scores. They reported that patients of providers trained in problem defining skills only showed significant reductions in emotional distress at each time point (two weeks, three months, six months from post intervention medical visit) compared with control patients. There was no significant difference in levels of emotional distress for patients of providers trained in emotion handling skills only, compared with control patients.

Putnam 1988 reported no significant differences within the intervention or control groups for general symptom improvement preand post- intervention.

\section{Comparison 2}

Patient-centred training for providers plus patient-centred materials for patients compared to no intervention (Joos 1996; Lewis
1991) or to condition-specific materials for provider and patient (Pill 1998). All three studies included in this group are RCTs.

(a) Consultation processes (Table 5)

All three studies assessed consultation processes, including provider behaviours and a range of patient behaviours such as initiating discussion on a topic, responses, information recall and participation in healthcare discussions. For this category between three and six outcomes were assessed per study.

Joos 1996 examined three consultation process measures, of which two showed statistically significant differences. Providers in the intervention group elicited patient concerns in a greater proportion of visits than those in the control group (not stated how long post intervention). Patients' perceptions immediately following the medical visit regarding the amount of information on disease conditions given to them by their provider were found to be higher in the intervention group. There was no difference between the intervention and control groups for patients' perceptions of the amount of information given by providers about medications and side effects.

Lewis 1991, which focused on communication between providers, children and parents, assessed five consultation process measures, of which two showed statistically significant differences. This study reported that there was a greater percentage of provider recommendations addressed to child, or child and parent, in the intervention group compared to the control group (not stated how long post intervention). With regard to patient perceptions, children in the intervention group recalled a higher percentage of medical recommendations compared with the control group (not stated when this was measured in relation to post intervention medical visit). There was no statistically significant difference between the intervention and control groups for the number of child substantive initiations and responses; percentage of provider recommendations recalled by child; and total number of statements during the consultation.

Pill 1998, which aimed to improve the care given to people with type 2 diabetes, reported six consultation process measures, of which two showed statistically significant differences. The study showed that a higher percentage of patients in the intervention group affirmed their current behaviour and initiated discussion of change compared with the control group (measured eight to nine months post intervention). No significant difference was found between the intervention and control group in the percentage of patients who were involved in other aspects of the consultation, such as deciding on topics to discuss and target setting.

b) Patient satisfaction (Table 6)

All three studies measured aspects of patient satisfaction. Lewis 1991 measured two outcomes. Immediately after the medical visit, children in the intervention were found to be significantly more satisfied with the consultation visit compared with children in the control group, although there was no statistically significant difference between the intervention and control group for parent's satisfaction with the consultation. Pill 1998 measured one out- 
come. The study found a statistically significant before and after difference for satisfaction with recent consultations and treatment received in the control group of patients, although there was no statistically significant change within the intervention group. Joos 1996 measured general satisfaction, but found no statistically significant difference between the two groups.

c) Healthcare behaviours (Table 7)

Two studies measured healthcare behaviours, measuring respectively one and two outcomes for this category. Neither study reported any significant differences between the intervention and control groups in appointment adherence/attendance at twelve and eighteen months respectively after the post intervention medical visit (Joos 1996; Pill 1998). Joos 1996 also found no significant difference between the intervention and control group for medication adherence three months after the post intervention medical visit.

d) Health status and wellbeing (Table 8)

Two of the studies examined aspects of health status and wellbeing. Pill 1998 assessed thirteen outcomes, of which one showed a statistically significant difference: the control group reported better physical functioning compared with the intervention group, as measured by self-reports of limitations to everyday activities at nine and eighteen months after post intervention medical visit. There were no statistically significant differences between the two groups eighteen months after recruitment for glycosylated haemoglobin readings, body mass index, weight, diastolic and systolic blood pressure, and in the number of complications experienced. Lewis 1991 measured one outcome - mean levels of anxiety and showed no statistically significant differences between children in the intervention and control group (not stated when this was measured in relation to post intervention medical visit).

\section{Comparison 3}

Patient-centred training for providers plus condition- or behaviour-specific training or material for both providers and patients compared with no training intervention (Clark 1998) or with behaviour-specific material only for providers (Meland 1997). Both studies included in this group are RCTs.

a) Consultation processes (Table 9)

Only one of the two studies in this comparison group measured consultation behaviours, assessing eight consultation process outcomes of which five showed statistically significant differences (Clark 1998). The intervention in this study was designed to improve healthcare behaviours/outcomes in paediatric patients with asthma and not all of the consultation behaviours measured reflected aspects of patient-centred care. Some provider behaviours were assessed by provider self report only. We decided to exclude these provider self-report measures as they were more likely to reflect intention than actual practice. Only the behaviours that were assessed by parent self-report are reported here. A complete list of all consultation processes measured appears in the additional tables section.

Clark 1998 showed that parents of children in the intervention group were statistically significantly more likely than parents in the control group to report that the paediatrician was reassuring, encouraging and gave information to relieve specific worries, when assessed on average two months after the post intervention medical visit. However, no statistically significant differences were found between intervention and control group parents in terms of feeling that they knew how to make decisions about managing asthma at home (Clark 1998).

b) Patient satisfaction

This outcome was not assessed in either of the two studies in this comparison group.

c) Healthcare behaviours (Table 10)

Both studies assessed healthcare behaviours. Clark 1998 reported on four outcomes, of which two showed statistically significant differences. The study assessed the medical care utilisation of paediatric patients with asthma. According to parent self report, children in the intervention group made significantly fewer non emergency physician office visits for asthma in the follow up period (on average within two months of the post intervention medical visit) and significantly fewer visits following an episode of symptoms when compared with children in the control group. There were no statistically significant differences reported between the groups for number of emergency department visits or the number of hospitalisations.

Meland 1997 focused on encouraging patient behaviour change in a sample of men at risk of coronary heart disease and measured lifestyle behaviours such as exercise and smoking. The study assessed three outcomes. None showed any statistically significant differences. According to patient self report, there were no differences between the intervention and the control group for weekly duration of exercise or global self-evaluated level of physical activity, and no differences between the groups for the mean numbers of cigarettes smoked per day at twelve months after the intervention.

d) Health status and wellbeing (Table 11)

Both studies measured aspects of health status and wellbeing, each assessing four outcomes for this category. Two of the four outcomes reported by Clark 1998 showed statistically significant differences. For children not using inhaled anti-inflammatory medication at baseline and using it at follow up (on average within two months of post intervention medical visit), those in the intervention group were more likely than children in the control group to have a lower average number of days per month with asthma symptoms during the spring and summer months. However, no differences between the two groups were found for the autumn and winter months.

Meland 1997 found no statistically significant differences between the intervention and the control group (at twelve months after post intervention medical visit) for mean systolic and diastolic blood pressure; mean total serum cholesterol; total/high density lipoprotein cholesterol ratio and mean log infarction score. 


\section{Comparison 4}

Patient-centred training for providers, patient-centred materials for patients plus condition- or behaviour-specific materials for both providers and patients compared with condition- or behaviour-specific materials for both providers and patients.

One RCT made this comparison using an intervention designed to improve healthcare behaviours and outcomes in patients with newly diagnosed type 2 diabetes (Kinmonth 1998).

a) Consultation processes (Table 12)

Kinmonth 1998 assessed three consultation processes of which one showed a statistically significant difference. At one year follow up, patients in the intervention group were more likely than patients in the control group to report maximum communication with GPs (covering the ability to tell the provider personal or troubling things and feeling understood). Differences between the two groups were not statistically significant for communication with nurses and there was no significant difference between the two groups for agreement between patient and provider on main concerns discussed over the year.

b) Patient satisfaction (Table 13)

Kinmonth 1998 reported two patient satisfaction outcomes of which one showed a statistically significant difference. Patients in the intervention group were more likely than the control group to report high satisfaction with treatment at one year. There was no statistically significant difference between the two groups for satisfaction with style of care.

c) Healthcare behaviours (Table 14)

Kinmonth 1998 examined three healthcare behaviours: the proportion of patients smoking at one year post intervention; diet scores; and exercise scores. None of these showed statistically significant differences between the intervention and control groups. d) Health status and wellbeing (Table 15)

Kinmonth 1998 assessed eight outcomes relating to health status and wellbeing, of which three showed statistically significant differences. One year after the intervention, average blood triglyceride concentrations were significantly higher (i.e. worse) in the intervention group than the control group and average body mass index was also significantly higher (i.e. worse) in the intervention group compared with the control group. Overall wellbeing scores were significantly higher in the intervention group compared with the control group.

One year after the intervention, there were no significant differences between the intervention and the control group for mean haemoglobin A1c concentrations; mean total cholesterol; and for mean systolic and diastolic blood pressure. There were also no significant differences between the groups for mean scores on diabetes-specific quality of life and depressed wellbeing questionnaires, or on various subscales of a generic wellbeing questionnaire (depression, anxiety, and energy subscales).

\section{DISCUSSIO N}

This review identified 17 studies that evaluated interventions intended to promote patient-centred care in clinical consultations. The included studies display considerable heterogeneity in terms of the interventions themselves, the clinical conditions on which the interventions focused, the comparisons made and the outcomes assessed.

\section{Defining patient-centred care and classifying studies}

Patient-centred care is a widely used phrase but a complex and contested concept. This review used a broad, inclusive definition of patient-centred care based on shared control of the consultation, decisions about interventions or the management of health problems with the patient and/or a focus in the consultation on the patient as a whole person who has individual preferences situated within social contexts (see Criteria for considering studies for this review). We focused on interventions to promote patient centredness within clinical consultations because these seemed to be the most important setting in terms of volume of studies and policy implications. Some of the included studies explicitly defined patient-centred care, using a range of different definitions. Some studies viewed patient-centred care as an important end in itself while others viewed patient-centred care as a means to improving particular healthcare behaviours/outcomes. The lack of a widely accepted definition of patient-centred care, and the heterogeneity of interventions to promote it, may raise questions regarding the inclusion and exclusion of studies in this review and created difficulties in synthesizing data from the included studies.

\section{Consumer involvement in selecting outcomes for assessing the effects of interventions}

None of the authors mentioned whether consumers were consulted regarding the most important or relevant outcomes for consumers in terms of assessing the effects of the proposed interventions. Three studies assessed patients' perceptions of aspects of the consultation process including perceptions of providers' humaneness during the visit (Thom 1999); whether the provider was reassuring and encouraging and gave information to relieve specific worries (Clark 1998); and perceptions of communication and whether there was agreement between provider and patient on main concerns (Kinmonth 1998). Eleven studies assessed patients' satisfaction with a range of aspects of the consultation process, from general satisfaction with care to more specific aspects such as the 'art' and 'technical' quality of care received, provider warmth and patient feelings of trust, confidence, freedom to express oneself, and understanding of the diagnosis, etiology, prognosis, and treatment of the illness (Cope 1986; Joos 1996; Kinmonth 1998; Langewitz 1998; Lewis 1991; Pill 1998; Putnam 1988; Roter 1998; Smith 1995; Smith 1998; Thom 1999). Although these outcomes could be described as consumer 'related', in the sense 
that patients were directly involved in their assessment, it is not clear whether consumers value these types of process outcomes more than outcomes relating to healthcare behaviours and health status or wellbeing.

\section{Problems with study designs and methods}

The methodological quality of the studies varied and the reporting of key methodological features was often not sufficiently detailed or complete to determine whether studies had adhered to good practice, for example as outlined in the CONSORT statement (Begg 1996). Firstly, of the fourteen studies which randomised healthcare providers or practices/clinics to intervention or control groups and then collected some data at the level of the individual patient (Clark 1998; Cope 1986; Joos 1996; Kinmonth 1998; Levinson 1993; Lewis 1991; Meland 1997; Pill 1998; Putnam 1988; Roter 1995; Roter 1998; Smith 1995; Smith 1998; Thom 1999), three did not adjust for potential unit of analysis error (Cope 1986; Meland 1997; Pill 1998). This may have resulted in the overestimation of the significance of the effects of the intervention. Secondly, three studies presented certain outcomes measures as within-group differences, measured before and after the intervention (Putnam 1988; Robbins 1979; Roter 1998). These results are subject to the same problems of interpretation as those from before and after studies. Third, a number of the studies had small sample sizes and may have been underpowered to detect between group differences. Finally, some studies assessed a large number of outcomes and it is therefore possible that some of the statistically significant findings are due to chance.

\section{Other factors affecting interpretation of the review findings}

1. While all of the included studies used training for healthcare providers as an element of the intervention, seven studies evaluated multi-faceted interventions which included training for healthcare providers; patient-centred training or materials for patients; and behaviour / condition specific training or materials for provider and / or patients (see Description of Studies). While multi-faceted interventions may be useful, they raise difficulties in ascertaining which components, or combination of components, were responsible for the measured effects. Furthermore, the number of studies in each of the comparison groups, apart from patient-centred training only compared with control, was small. None of the studies included organisational changes, such as increasing the length of appointment times or follow-up procedures, as part of the intervention.

2. The intensity of the interventions varied across studies, both in terms of teaching/training tactics (duration of training; didactic versus interactive approaches; additional materials; use of consultation tools) and patient centredness (see Methods and Description of studies). Attempts within the review to standardise assessments of the teaching and patient centredness intensity of the interventions were unsuccessful. It has therefore not been possible to explore the relationship between intervention intensity and study outcomes and we cannot draw any conclusions in this regard.

3. The range of patients recruited by the studies was wide, including adults and children presenting in primary care with various problems and adults and children presenting with particular medical conditions. It may be difficult to generalise findings from the latter group of studies to primary care patients in general or to secondary care settings.

4. Only two studies (Kinmonth 1998; Pill 1998) included providers other than physicians and most studies were conducted in either North America or the United Kingdom. It is therefore difficult to generalise their findings to other cadres of healthcare providers, other healthcare systems or other cultural or social contexts.

5. It is difficult to assess the complex cause-effect pathway from intervention through consultation processes to health status. Only three studies assessed outcomes in all of the four predefined categories (Kinmonth 1998; Pill 1998; Putnam 1988), thereby allowing the cause-effect pathway from consultation process to health status to be explored.

Given these factors, we cannot make clear evidence-based recommendations about the types of patient-centred interventions which healthcare institutions and funders should promote.

\section{AUTHORS, CONCLUSIONS}

\section{Implications for practice}

Overall, there is fairly strong evidence to suggest that some interventions to promote patient-centred care in the clinical consultation may lead to significant increases in the patient centredness of consultation processes, as indicated by a range of measures relating to clarifying patients' concerns and beliefs; communicating about treatment options; levels of empathy etc. It is important to note that none of the included studies used measures explicitly designed to assess the patient centredness of the consultation. There is currently no gold standard measure for patient centredness, and this area needs further work if the effects on consultation processes of interventions to promote patient-centred care are to be appropriately assessed (Mead 2000).

There is also some evidence that training healthcare providers in patient-centred approaches may impact positively on patient satisfaction with care. Of the eleven studies that assessed patient satisfaction, six demonstrated significant differences in favour of the intervention group on one or more measures.

The limited and mixed nature of the evidence available means we are as yet unable to reach confident conclusions about the effects of interventions that encourage healthcare providers to use patient- 
centred approaches in consultations on healthcare behaviours or health status.

It is difficult to quantify the benefits/effects of training healthcare providers in patient-centred care on health status and therefore difficult to give recommendations to policy makers and professional bodies regarding investment into the development of such training on the basis of available research evidence. However, if patient-centred care is seen as worthy in its own right, such investment is probably justified because interventions to promote patient-centred care within clinical consultations may lead to significant increases in the patient centredness of care.

\section{Implications for research}

Future trials need to focus on assessing the effects of interventions to promote patient-centred care on healthcare behaviour and health status outcomes. The effects of variations in the intensity of the interventions, in terms of patient centredness and teaching tactics, also need to be examined.

Future trials should also specifically assess the effects of interventions other than healthcare provider training, such as changes in the organisation of care, in promoting patient-centred care in the clinical consultation.

More attention needs to be paid to the methodological quality of studies, particularly where cluster randomisation is used.

A widely acceptable definition of patient-centred care that can be operationalised in effectiveness studies needs to be developed.
There is currently no gold standard measure for patient centredness, and this area needs further work in order to develop valid, reliable and appropriate tools to assess the effects of interventions to promote patient-centred care on consultation processes (Mead 2000).

Ways of involving healthcare consumers in the design, planning and delivery of interventions to promote patient-centred care need to be explored. In particular, the outcomes assessed in evaluations of interventions to promote patient-centred care should include measures of issues seen as important by consumers for quality of care.

\section{ACKNOWLEDGEMENTS}

Peer-reviewers: Hilda Bastian, Dominique Broclain and anonymous Consumer and Communication Group reviewers.

Statistical advice: Ben Armstrong, Carl Lombard, Graeme MacLennan.

The study authors who provided us with additional information regarding study designs and interventions.

Sophie Hill and Megan Prictor at the editorial base for the Consumer and Communication Group.

Funders: Principle funding for this review was provided by the Health in Partnership initiative of the UK Department of Health (3700512). Additional funding for members of the review team was provided by the Medical Research Council of South Africa; the UK Department for International Development; the Chief Scientist Office of the Scottish Executive Health Department; and the Nuffield Commonwealth Programme.

\section{R E F E R E N C E S}

\section{References to studies included in this review}

Clark 1998 \{published data only\}

Clark NM, Gong M, Schork MA, Evans D, Roloff D, Hurwitz M, et al.Impact of education for physicians on patient outcomes. Pediatrics 1998;101(5):831-6.

Cope 1986 \{published data only\}

Cope DW, Linn LS, Leake BD, Barrett PA. Modification of residents' behavior by preceptor feedback of patient satisfaction. Journal of General Internal Medicine 1986;1: $394-8$.

Howe 1996 \{published data only\}

Howe A. Detecting psychological distress: Can general practitioners improve their own performance?. British Journal of General Practice 1996;46:407-10.
Joos 1996 \{published data only\}

Joos SK, Hickam DH, Gordon GH, Baker LH. Effects of a physician communication intervention on patient care outcomes. Journal of General Internal Medicine 1996;11: $147-55$.

Kinmonth 1998 \{published data only\}

Kinmonth AL, Spiegal N, Woodcock A. Developing a training programme in patient-centred consulting for evaluation in a randomised controlled trial; diabetes care from diagnosis in British primary care. Patient Education and Counseling 1996;29:75-86.

* Kinmonth AL, Woodcock A, Griffin S, Spiegal N, Campbell MJ. Randomised controlled trial of patient centred care of diabetes in general practice: impact on 
current wellbeing and future disease risk. $B M J$ 1998;317: $1202-8$.

Woodcock AJ, Kinmonth AL, Campbell MJ, Griffin SJ, Spiegal NM. Diabetes care from diagnosis: effects of training in patient-centred care on beliefs, attitudes and behaviour of primary care professionals. Patient Education and Counseling 1999;37:65-79.

Langewitz 1998 \{published data only\}

Langewitz WA, Eich P, Kiss A, Wossmer B. Improving communication skills: a randomized controlled behaviorally oriented intervention study for residents in internal medicine. Psychosomatic Medicine 1998;60:268-76.

Levinson 1993 \{published data only\}

Levinson W, Roter D. The effects of two continuing medical education programs on communication skills of practicing primary care physicians. Journal of General Internal Medicine 1993;8:318-24.

Lewis 1991 \{published data only\} Lewis CC, Pantell RH, Sharp L. Increasing patient knowledge, satisfaction, and involvement: Randomized trial of a communication intervention. Pediatrics 1991;88 (2):351-8

Meland 1997 \{published data only\}

Meland E, Laerum E, Ulvik RJ. Effectiveness of two preventive interventions for coronary heart disease in primary care. Scand J Prim Health Care 1997;15(1):57-64.

Pill 1998 \{published data only\}

* Pill R, Stott NCH, Rollnick SR, Rees M. A randomized controlled trial of an intervention designed to improve the care given in general practice to type II diabetic patients: patient outcomes and professional ability to change behaviour. Family Practice 1998;15(3):229-35. Stott NCH, Rees M, Rollnick S, Pill RM, Hackett P. Professional responses to innovation in clinical method: diabetes care and negotiating skills. Patient education and counseling 1996;29:67-73.

Stott NCH, Rollnick S, Rees MR, Pill RM. Innovation in clinical method: diabetes care and negotiating skills. Family Practice 1995;12(4):413-18.

Putnam 1988 \{published data only\}

Putnam SM, Stiles WB, Jacob MC, James SA. Teaching the medical interview: an intervention study. Journal of General Internal Medicine 1988;3:38-47.

Robbins 1979 \{published data only\}

Robbins AS, Kauss DR, Heinrich R, Abrass I, Dreyer J, Clyman B. Interpersonal skills training: evaluation in an internal medicine residency. Journal of Medical Education 1979;54:885-94.

Roter 1995 \{published data only\} Roter DL, Hall JA, Kern DE, Barker R, Cole KA, Roca RP. Improving physicians' interviewing skills and reducing patients' emotional distress. Archives of Internal Medicine 1995;155:1877-84.

Roter 1998 \{published data only\}

Roter D, Rosenbaum J, de Negri B, Renaud D, DiPreteBrown L, Hernandez $\mathrm{O}$. The effects of a continuing medical education programme in interpersonal communication skills on doctor practice and patient satisfaction in Trinidad and Tobago. Medical Education 1998;32:181-9.

Smith 1995 \{published data only\}

* Smith RC, Lyles JS, Mettler JA, Marshall AA, Van Egeren LF, Stoffelmayr BE, et al.A strategy for improving patient satisfaction by the intensive training of residents in psychosocial medicine: a controlled, randomized study. Academic Medicine 1995;70(8):729-32.

Smith RC, Mettler JA, Stoffelmayr BE, Lyles JS, Marshall AA, Van Egeren LF, et al.Improving residents' confidence in using psychosocial skills. Journal of General Internal Medicine 1995;10:315-20.

Smith 1998 \{published data only\}

Smith RC, Lyles JS, Mettler J, Stoffelmayr BE, Vanegeren LF, Marshall AA, et al.The effectiveness of intensive training for residents in interviewing: A randomized controlled study. Annals of Internal Medicine 1998;128(2):118-26.

Thom 1999 \{published data only\}

Thom DH, Bloch DA, Segal ES. An intervention to increase patients' trust in their physicians. Academic Medicine 1999; 74(2): 195-8.

\section{References to studies excluded from this review}

Alroy 1984 \{published data only\}

Alroy G, Ber R, Kramer D. An evaluation of the short-term effects of an interpersonal skills course. Medical Education 1984;18:85-89.

Baile 1997 \{published data only\} Baile WF, Lenzi R, Kudelka AP, Maguire P, Novack $\mathrm{D}$, Goldstein $\mathrm{M}$, et al.Improving physician-patient communication in cancer care. Journal of Cancer Education 1997;12(3):166-73.

Baile 1999 \{published data only\} Baile WF, Kudelka AP, Beale EA, Glober GA, Myers EG, Greisinger AJ, et al.Communication skills training in oncology. American Cancer Society 1999;86(5):887-97.

Beckman 1990 \{published data only\}

Beckman H, Frankel R, Kihm J, Kulesza G, Geheb M. Measurement and improvement of humanistic skills in firstyear trainees. Journal of General Internal Medicine 1990;5: $42-5$.

Bensing 1985 \{published data only\}

Bensing JM, Sluijs EM. Evaluation of an interview training course for general practitioners. Social Science and Medicine 1985;20(7):737-44.

Berg 1983 \{published data only\} Berg RA, Rimsza ME, Eisenberg N, Ganelin RS. Evaluation of a successful biosocial rotation. American Journal of Diseases of Children 1983;137:1066-8.

Blaasvaer 1998 \{published data only\}

Blaasvaer S, Laerum E. A patient-centred approach to health care: the effects on health-related behaviour, consultation satisfaction and psychological well-being [Effekter av helsepedagogisk tilnaerming pa helseatferd, 
konsultasjonstilfredshet og psykisk velvaere]. Tidsskr Nor Loegeforen $\mathrm{nr}$ 1998;118(3):370-6.

Bohme 1998 \{published data only\}

Bohme H, Finke J, Teusch L. Effects of inpatient clientcentered psychotherapy in various illness: 1-year followup [Effekte stationarer gesprachspsychotherapie bei verschiedenen krankheitsbildern: 1-jahres-katamnese]. Psychotherapie, Psychosomatic Medizinche Psychologie 1998; 48(1):20-29.

Breunlin 1990 \{published data only\}

Breunlin DC, Richman JS, Lattimer A. An evaluation strategy for behavioural pediatrics training. Family Systems Medicine 1990;8(1):48-56.

Calhoun 1985 \{published data only\} Calhoun JG, Woolliscroft JO, Beauchamp C. Changing orientations of medical students to patients' care: biomedical versus biopsychosocial models. Psychological Reports 1985; 56:91-4.

Caris-Verhallen 2000 \{published data only\} Caris-Verhallen WMCM, Kerkstra A, Bensing JM, Grypdonck MHF. Effects of video interaction analysis training on nurse-patient communication in the care of the elderly. Patient Education and Counseling 2000;39:91-103.

Covinsky 1998 \{published data only\}

Covinsky KE, Palmer RM, Kresevic DM, Kahana E, Counsell SR, Fortinsky RH, et al.Improving functional outcomes in older patients: lessons from an acute care for elders unit. Joint Commission Journal on Quality Improvement 1998;24(2):64-76.

Cox 1981 \{published data only\} Cox A, Holbrook D, Rutter M. Psychiatric interviewing techniques VI. Experimental study: eliciting feelings. British Journal of Psychiatry 1981;139:144-52.

Cummings 1989 \{published data only\} Cummings SR, Richard RJ, Duncan CL, Hansen B, Martin RV, Gerbert B, Coates TJ. Training physicians about smoking cessation: a controlled trial in private practices. Journal of General Internal Medicine 1989;4:482-9.

Dick 1997 \{published data only\}

Dick J, Lombard C. Shared vision - a health education project designed to enhance adherence to anti-tuberculosis treatment. The International Journal of Tuberculosis and Lung Disease 1997;1(2):181-6.

Dougherty 1998 \{published data only\} Dougherty MC, Dwyer JW, Pendergast JF, Tomlinson BU, Boyington AR, Vogel WB, et al.Community-based nursing: continence care for older rural women. Nursing Outlook 1998;46(5):233-44.

Douglas 1996 \{published data only\} Douglas S, Daly BJ, Rudy EB, Sereika SM, Menzel L, Song R, et al.Survical experience of chronically critically ill patients. Nursing Research 1996;45(2):73-7.
Edberg 1996 \{published data only\} Edberg AK, Hallberg IR, Gustafson L. Effects of clinical supervision on nurse-patient cooperation quality. Clinical Nursing Research 1996;5(2):127-49.

Eijkman 1977 \{published data only\} Eijkman MAJ, Karsdorp NE, Boeke B, KarsdorpBimmerman EHLM. Experiences with a training course in patient counseling. Journal of Dental Education 1977;41 (10):623-625.

Ericson 1997 \{published data only\}

Ericson D, Christersson C, Manogue M, Rohlin M. Clinical guidelines and self-assessment in dental education. European Journal of Dental Education 1997;1:123-8.

Evans 1987 \{published data only\}

Evans BJ, Kiellerup FD, Stanley RO, Burrows GD, Sweet B. A communication skills programme for increasing patients' satisfaction with general practice consultations. British Journal of Medical Psychology 1987;60:373-8.

Evans 1991 \{published data only\}

Evans BJ, Stanley RO, Mestrovic R, Rose L. Effects of communication skills training on students' diagnostic efficiency. Medical Education 1991;25:517-526.

Evans 1992 \{published data only\}

* Evans BJ, Stanley RO, Burrows GD. Communication skills training and patients' satisfaction. Health Communication 1992;4(2):155-70.

Evans BJ, Stanley RO, Burrows GD, Sweet B. Lectures and skills workshops as teaching formats in a history-taking skills course for medical students. Medical Education 1989; 23:364-70.

Evans 1993 \{published data only\}

Evans BJ, Sweet B, Coman GJ. Behavioural assessment of the effectiveness of a communication programme for medical students. Medical Education 1993;27:344-50.

Fallowfield 1998 \{published data only\}

Fallowfield L, Lipkin M, Hall A. Teaching senior oncologists communication skills: results from phase I of a comprehensive longitudinal program in the United Kingdom. Journal of Clinical Oncology 1998;16(5):1961-8.

Family Heart Study \{published data only\}

Family Heart Study Group. Randomised controlled trial evaluating cardiovascular screening and intervention in general practice: principal results of British family heart study. British Medical Journal 1994;308:313-20.

\section{Farhall 1998 \{published data only\}} Farhall J, Webster B, Hocking B, Leggatt M, Riess C, Young J. Training to enhance partnerships between mental health professionals and family caregivers: a comparative study. Psychiatric Services 1998;49(11):1488-90.

Farsad 1978 \{published data only\}

Farsad P, Galliguez P, Chamberlin R, Roghmann KJ. Teaching interviewing skills to pediatric house officers. Pediatrics 1978;61(3):384-388. 
Fine 1977 \{published data only\}

Fine, VK, Therrien ME. Empathy in the doctor-patient relationship: skill training for medical students. Journal of Medical Education 1977;52:752-7.

Finnema 2000 \{published data only\}

Finnema EJ, Droes RM, Ettema TP, Ooms ME, Ader HJ, Ribbe MW, et al.The effect of emotion-oriented care on nursing home residents with dementia and their nursing assistants: a randomized clinical trial. In: Finnema $\mathrm{E}$ editor(s). Emotion-oriented care in dementia: a psychosocial approach. Amsterdam: Vrije Universiteit, 2000:135-63.

Foley 1997 \{published data only\}

Foley ME, Nespoli G, Conde E. Using standardized patients and standardized physicians to improve patient-care quality: results of a pilot study. The Journal of Continuing Education in Nursing 1997;28(5):198-204.

Fox 1997 \{published data only\}

Fox PJ, Breuer W, Wright JA. Effects of a health promotion program on sustaining health behaviors in older adults. American Journal of Preventive Medicine 1997;13(4): 257-64.

Goldberg 1980 \{published data only\} Goldberg DP, Steele JJ, Smith C, Spivey L. Training family doctors to recognise psychiatric illness with increased accuracy. The Lancet 1980;2(8193):521-3.

Greenberg 1999 \{published data only\} Greenberg LW, Ochsenschlagert D, O’Donnell R, Mastruserio J, Cohen GJ. Communicating bad news: a pediatric department's evaluation of a simulated intervention. Pediatrics 1999;103(6):1210-1217.

Greenfield 1988 \{published data only\} Greenfield S, Kaplan SH, Ware JE, Yano EM, Frank HJL. Patients' participation in medical care: effects on blood sugar control and quality of life in diabetes. Journal of General Internal Medicine 1988;3:448-57.

Guillory-Dunbar 1994 \{published data only\} Guillory-Dunbar BM. Effects of staff-patient relations training on employees and their feelings about their work. Health Care Superv 1994;13(1):26-30.

Haisch 1996 \{published data only\}

Haisch J, Braun S, Bohm BO, Stock D. Effects of patient education in type II diabetic patients after clinic admission. Results of a 3 month catamnesis after new patient-centered education [Schulungseffekte bei typ-II-diabetikern nach einem klinikaufenthalt]. Psychotherapie, Psychosomatic, Medizinis Che Psychologie 1996;46(11):400-4.

Handmaker 1999 \{published data only\} Handmaker NS, Miller WR, Manicke M. Findings of a pilot study of motivational interviewing with pregnant drinkers. Journal of Studies on Alcohol 1999;60(2):285-7.

Hebert 1992 \{published data only\}

Hebert JR, Kristeller J, Ockene JK, Landon J, Luippold R, Goldberg RJ, et al.Patient characteristics and the effect of three physician-delivered smoking interventions. Preventive Medicine 1992;21:557-573.
Hunsdon 1984 \{published data only\}

Hunsdon S, Clarke SS. The impact of illness on patients and families: social workers teach medical students. Social Work in Health Care 1984;10(2):41-52.

Inui 1976 \{published data only\}

Inui TS, Yourtee EL, Williamson JW. Improved outcomes in hypertension after physician tutorials: a controlled trial. Annals of Internal Medicine 1976;84:646-51.

\section{Jacob 1988 \{published data only\}}

Jacob MR. Putting research into practice: the impact of interpersonal skills training on responses to patients' emotional concerns by nursing staff in a general hospital. The Florida Nurse 1988;36(9):18.

* Jacob MR. The impact of interpersonal skills training on responses to patients' emotional concerns by nursing staff in a general hospital. A dissertation submitted to the graduate faculty of the University of Georgia in partial fulfillment of the requirements for the degree, Doctor of Education 1987.

Johnson 1996 \{published data only\} Johnson JA, Kopp KC. Effectiveness of standardized patient instruction. Journal of Dental Education 1996;60(3):262-6.

Kauss 1980 \{published data only\}

Kauss DR, Robbins AS, Abrass I, Bakaitis RF, Anderson LA. The long-term effectiveness of interpersonal skills training in medical schools. Journal of Medical Education 1980;55: 595-601.

Kihlgren 1990 \{published data only\} Kihlgren M, Hallgren A, Norberg A, Brane G, Karlsson I. Effects of the training of integrity-promoting care on the interaction at a long-term ward. Scandinavian Journal of Caring Sciences 1990;4(1):21-8.

Kihlgren 1992 \{published data only\} Kihlgren M, Lindsten IG, Norberg A, Karlsson I. The content of the oral daily reports at a long-term ward before and after staff training in integrity promoting care. Scandinavian Journal of Caring Sciences 1992;6(2):105-12.

Kihlgren 1993 \{published data only\} Kihlgren M, Kuremyr D, Norberg A, Brane G, Karlson I, Engstrom B, et al.Nurse-patient interaction after training in integrity promoting care at a long-term ward: analysis of video-recorded morning care sessions. International Journal of Nursing Studies 1993;30(1):1-13.

Kosower 1996 \{published data only\} Kosower E, Inkelis S, Berman N, Seidel J. Evaluating telephone T.A.L.K. Journal of Biocommunication 1996;23 (1):27-31.

Kramer 1987 \{published data only\} Kramer D, Ber R, Moore M. Impact of workshop on students' and physicians' rejecting behaviors in patient interviews. Journal of Medical Education 1987;62:904-10.

Ladyshewsky 1997 \{published data only\}

Ladyshewsky R, Gotjamanos E. Communication skill development in health professional education: the use of standardised patients in combination with a peer assessment strategy. Journal of Allied Health 1997;26(4):177-86. 
Landefeld 1995 \{published data only\}

Landefeld CS, Palmer RM, Kresevic DM, Fortinsky RH, Kowal J. A randomized trial of care in a hospital medical unit especially designed to improve the functional outcomes of acutely ill older patients. NEJM 1995;332(20):1338-44.

Llewellyn-Jones 1999 \{published data only\} Llewellyn-Jones RH, Baikie KA, Smithers H, Cohen J, Snowdon J, Tennant CC. Multifaceted shared care intervention for late life depression in residential care: randomised controlled trial. BMJ 1999;319:676-82.

Maguire 1977 \{published data only\} Maguire GP, Clarke D, Jolley B. An experimental comparison of three courses in history-taking skills for medical students. Medical Education 1977;11:175-82.

Maguire 1986 \{published data only\}

Maguire P, Fairbairn S, Fletcher C. Consultation skills of young doctors: I - Benefits of feedback training in interviewing as students persist. British Medical Journal 1986;292:1573-7.

Maiman 1988 \{published data only\}

Maiman LA, Becker MH, Liptak GS, Nazarian LF, Rounds KA. Improving pediatricians' compliance-enhancing practices. American Journal of Diseases of Children 1988; 142:773-9.

Maisiak 1996 \{published data only\}

Maisiak R, Austin JS, West SG, Heck L. The effect of person-centered counseling on the psychological status of persons with systemic lupus erythematosus or rheumatoid arthritis. Arthritis Care and Research 1996;9(1):60-6.

Martin 1998 \{published data only\}

Martin DP, Diehr P, Conrad DA, Davis JH, Leickly R, Perrin EB. Randomized trial of a patient-centered hospital unit. Patient Education and Counseling 1998;34:125-33.

Mayer 1998 \{published data only\}

Mayer TA, Cates RJ, Mastorovich MJ, Royalty DL. Emergency department patient satisfaction: customer service training improves patient satisfaction and ratings of physician and nurse skill. Journal of Healthcare Management 1998;43(5):427-41.

McCourt 1998 \{published data only\}

McCourt C, Page L, Hewison J, Vail A. Evaluation of oneto-one midwifery: women's responses to care. Birth 1998; 25(2):73-80.

McManus 1993 \{published data only\} McManus IC, Vincent CA, Thom S, Kidd J. Teaching communication skills to clinical students. BMJ 1993;306: $1322-7$.

\section{Meland 1996 \{published data only\}}

Meland E, Laerum E, Maeland JG. Life style intervention in general practice: effects on psychological well-being and patient satisfaction. Quality of Life Research 1996;5:348-54.

Miller 1993 \{published data only\}

Miller WR, Benefield RG, Tonigan JS. Enhancing motivation for change in problem drinking: a controlled comparison of two therapist styles. Journal of Consulting

and Clinical Psychology 1993;61(3):455-61.

Morgan 1996 \{published data only\}

Morgan ER, Winter RJ. Teaching communication skills. Archives of Pediatric and Adolescent Medicine 1996;150: 638-42.

Myers 1991 \{published data only\} Myers RE, Stephens SA, Boyce AA, Hermann J. Educating allied health professionals to provide care for cancer patients and their families. Journal of Health \& Social Policy 1991;3 (2):49-69.

Nathan 1991 \{published data only\}

Nathan RG, Hohmann LK, Nusbaum HJ. Initial evaluation of a hidden agenda - method of teaching the interview. Family Medicine 1991;23(4):285-6.

Novack 1992 \{published data only\} Novack DH, Dube C, Goldstein MG. Teaching medical interviewing: a basic course on interviewing and the physician-patient relationship. Archives of Internal Medicine 1992;152:1814-20.

Ockene 1988 \{published data only\} Ockene JK, Quirk ME, Goldberg RJ, Kristeller JL, Donnelly G, Kalan KL, et al.A residents' training program for the development of smoking intervention skills. Archives of Internal Medicine 1988;148:1039-45.

Ockene 1991 \{published data only\} Ockene JK, Kristeller J, Goldberg R, Amick TL, Pekow PS, Hosmer D, et al.Increasing the efficacy of physiciandelivered smoking interventions: a randomized clinical trial. Journal of General Internal Medicine 1991;6:1-8.

Ockene 1994 \{published data only\} Ockene JK, Adams A, Pbert L, Luippold R, Herbert JR, Quirk M, et al.The physician-delivered smoking intervention project: factors that determine how much the physician intervenes with smokers. Journal of General Internal Medicine 1994;9:379-84.

Ockene 1995 \{published data only\} Ockene JK, Ockene IS, Quirk ME, Hebert JR, Saperia GM, Luippold RS, et al.Physician training for patient-centered nutrition counseling in a lipid intervention trial. Preventive Medicine 1995;24:563-70.

Ockene 1997 \{published data only\} Ockene JK, Wheeler EV, Adams A, Hurley TG, Hebert J. Provider training for patient-centered alcohol counseling in a primary care setting. Archives of Internal Medicine 1997; 157(20):2334-41.

Ockene 1999 \{published data only\} Ockene IS, Hebert JR, Ockene JK, Merriam PA, Hurley TG, Saperia GM. Effect of training and a structured office practice on physician-delivered nutrition counseling: the Worchester-area trial for counseling in hyperlipidemia (WATCH). American Journal of Preventive Medicine 1996; 12(4):252-8.

* Ockene IS, Hebert JR, Ockene JK, Saperia GM, Stanek Ed, Nicolosi R, et al.Effect of physician-delivered nutrition 
counseling training and an office-support program on saturated fat intake, weight, and serum lipid measurements in a hyperlipidemic population. Archives of Internal Medicine 1999;159:725-31.

Ockene 1999b \{published data only\} Ockene JK, Adams A, Hurley TG, Wheeler EV, Hebert JR. Brief physician- and nurse practitioner-delivered counseling for high-risk drinkers. Archives of Internal Medicine 1999b; 159(Oct 11):2198-205.

Ogden 1997 \{published data only\}

Ogden J, Hoppe R. The relative effectiveness of two styles of educational package to change practice nurses' management of obesity. International Journal of Obesity 1997;21:963-71.

Olson 1987 \{published data only\}

Olson JK, Iwasiw CL. Effects of a training model on active listening skills of post-RN students. Journal of Nursing Education 1987;26(3):104-7.

OXCHECK study group \{published data only\}

Muir J, Mant D, Jones L, Yudkin P. Effectiveness of health checks conducted by nurses in primary care: results of the OXCHECK study after one year. British Medical Journal 1994;308:308-312.

Perkonigg 1995 \{published data only\}

Perkonigg A, Wittchen HU, Winkler S. The "patient anxiety seminar" as a graduate education program - effectiveness and use in general practice [Das fortbildungsprogramm "patientenseminar angst" - wirksamkeit and einsatz in der praxis]. Zeitschrift fur Arztliche Fortbildung (Jena) 1995;89 (4):370-7.

Phillips 1997 \{published data only\} Phillips RM, Baldwin BA. Teaching psychosocial care to long-term care nursing assistants. Journal of Continuing Education in Nursing 1997;28(3):130-4.

Poole 1979 \{published data only\} Poole AD, Sanson-Fisher RW. Understanding the patient: a neglected aspect of medical education. Social Science \& Medicine - Medical Psychology \& Medical Sociology 1979; 13A(1):37-43.

Poole DA, Sanson-Fisher RW. Long-term effects of empathy training on the interview skills of medical students. Patient Counselling and Health Education 1980; Third Quarter: $125-7$.

Quirk 1993 \{published data only\} Quirk ME, Godkin MA, Schwenzfeier E. Evaluation of two AIDS prevention interventions for inner-city adolescent and young adult women. American Journal of Preventive Medicine 1993;9(1):21-6.

Rabinowitz 1994 \{published data only\} Rabinowitz S, Kushnir T, Ribak J. Developing psychosocial mindedness and sensitivity to mental health issues among primary care nurses using the balint group method. Israel Journal of Psychiatry and Related Sciences 1994;31(4):280-6.

Razavi 1988 \{published data only\}

Razavi D, Delvaux N, Farvacques C, Robaye E. Immediate effectiveness of brief psychological training for health professionals dealing with terminally ill cancer patients: a controlled study. Social Science and Medicine 1988;27(4): 369-75.

Robins 1989 \{published data only\}

Robins LS, Wolf FM. The effect of training on medical students' responses to geriatric patient concerns: results of a linguistic analysis. The Gerontologist 1989;29(3):341-4.

Roche 1996 \{published data only\}

Roche AM, Eccleston P, Sanson-Fisher R. Teaching smoking cessation skills to senior medical students: a blockrandomized controlled trial of four different approaches. Preventive Medicine 1996;25:251-8.

Rollnick 1997 \{published data only\} Rollnick S, Butler CC, Stott N. Helping smokers make decisions: the enhancement of brief intervention for general medical practice. Patient Education and Counseling 1997; 31:191-203.

Roter 1990 \{published data only\}

Roter DL, Cole KA, Kern DE, Barker LR, Grayson M. An evaluation of residency training in interviewing skills and the psychosocial domain of medical practice. Journal of General Internal Medicine 1990;5:347-54.

Saltmarche 1998 \{published data only\} Saltmarche A, Kolodny V, Mitchell GJ. An educational approach for patient-focused care. Journal of Nursing Staff Development 1998;14(2):81-6.

Sanson-Fisher 1978 \{published data only\} Sanson-Fisher RW, Poole AD. Training medical students to empathize: an experimental study. Medical Journal of Australia 1978;1:473-6.

Scheidt 1986 \{published data only\} Scheidt PC, Lagoritz S, Ebbeling WL, Figelman AR, Moessner HF, Singer JE. Evaluation of system providing feedback to students on videotaped patient encounters. Journal of Medical Education 1986;61(July):585-90.

Schubert 1989 \{published data only\} Schubert DSP, Billowitz A, Gabinet L, Friedson W. Effect of liaison psychiatry on attitudes toward psychiatry, rate of consultation, and pychosocial documentation. General Hospital Psychiatry 1989;11:77-87.

\section{Seim 1995 \{published data only\}} Seim HC, Verhoye JR. Comparison of training techniques using a patient-centred approach to smoking cessation. Medical Education 1995;29:139-143.

Sidorov 1997 \{published data only\} Sidorov J, Christianson M, Girolami S, Wydra C. A successful tobacco cessation program led by primary care nurses in a managed care setting. The American Journal of Managed Care 1997;3(3):207-14.

\section{Simek-Downing 1985 \{published data only\}}

Simek-Downing L, Quirk M. Videotape analyses of medical students' interviewing skills. Family Medicine 1985;17(2): $57-60$.

Simkin-Silverman1997 \{published data only\} Simkin-Silverman LR, Wing RR. Management of obesity in primary care. Obesity Research 1997;5(6):603-612. 
Smith 1991 \{published data only\}

Smith RC, Osborn G, Hoppe RB, Lyles JS, Van Egeren

L, Henry R, et al.Efficacy of a one-month training block in psychosocial medicine for residents: a controlled study. Journal of General Internal Medicine 1991;6:535-43.

Snoek 1986 \{published data only\}

Snoek FJ, Verrips GHW. Learning cooperation. An evaluation of a training programme in co-operative skills for dental students [Evaluatie van een training in samenwerkingsvaardigheden ten behoeve van doctoraalstudenten tandheelkunde]. Ned Tijdschr Tandheelkd 1986;93(3):120-3.

Stein 1999 \{published data only\}

Stein TS, Kwan J. Thriving in a busy practice: physicianpatient communication training. Effective Clinical Practice 1999;2(2):63-70.

Steyn 1997 \{published data only\}

Steyn M, van der Merwe N, Dick J, Borcherds R, Wilding RJC. Communication with TB patients; a neglected dimension of effective treatment?. Curationis 1997;20(1): 53-6.

Stillman 1977 \{published data only\}

Stillman PL, Sabers DL, Redfield BM. Use of trained mothers to teach interviewing skills to first-year medical students: a follow-up study. Pediatrics 1977;60(2):165-9.

Szekely 1986 \{published data only\}

Szekely B, Botwin D, Eidelman BH, Becker M, Elman N, Schemm R. Nonpharmacological treatment of menstrual headache: relaxation-biofeedback behavior therapy and person-centered insight therapy. Headache 1986;26(2): 86-92.

Ter Horst 1980 \{published data only\}

Ter Horst G, Bekker M, Moltzer G. Communication skills training by means of videotaped interaction of dental students with their patients. Development, realisation and evaluation of a trial educational method [Training in communicatieve vaardigheden met behulp van video-opnamen vanpatientenbehandelingen]. Ned Tijdschr Tandheelkd 1980;87(December):480-4.

Ter Horst 1984 \{published data only\}

Ter Horst G, Leeds JG, Hoogstraten J. Effectiveness of communication skills training for dental students. Psychological Reports 1984;55:7-11.

Teusch 1997 \{published data only\}

Teusch L, Bohme H, Gastpar M. The benefit of an insight-oriented and experiential approach on panic and agoraphobia symptoms. Psychotherapy and Psychosomatics 1997;66:293-301.

Thompson 1982 \{published data only\}

Thompson TL, Stoudemire A, Mitchell WD. Effects of a psychiatric liaison program on internists' ability to assess psychosocial problems. International Journal of Psychiatry in Medicine 1982;12(2):153-60.
Thompson 1990 \{published data only\}

Thompson SC, Nanni C, Schwankovsky L. Patient-oriented interventions to improve communication in a medical office visit. Health Psychology 1990;9(4):390-404.

Utting 2000 \{published data only\}

Utting MR, Campbell F, Rayner C, Whitehouse CR, Dornan TL. Consultation skills of medical students before and after changes in curriculum. Journal of the Royal Society of Medicine 2000;93:247-53.

Vaidya 1999 \{published data only\} Vaidya VU, Greenberg LW, Patel KM, Strauss LH, Pollack MM. Teaching physicians how to break bad news. Arch Pediatr Adolesc Med 1999;153:419-422.

Vail 1996 \{published data only\}

Vail R, Mahon-Salazar C, Morrison A, Kalet A. Patients as teachers: an integrated approach to teaching medical students about the ambulatory care of HIV infected patients. Patient Education and Counseling 1996;27: 95-101.

Verhaak 1988 \{published data only\} Verhaak PFM. Detection of psychologic complaints by general practitioners. Medical Care 1988;26(10):1009-20.

Ward 1975 \{published data only\}

Ward NG, Stein L. Reducing emotional distance: a new method to teach interviewing skills. Journal of Medical Education 1975;50:605-14.

Ward 1996 \{published data only\}

Ward J, Sanson-Fisher R. Does a 3-day workshop for family medicine trainees improve preventive care? A randomized control trial. Preventive Medicine 1996;25:741-7.

White 1999 \{published data only\}

White MK, Malik T. Teaching clinician-patient communication in the treatment of breast diseases. Journal of Women's Health 1999;8(1):39-44.

Wilkinson 1998 \{published data only\} Wilkinson S, Roberts A, Aldridge J. Nurse-patient communication in palliative care: an evaluation of a communication skills programme. Palliative Medicine 1998;12:13-22.

Willetts 1997 \{published data only\} Willets LE, Leff J. Expressed emotion and schizophrenia: the efficacy of a staff training programme. Journal of Advanced Nursing 1997;26:1125-33.

Wist 1993 \{published data only\}

Wist E. Teaching communication with cancer patients and terminally ill patients to medical students. Journal of Cancer Education 1993;8(2):119-22.

\section{References to studies awaiting assessment}

\section{Allen 1990 \{published data only\}}

Allen SS, Bland CJ, Dawson SJ. A mini-workshop to train medical students to use a patient-centered approach to smoking cessation. American Journal of Preventive Medicine 1990;6(1):28-33. 
Brown 1999a \{published data only\}

Brown JB, Boles M, Mullooly JP, Levinson W. Effect of clinician communication skills training on patient satisfaction. A randomised, controlled trial. Annals of Internal Medicine 1999 Dec 7;131(11):822-9.

Fallowfield 2000 \{unpublished data only\} Fallowfield L, Duffy T, Fair A, et al.A randomised trial of the CRCPOG communication skills training model.

\section{Mason 1988 \{published data only\}} Mason JL, Barkley SE, Kappelman MM, Carter DE, Beachy WV. Evaluation of a self-instructional method for improving doctor-patient communication. Journal of Medical Education 1988;63:629-635.

\section{Oleinik 1990 \{published data only\}}

Oleinik 1990. Influence of changes in physicians' patterns of explanation on patients' compliance. Harefuah 1990;118 (9):514-7.

Ruiz Moral 2001 \{published data only\} Ruiz Moral R, Munoz Alamo M, Alba Jurado M, Perula de Torres L. Effectiveness of a learner-centred training programme for primary care physicians in using a patientcentred consultation style. Family Practice 2001;18(1): 60-63.

\section{Additional references}

\section{Anderson 1990}

Anderson LA, Dedrick RF. Development of the trust in physician scale: a measure to assess interpersonal trust in patient-physician relationships. Psychological Reports 1990; 67:1091-100.

\section{Annon 1974}

Annon JS. The behavioural treatment of sexual problems. Vol. 1, brief therapy, Honolulu: Enabling Systems, 1974.

\section{Armstrong 1982}

Armstrong D. The Doctor-Patient Relationship:1930-80. In: Wright P, Treacher A editor(s). The Problem of Medical Knowledge. Examining the Social Construction of Medicine. Edinburgh: Edinburgh University Press, 1982.

Balint 1955

Balint M. The doctor, his patient and the illness. Lancet 1955;1:318

\section{Balint 1956}

Balint M. The doctor, his patient and the illness. London: Pitman, 1956.

Begg 1996

Begg C, Cho M, Eastwood S, Horton R, Moher D, Olkin I, et al.Improving the quality of reporting of randomised controlled trials: the CONSORT statement. JAMA 1996; 276:637-9.

\section{Bjartveit 1987}

Bjartveit K. Handbook for the cardiovascular disease survey. Vol. 160, National Health Screening service, 1987.

\section{Blair 1985}

Blair SN, Haskell WL, Ho P, Paffenbarger RS, Vranizan KM, Farquhar JW, et al.Assessment of habitual physical activity by a seven-day recall in a community survey and controlled experiments. American Journal of Epidemiology 1985;122:794-804.

\section{Bradley 1994}

Bradley C, ed. Handbook of psychology and diabetes: a guide to psychological measurement in diabetes research and management. Chur, Switzerland: Harwood Academic, 1994.

\section{Brockway 1978}

Brockway BS. Evaluating physician competency: what difference does it make?. Evaluation and Program Planning 1978;1:211-20.

\section{Brown 1999b}

Brown SJ. Patient-centred communication. Annual Review of Nursing Research 1999;17:85-104.

\section{Byrne 1976}

Byrne P, Long B. Doctors talking to patients. London: HMSO, 1976.

\section{Campbell 2000}

Campbell M, Fitzpatrick R, Haines A, Kinmonth AL, Sandercock P, Spiegelhalter D, Tyrer P. Framework for design and evaluation of complex interventions to improve health. British Medical Journal 2000;321(7262):694-6.

\section{Carter 1989}

Carter WB, Inui TS. How patients judge the humanistic skills of their physicians. Philadelphia: American Board of Internal Medicine Final Report on the Patient Satisfaction Questionnaire 1989.

\section{Coulter 1998}

Coulter A, Entwistle V, Gilbert D. Informing patients: an assessment of the quality of patient information materials. London: Kings Fund, 1998.

\section{Crossley 1992}

Crossley D, Myers P, Wilkinson G. Assessment of psychological care in general practice. BMJ 1992;305: 1333-6.

\section{Davis 1991}

Davis AR, Ware JE. GHAA's consumer satisfaction survey. Group Health Association of America. Washington, DC 1991.

Ford 1996

Ford S, Fallowfield L, Lewis S. Doctor-patient interactions in oncology. Social Science and Medicine 1996;42(11): 1511-19.

\section{Godin 1985}

Godin G, Shephard RJ. A simple method to assess exercise behaviour in the community. Canadian Journal of Applied Sport Sciences 1985;10:141-6.

Goldberg 1979 Goldberg DP, Hillier VF. A scaled version of the General Health Questionnaire. Psychological Medicine 1979;9: 139-45.

\section{Goldberg 1988}

Goldberg D, Williams P. A user's guide to the General Health Questionnaire. Windsor: NFER Nelson, 1988. 


\section{Greenfield 1985}

Greenfield S, Kaplan S, Ware JE. Expanding patient involvement in care. Effects on patient outcomes. Annals of Internal Medicine 1985;102:520-8.

\section{Hackett 1996}

Hackett PMW, Pill RM, Stott NCH. Tests for diabetes treatment satisfaction tested. Diabetic Medicine 1996;13: 685-6.

\section{Henbest 1989}

Henbest RJ, Stewart MA. Patient-centredness in the consultation: a method for measurement. Family Practice 1989;6(4):249-53.

\section{Kagan 1975}

Kagan N. Influencing human interaction: eleven years with IPR. Canadian Counsellor 1975;9:74-97.

\section{Kinmonth 1996}

Kinmonth A, Spiegal N, Woodcock A. Developing a training programme in patient-centred consulting for evaluation in a randomised controlled trial; diabetes care from diagnosis in British primary care. Patient Education and Counselling 1996;29:75-86.

\section{Kiresuk 1986}

Kiresuk R, Sherman RE. Goal attainment scaling: A general method for evaluating comprehensive community mental health programs. Community Mental Health Journal 1986; 44:443-53.

Laine 1976

Laine C, Davidoff F. Patient-centered medicine: a professional evolution. JAMA 1996;275:152-6.

\section{Lewis 1986}

Lewis C, Scott DE, Pantell RH, et al.Parent satisfaction with children's medical care: development, field test and validation of a questionnaire. Medical Care 1986;24: 209-15.

\section{Maere 1991}

Maere A, Bjorndal A, Holmen J, Midthjell K, Kjaersgaard P. Physical activity among adults in a Norwegian county. Tidsskr Nor Laegeforen 1991;111:3695-9.

\section{Matthews 1989}

Matthews DA, Feinstein AR. A new instrument for patients' ratings of physician performance in the hospital setting. Journal of General Internal Medicine 1989;4:14-22.

\section{McWhinney 1989}

McWhinney I. The need for a transformed clinical method. In: Stewart M, Roter D editor(s). Communicating with medical patients. London: Sage, 1989.

\section{Mead 2000}

Mead N, Bower P. Patient-centredness: a conceptual framework and review of the empirical literature. Social Science and Medicine 2000;51(7):1087-110.

\section{Murphy 1992}

Murphy E. Lay health concepts and response to medical advice about lifestyle modification: the case of people with a diagnosis of non insulin dependent diabetes. [Dissertation], Southhampton: University of Southampton 1992.

\section{Mushlin 1978}

Mushlin AI, Appel FA. Developing a quality assurance strategy for primary care. The Experimental Medical Care Review Organisation (EMCRO) at the Columbia Medical Plan 1978.

Ong 1995

Ong LML, de Haes JCJM, Hoos AM, Lammes FB. Doctorpatient communication: a review of the literature. Social Science and Medicine 1995;40(7):903-18.

\section{Rifkin 1988}

Rifkin L, Wolf M, Lewis C, et al.Children's perceptions of physicians and medical care: two measures. Journal of Pediatric Psychology 1988;13:247-54.

\section{Roe 1994}

Roe L, Strong C, Whiteside C, Neil A, Mant D. Dietary interventions in primary care: validity of the DINE method for dietary assessment. Family Practice 1994;11:375-81.

\section{Roter 1977}

Roter DL. Patient participation in the patient-provider interaction: the effects of patient question asking on the quality of interaction, satisfaction and compliance. Health Education Monographs 1977;5:281-315.

\section{Roter 1991}

Roter DL. The Roter Interactional Analysis System (RIAS) Coding Manual. Baltimore MD: School of Hygiene and Public Health, Johns Hopkins University, 1991.

Roter 1997

Roter DL. The Roter Interaction Analysis System (RIAS) Coding Manual. School of Hygiene and Public Health, Johns Hopkins University: Baltimore, MA, USA, 1997.

\section{Stewart 1981}

Stewart TJ, Pantell RH, Dias JK, Wells PA, Ross AW. Children as patients: a communications process study in family practice. Journal of Family Practice 1981;13(6): $827-835$.

\section{Stewart 1995a}

Stewart M. Effective physician-patient communication and health outcomes: a review. Canadian Medical Association Journal 1995;152(9):1423-33.

\section{Stewart 1995b}

Stewart M, Brown JB, Weston WW, McWhinney IR, McWilliam CL, Freeman TR. Patient-centred medicine. transforming the clinical method. Sage, 1995.

\section{Stiles 1978}

Stiles WB. Manual for a taxonomy of verbal response modes. Institute for Research in Social Science: University of North California at Chapel Hill, Chapel Hill, 1978.

\section{Toop 1998}

Toop L. Primary care: core values. Patient centred primary care. BMJ 1998;316:1882-3.

Truax 1967

Truax CB, Carkhuff RR. Toward effective counseling and psychotherapy. Chicago: Aldine Press, 1967. 
van Thiel 1991

van Thiel J, Kraan HF, van der Vleuten CP. Reliability and feasibility in measuring medical interviewing skills: the revised Maastricht History-Taking and Advice Checklist (MAAS-R). Medical Education 1991;25:224-229.

\section{Venham 1979}

Venham LL, Gaulin-Kremer E. A self-report measure of situational anxiety for young children. Pediatr Dentistry 1979;2:91-96.

Ware 1978

Ware JE, Davies-Avery A, Stewart AL. The measurement and meaning of patient satisfaction. Health and Medical Care Services Review 1978;1:1-15.

\section{Weaver 1993}

Weaver MJ, Ow CL, Walker DJ, Degenhardt EF. A questionnaire for patients' evaluations of their physicians' humanistic behaviors. J Gen Intern Med 1993;8:135-9.

\section{Wolf 1978}

Wolf MH, Putnam SM, James SA, Stiles WB. The medical interview satisfaction scale: development of a scale to measure patient perceptions of physician behaviour. Journal of Behavioural Medicine 1978;1:391-401.

\section{Wolf 1980}

Wolf MH. Patient beliefs, personality traits, health perceptions, and response biases are predictors of medical interview satisfaction. $\mathrm{PhD}$ dissertation, University of North Carolina at Chapel Hill 1980.

\section{Wolf 1981}

Wolf MH, Stiles WB. [Further development of the medical inteview satisfaction scale]. Paper presented at the American Psychological Association Convention. Los Angeles, California, August 1981.

* Indicates the major publication for the study 


\section{CHARACTERISTICS OF STUDIES}

\section{Characteristics of included studies [ordered by study ID]}

\section{Clark 1998}

$\begin{array}{ll}\text { Methods } & \text { Study design: RCT } \\ & \text { Allocation procedure: Unclear if blind/secure } \\ & \text { Protection against contamination: Unclear } \\ \text { Outcome assessors blind?: Unclear } \\ \text { Intention to treat analysis: Unclear } \\ \text { Potential for unit of analysis error for some outcomes?: } \\ \text { Yes, but adjustments made }\end{array}$

Participants

Speciality: Paediatric doctors

Clinical setting: Primary care practices, USA

Types of patients: Paediatric asthma patients and parents

Interventions Content of intervention:

Based on theoretic principles of self-regulation (guiding providers to examine ways to develop a partnership with their patients). The training focused on helping providers to create interactive conversation between themselves and patients to derive information for making therapeutic decisions, create a congenial and supportive atmosphere so that patients would be candid, reinforce positive efforts of families to self-manage, provide a supportive climate for mutual problem-solving, strengthen patients' skills in using medicines, provide the patient with a view of the longterm therapeutic plan, and build patients' confidence to control symptoms

Two components to content:

- optimal clinical practice (based on National Asthma Education and Prevention Programme guidelines). This was delivered through brief lectures, a video, case studies presenting troublesome clinical problems, and a review of messages to communicate and materials to use when teaching patients e.g. what happens in an asthma attack; how medicines work; how to take medicines etc.

- patient teaching and communications. This was delivered through a video; and a protocol where providers could assess their own behaviour regarding patient communications

Duration and timing: two x group meetings lasting -2.5 hours each held over a two to three week period

Numbers of providers receiving intervention: 37

Numbers of patients followed up in IG: not stated (472 patients overall)

Review authors' score for intensity of the patient centredness of the intervention: 5/10

Review authors' score for intensity of the teaching strategies used: $3 / 10$

Control group received no training

Numbers of providers in CG: 37

Numbers of patients followed up in CG: not stated (472 patients overall)

Outcomes Consultation / practice process measures: Various provider behaviours (for full list see Additional Table 9)

Patient satisfaction with care: N/A

Healthcare behaviours: Use of healthcare services for asthma

Health status and well being: Symptom status of child with asthma

Notes $\quad$ Measures used:

For the various provider behaviours:

Type: Parent interview

Index: 6 point scale (no reference given) 
A Likert-type response scale was used where $1=$ strongly disagree and $6=$ strongly agree For use of healthcare services for asthma; symptom status of child with asthma:

Type: Parent interview

\section{Cope 1986}

\section{Methods Study design: CCT}

Allocation procedure: Not blind/secure

Protection against contamination:

Unclear

Outcome assessors blind?: Unclear

Intention to treat analysis: Done

Potential for unit of analysis error for some outcomes?: Yes. Not acknowledged or adjusted for

Participants Speciality: Internal medicine residents

Clinical setting: Internal medicine outpatient department, USA

Types of patients: Adults consulting with various problems

\section{Interventions Content of intervention:}

Providers were shown the results of a patient satisfaction questionnaire that had been previously completed (over a six month period) by at least six of their patients after a consultation.

They were shown their mean scores on each questionnaire item and the mean item scores for all providers as a group. During the feedback session, the provider was advised of provider behaviours that could increase patient satisfaction with the art and technical quality of care.

The P-LI-SS-IT model (P, permission; LI, limited information; SS, specific suggestions; and IT, intensive therapy) introduced by Annon for sexual counseling was followed (Annon 1974), although the 4th level (IT) was not included in the study. Aspects of the model included:

- encouraging the provider to prioritise with the patient about what would be accomplished in a given visit

- encouraging the provider to show concern for the patient as a person apart from his or her illness, expression of empathy, attention to what the patient desires in the medical encounter etc

Specific suggestions were given about the provider behaviours that would achieve the above aims. These included:

- introducing oneself to the patient;

- inquiring about non medical issues;

- use of empathic statements;

- avoidance of medical jargon;

- clarifying patients' responses;

- ascertaining patients' beliefs about the causes of their problems and their expectations regarding evaluation and treatment so as to guide the provider's explanation of planned diagnostic and therapeutic modalities; and - allowing time for questions and explanations at the end of the interview

Duration and timing: $1 \mathrm{x}$ highly structured 30 -minute private interview with the program director

Numbers of providers receiving intervention: 9

Numbers of patients followed up in IG: not stated (114 patients followed up overall)

Review authors' score for intensity of the patient centredness of the intervention: $6 / 10$

Review authors' score for intensity of the teaching strategies used: 2/10

Control group received no training

Numbers of providers in CG: 9

numbers of patients followed up in CG: not stated (114 patients followed up overall) 


\section{Cope 1986 (Continued)}

Outcomes Consultation/practice process measures: N/A

Patient satisfaction with care: Patient's perspectives of the 'art of care' given; Patient's perspectives of the 'technical quality of care' given (for full list see Additional Table )

Healthcare behaviours: N/A

Health status and well being: N/A

Notes $\quad$ Measures used:

For patient satisfaction with care:

Type: Patient satisfaction questionnaire

Index: 14 items

Adapted from the Rand Health Insurance Study and used in Ware 1978.

For comparison, all items were adjusted so that higher scores indicated greater satisfaction

Howe 1996

Methods

Study design: RCT

Allocation procedure: Unclear if blind/secure

Protection against contamination: Unclear

Outcome assessors blind?: Unclear

Intention to treat analysis: Unclear

Potential for unit of analysis error for some outcomes?: Yes

Participants Speciality: General practitioners

Clinical setting: General practices, UK

Types of patients: Adults consulting with various problems

Interventions Content of intervention:

Training was in the form of a self-directed educational package. It aimed to help providers improve their detection of psychological distress in patients (through a process of reflexive learning). It included:

1) Written theoretical material

This included background to the role of reflection in learning and discussed strategies that can improve detection of psychological distress such as: helping people talk/show feelings; expressing empathy for patient/developing rapport; use of facilitative behaviours such as nodding and showing interest; exploring psychosocial aspects; using strategies to cover the patient's agenda

2) Assessment data on their own performance and that of their peers (from baseline video data collection stage)

This data included bar charts showing percentage of cases accurately identified as having psychological distress, and comparing study providers results with 'average' statistics

3) A checklist to help analyse four of their consultations on video (two patients had been correctly identified as distressed, two had been 'missed')

The checklist was designed to enable providers to reflect on the consultation process and to identify the extent to which they had used certain behaviours

Duration and timing: This work was undertaken in the providers own time, and within three months of doing the exercise, the data collection procedure was repeated to see if their performance as detectors of distress had altered

Numbers of providers receiving intervention: 10

Numbers of patients followed up in IG: not stated (2764 patients overall)

Review authors' score for intensity of the patient centredness of the intervention: 4/10

Review authors' score for intensity of the teaching strategies used: 1/10 


\section{Howe 1996 (Continued)}

Control group received no training

Numbers of providers in CG: 9

Numbers of patients followed up in CG: not stated (2764 patients overall)

Outcomes Consultation/practice process measures: Provider's psychological detection rate

Patient satisfaction with care: N/A

Healthcare behaviours: N/A

Health status and well being: N/A

Notes Measures used:

For provider's psychological detection rate:

Type: GP rating scale of psychological distress

Index: 6 point scale (Goldberg 1988; Crossley 1992) indicating the degree of psychological disturbance present in patient

Joos 1996

Methods Study design: RCT

Allocation procedure: Unclear if blind/secure

Protection against contamination: Unclear

Outcome assessors blind?: Unclear

Intention to treat analysis: Unclear

Potential for unit of analysis error for some outcomes?: Yes, but adjustments made

Participants Speciality: General physicians and internal medicine residents

Clinical setting: General medicine outpatient clinics, USA

Types of patients: Adults taking oral medication for at least one chronic condition

Interventions Content of intervention:

The intervention was designed to enhance providers' ability to elicit, identify and respond effectively to patient requests. Teaching methods included readings, lecture, discussion, review of videotapes, and role-playing. Outlines and two or three focused readings were prepared for each session

The first session included:

1. the importance of identifying and eliciting the patient's agenda;

2. negotiating a realistic, consensual agenda for the visit;

3. identifying patient's attributions and expectations;

4. relationship building skills and using the clinical tool (providers were encouraged to practice using this between each session).

The 16 item Patient Requests for Services questionnaire/clinical tool was designed to enhance information transfer between patient and provider. Patients filled this out prior to a clinic visit and it was attached to the front of their medical chart. Providers were encouraged to review it before seeing the patient.

The types of services patients could request on the form included information about their disease conditions and treatment; counseling regarding habit and behaviour change; discussions of their concerns with the provider; assistance with emotional and social problems; and tests and referral to specialists

The second session reviewed providers experience with using the tool during the previous week and focused on how to help patients follow recommendations

The third session was devoted to practice and feedback of skills using simulated patients who role-played four different scenarios 
Duration and timing: 3 x 90 minute sessions at two week intervals

Numbers of providers receiving intervention: 22

Numbers of patients followed up in IG: 185

Review authors' score for intensity of the patient centredness of the intervention: 9/10

Review authors' score for intensity of the teaching strategies used: $3 / 10$

Control group received training in medical decision making

Numbers of providers in CG: 20

Numbers of patients followed up in CG: 163

Outcomes Consultation/practice process measures: Provider use of clinical tool using visit; frequency with which provider elicited all of a patient's concerns; patient's perceptions of amount of information they received about their disease conditions and medications

Patient satisfaction with care: Patient's perceptions of provider's personal manner, communication skills and technical competence

Healthcare behaviours: Medication compliance; appointment keeping

Health status and well being: N/A

Notes Measures used:

For provider use of clinical tool and frequency with which all patient's concerns were elicited:

Type: Analysis of audiotapes (Roter coding system, Roter 1977)

For patient satisfaction with care:

Type: American Board of Internal Medicine Patient Satisfaction Questionnaire

Index: 26 items (Carter 1989) where 1 = poor; 5 = excellent

For patient's perceptions of amount of information they received about their disease conditions and medications:

Type: Patient questionnaire

Index: 5 point scale (no reference given) where $1=$ nothing at all; $5=$ all there is to know

For medication compliance and appointment keeping:

Type: pharmacy records; appointment files.

\section{Kinmonth 1998}

Methods Study design: RCT

Allocation procedure: Blind and secure

Protection against contamination: Unclear

Outcome assessors blind?: Yes

Intention to treat analysis: Done

Potential for unit of analysis error for some outcomes?: Yes, but adjustments made

Participants Speciality: General practitioners and practice nurses

Clinical setting: General practices, UK

Types of patients: Adults with type 2 diabetes

Interventions Content of intervention:

Practices were encouraged to base care on British Diabetic Association Guidelines. Practices were given BDA materials for the practice and for the patients as suggested resources.

At least one GP and one practice nurse from each practice attended a half day training session. During the training session they reviewed the evidence for the patient centred approach and were encouraged to consider both patient and provider agendas. They were given booklets for patients that encouraged patients to prepare for their consultation 
and the consideration of both patient and provider agendas.

Practice nurses attended a further full day of skills training to practice skills learned. These included:

- eliciting and listening well to the patient agenda;

- learning to negotiate behaviour change;

- using a framework for the consultation and behavioural change materials

Practice nurses attended two follow-up half days at six-monthly intervals for group support concerning the patient centred approach and to review recruitment to the trial with the research team

Duration and timing: For GPs = $1 \mathrm{x} 0.5$ days

For nurses $=3 \mathrm{x} 0.5$ days ( 2 were optional support sessions); $1 \mathrm{x} 1.0$ days. Timespread from 1 st to last session $=12$ months

Numbers of providers receiving intervention: 23 GPs; 32 practice nurses (21 practices)

Numbers of patients followed up in IG: 142

Review authors' score for intensity of the patient centredness of the intervention: For GPs $=3 / 10$, for nurses $=5 / 10$

Review authors' score for intensity of the teaching strategies used: For GPs $=1 / 10$, for nurses $=7 / 10$

Control group received condition specific material for providers and patients

Numbers of providers in CG: 23 practice nurses (20 practices)

Numbers of patients followed up in CG: 108

Outcomes

Consultation/practice process measures: Agreement between patient and provider on main concerns over the previous year; patient ratings of communication with doctors and nurses

Patient satisfaction with care: Patient satisfaction with treatment and style of care

Healthcare behaviours: Patients' lifestyle: diet, exercise, smoking

Health status and well being: Height; weight; mean blood triglyceride concentrations; mean haemoglobin A1c concentrations; mean total cholesterol; mean systolic and diastolic blood pressure; body mass index

Perceived control of diabetes

Functional and psychological status

Notes Measures used:

For agreement between patient and provider on main concerns over the previous year:

Type: patient questionnaire

Index: 4 point scale (no reference given)

For patient ratings of communication with doctors and nurses:

Type: patient questionnaire

Index: 6 point scale (no reference given) where $6=$ patient always able to tell practitioner very personal things, ask the practitioner about troubling things, and get the practitioner to understand his or her point of view

For patient satisfaction with treatment and style of care:

Type: patient questionnaire

Index: 36 point scale (Bradley 1994)

For patients' lifestyle:

Type: patient questionnaire

Index: Not stated (Roe 1994; Murphy 1992; Godin 1985). Smoking was confirmed by clinical measure

For all clinical health status and well being outcomes:

Type: various clinical measures

For perceived control of diabetes

Type: patient questionnaire

Index: 30 point scale (Bradley 1994)

For functional and psychological status:

Type: Quality of life and wellbeing patient questionnaire

Index: Various different scales including depression, anxiety, energy and positive wellbeing subscales (Bradley 1994) 


$\begin{array}{ll}\text { Methods } & \text { Study design: RCT } \\ \text { Allocation procedure: Unclear if blind/secure } \\ \text { Protection against contamination: Unclear } \\ \text { Outcome assessors blind? Yes } \\ \text { Intention to treat analysis: Not done (no loss to follow up) } \\ \text { Potential for unit of analysis error for some outcomes?: No }\end{array}$

Participants Speciality: Paediatric doctors

Clinical setting: Primary care practices, USA

Types of patients: Paediatric asthma patients and parents

\section{Interventions Content of intervention:}

The four teaching objectives of the intervention were; to help the patient clarify his/her concerns; to find relevant information; to offer a negotiation process and; to invite patient participation in decision making. Techniques of active listening were taught and providers were encouraged to use patient-centred communication techniques.

NB: Providers were instructed to clarify time limits and to announce explicitly a change in the topic and the structure of the communication, eg, by announcing a shift from a patient centred phase to a provider centred part The intervention consisted of three elements:

1. Initial 1.5 day seminar (14 hours) to increase awareness of possible shortcomings in provider-patient communication and to allow participants to practice (in small group sessions) alternative communication techniques through role play and the use of simulated patients. Time was devoted to the formulation of individual behaviour goals and participants filled in a goal attainment booklet (Kiresuk 1986);

2. Six progress assessment meetings ( $6 \times 45 \mathrm{mins}$, six to eight months after initial seminar). Behavioural goals are checked six times in small group sessions. Participants discuss difficulties encountered and set new goals or refine existing ones;

3. Six one-to-one preceptor feedback sessions. Participants' behaviour with patients was observed during $6 \times 1.5$ hrs sessions (either during ward rounds or during interviews with outpatients) and then results were fed back to the participant during a 20 minute session.

All participants performed two videotaped interviews with simulated patients three weeks before the intervention started and ten months later performed two videotaped interviews with simulated patients

Duration and timing: 22.5 hrs of specific communication training over a six month period

Numbers of providers receiving intervention: 20

Numbers of patients followed up in IG: 4 (actors)

Review authors' score for intensity of the patient centredness of the intervention: 9/10

Review authors' score for intensity of the teaching strategies used: 10/10

Control group received no training

Numbers of providers in CG: 23

Numbers of patients followed up in CG: 4 (same 4 actors as in IG)

Outcomes Consultation/practice process measures: Provider use of behaviours relating to:

- helping the patient clarify his/her concerns;

- finding relevant information;

- inviting patient participation in decision making;

- offering a negotiation process;

and provider overall performance throughout the entire consultation

Patient satisfaction with care: patient satisfaction scores; proportion of patients who would recommend doctor to a friend

Healthcare behaviours: N/A

Health status and well being: N/A 


Notes
For all consultation/practice process outcomes:
Type: The Maastricht History and Advice Checklist-Revised rating scale (van Thiel 1991)
Index: MAAS-R contains two types of scores; global scores ranging from 0 (does not occur), 1 (bad performance)
to 5 (very good performance) that rate either specific behaviours or the quality of eg, data gathering, and checklists
where the occurrence of a certain behaviour or the mention of specific information is marked
For patient satisfaction with care:
Type: patient questionnaire (issued by the American Board of Internal Medicine)
Index: 14 item (Matthews 1989) and also contains two dichotomous (yes/no) variables.

\section{Levinson 1993}

\section{Methods Study design: RCT}

Allocation procedure: Unclear if blind/secure

Protection against contamination: Unclear

Outcome assessors blind?: Yes

Intention to treat analysis: Unclear

Potential for unit of analysis error for some outcomes?:

yes, but adjustments made

Participants Speciality: Family practitioners and general internists

Clinical setting: Primary care practices, USA

Types of patients: Adults consulting with various problems

Interventions Content of intervention

Providers attended a workshop which reviewed a wide range of communication skills that are consistent with a 'patient-centred' style of interviewing.

The programme includes didactic presentations and case-based discussions focusing on four fundamental skills in the medical interview: engaging patient participation, communicating empathy, educating patients, and enlisting patients in healthcare discussions.

Behaviours taught included:

- eliciting the patient's concerns;

- more use of open-ended questions/less closed-ended questions;

- more giving of information about medical illness and therapy;

- more psychosocial discussion;

- more asking the patient's opinion;

- more listening and less talking;

- summarizing what the patient says;

- allowing the patient to tell a story without interrupting.

All providers in this group had give routine medical visits audiotaped prior to the workshop

and five visits audiotaped after the workshop

Duration and timing: 1x 4 1/2 hour workshop

Numbers of providers receiving intervention: 16

Numbers of patients followed up in the IG: 75

Review authors' score for intensity of the patient centredness of the intervention:9/10

Review authors' score for intensity of the teaching strategies used: $2 / 10$

Control group received no training

Numbers of providers in CG: 15 


\section{Levinson 1993 (Continued)}

Numbers of patients followed up in CG: 75

Outcomes Consultation/practice process measures: Change scores in various provider and patient centred communication behaviours (for full list see Additional Table 1);

Provider and patients' negative and positive emotions during visits

Patient satisfaction with care: N/A

Healthcare behaviours: N/A

Health status and wellbeing: N/A

Notes $\quad$ Measures used:

For all consultation/practice process outcomes:

Type: Analysis of audiotapes

Index: Roter Interactional Analysis System (Roter 1991). This system codes each phrase or complete thought in the visit, by either patient or provider, into one of 34 mutually exclusive and exhaustive content categories

Lewis 1991

Methods

Study design: RCT

Allocation procedure: Unclear if blind/secure

Protection against contamination: Unclear

Outcome assessors blind?: Yes

Intention to treat analysis: Unclear

Potential for unit of analysis error for some outcomes?: Yes, but adjustments made

Participants Speciality: Paediatric residents and fellows

Clinical setting: General paediatric practices, USA

Types of patients: Children (accompanied by their patients) consulting with various problems

Interventions Content of intervention:

The intervention targeted all three participants in the medical interview (provider, parent and child). Each participant viewed a videotape. The three tapes shared four main aims:

- to provide an opportunity for thinking about the goals of the visit;

- to suggest as an important long-term goal the child's involvement as a competent, responsible participant in health care;

- to model some of the skills needed to achieve this goal; and

- to provide research evidence suggesting the importance of a child-inclusive model of pediatric communication

Child videotape - 10 minutes/viewed immediately prior to visit.

Featured a young boy demonstrating how to communicate effectively during a medical visit. Encouraged children to see themselves as active, thoughtful participants in their own health care and modelled communication and assertiveness skills. After viewing, the children received workbooks to note down questions for providers and any information discussed. Children formulated a question they wanted to ask the provider and practiced telling it to the researcher

Parent videotape - 10 minutes/viewed just prior to visit.

Presented vignettes of medical visits which demonstrated effective communication skills for parents. Presented evidence re. importance of provider-patient communication and child involvement in health care, as well as factors that affect children's understanding of medical information

Provider videotape - 15 minutes/viewed as part of a 1 hour training session (in which they also received research articles on health consequences of effective communication, examples of appropriate interviewing techniques for

Interventions for providers to promote a patient-centred approach in clinical consultations (Review) 


\section{Lewis 1991 (Continued)}

children, and an acronym designed to remind them of critical interviewing skills).

Presented research evidence relating to children's understanding of health-related information and the consequences of effective communication. Vignettes were also used to demonstrate a number of provider communication skills, including participating with the parent and child in agenda setting, and facilitating their expression of concerns.

After each visit with study patient, providers filled out a self-assessment form designed to help them reflect on their performance.

At three months, eight months, and 15 months after intervention providers received a written reminder of the intervention, data on the reported implementation of each goal and a self-assessment form

Duration and timing: providers received $1 \mathrm{x} 1 \mathrm{hr}$ training session

Numbers of providers receiving intervention: 20

Numbers of patients followed up in IG: 81

Review authors' score for intensity of the patient centredness of the intervention: 7/10

Review authors' score for intensity of the teaching strategies used: $6 / 10$

Control group (providers, children and parents) received non patient centred educational videotape intervention (providers on assessment of febrile infants; children and parents on bicycle safety).

Numbers of providers in CG: 14

Numbers of patients followed up in CG: 60

Outcomes

Consultation/practice process measures: percentage of provider recommendations addressed to child or child and parent; number of child substantive initiations and responses; total number of statements; percentage of provider recommendations recalled by child; percentage of medication recommendations recalled by child

Patient satisfaction with care: child satisfaction with visit; parent satisfaction

Healthcare behaviours: N/A

Health status and well being: child's anxiety.

\section{Notes Measures used:}

For percentage of provider recommendations addressed to child or child and parent; number of child substantive initiations and responses; and total number of statements:

Type: Analysis of consultation videotapes

Index: A coding system (Stewart 1981) was used to code the content, direction, origin, and type (initiation, response, interruption) of each statement during the medical visit.

For percentage of provider recommendations recalled by child; percentage of medication recommendations recalled by child:

Type: three open ended questions

For child satisfaction with visit:

Type: shortened version of Child Satisfaction Questionnaire

Index: 4 point scale where 4 = high satisfaction (Rifkin 1988)

For parent satisfaction:

Type: Parent Medical Interview Satisfaction Scale

Index: 5 point scale where $5=$ high satisfaction (Lewis 1986)

For child anxiety:

Type: child questionnaire

Index: 2 point scale where 2 = high anxiety (Venham 1979) 
Allocation procedure: Unclear if blind/secure

Protection against contamination: Unclear

Outcome assessors blind?: Unclear

Intention to treat analysis: Done

Potential for unit of analysis error for some outcomes?:

Yes. Not acknowledged or adjusted for

$\begin{array}{ll}\text { Participants } & \text { Speciality: General practitioners } \\ & \text { Clinical setting: General practices, Norway } \\ & \text { Types of patients: } \\ & \text { Adult males with coronary heart disease risk }\end{array}$

Interventions Content of intervention:

The educational session aimed at encouraging and sustaining the patient's presently performed health promotion efforts, and to counsel on behaviour change after each patient had chosen their task from a menu containing options on the following lifestyle changes:

- cholesterol reduction;

- weight reduction;

- salt reduced diets;

- leisure time exercise;

- smoking cessation; and

- stress management.

Providers were instructed to restrict themselves to an advisory function and to respect patient choice. They were encouraged to ask patients about what specific behaviours they would adopt in order to achieve their chosen goals and to make written contracts with their patients

Patients were given self-help material based on cognitive behaviour change principles. They were offered a stresscoping audiotape containing general relaxation and self cognitive instructions

Duration and Timing: 1x 2 hour educational session supported by a video tape demonstration.

Numbers of providers receiving intervention: 11

Numbers of patients followed up in IG: 58

Review authors' scores for intensity of the patient centredness of the intervention: 0/10

Review authors' scores for intensity of the teaching strategies: $0 / 10$

Control group received behaviour specific material (didactic brochures, aimed at cholesterol reduction, weight reduction, salt reduced diets, leisure time exercise, and smoking cessation).

Numbers of providers in CG: 11

Numbers of patients followed up in CG: 52

Outcomes Consultation/practice process measures: N/A

Patient satisfaction with care: N/A

Healthcare behaviours: Measure of physical activity; smoking behaviour

Health status and well being: Mean systolic and diastolic blood pressure; mean total serum cholesterol; total/HDLcholesterol ratio; Mean log infarction score (relative risk of myocardial infarction compared with a female without risk factors)

Notes $\quad$ Measures used:

For measure of physical activity:

Type: Patient questionnaire

Index: one question with 7 point scale (Blair 1985) and two questions from the Nord Trondelag health survey (Maere 
Meland 1997 (Continued)

1991)

For smoking behaviour; and all other health status and well being outcomes except mean log infarction score:

Type: various clinical measures

Mean log infarction scores were based on Norwegian epidemiological data (Bjartveit 1987)

\section{Pill 1998}

Methods Study design: RCT

Allocation procedure: Unclear if Blind/ secure

Protection against contamination: Unclear

Outcome assessors blind?: Yes

Intention to treat analysis: Unclear

Potential for unit of analysis error for some outcomes?: Yes. Not acknowledged or adjusted for

Participants Speciality: General practitioners and nurses

Clinical setting: Primary care practices, UK

Types of patients: Adults with type 2 diabetes

Interventions Content of intervention:

Training sessions comprising discussion, demonstration of the technology and often role play. Continuing contact with the practices was achieved by bimonthly newsletters, personal contacts with the research nurse, two group meetings held seven months apart and by being invited to make an audio recording of one or more clinical consultations in which the method was being used.

The intervention adopted many of the principles of motivational interviewing. It aimed to encourage the provider to negotiate individual care plans that built on the patient's perceptions of their disease and their readiness to change their lifestyles. The core message was that the patient should be allowed to air their personal concerns about their condition, to select which particular topic they felt most relevant for discussion and, if appropriate, to set a specific target for themselves

A visual agenda setting chart and three other visual aids were encouraged to be used with patients (a readiness-tochange ruler; a diary and a balance chart to weigh up the pros and cons of a given change)

Duration and timing: At least two training sessions (1.5 hour sessions)

Numbers of providers receiving intervention: 15

Numbers of patients followed up in IG: 77

Review authors' score for intensity of the patient centredness of the intervention: 5/10

Review authors' score for intensity of the teaching strategies used: 7/10

Control group were provided with the standard BDA leaflets to use with their patients

Numbers of providers in CG: 14

Numbers of patients followed up in CG: 95

Outcomes Consultation/practice process measures: Patient use of various key patient centred communication behaviours (for full list see Additional Table 5)

Patient satisfaction with care: Satisfaction with recent consultations and treatment received

Healthcare behaviours: Patient attendance at practice over last 12 months; smoking and alcohol use

Health status and well being: health status and diabetes-specific measures of well being; numbers of complications;

body mass index; weight; diastolic and systolic blood pressure; glyco-Hb readings

Interventions for providers to promote a patient-centred approach in clinical consultations (Review) 
Pill 1998 (Continued)

\begin{tabular}{|c|c|}
\hline Notes & $\begin{array}{l}\text { Measures used: } \\
\text { For all consultation/practice process outcomes: } \\
\text { Type: Analysis of audiotapes (no reference given) } \\
\text { For patient attendance at practice: } \\
\text { Type: patient questionnaire (no reference given) } \\
\text { For smoking and alcohol use; complications; body mass index; weight; blood pressure; and glyco-Hb readings: } \\
\text { Type: various clinical measures } \\
\text { For health status and diabetes-specific measures of well being and patient satisfaction with recent consultations and } \\
\text { treatment received: } \\
\text { Type: SF-36 questionnaire and } 7 \text { new scales (specifically designed for the intervention, Hackett 1996). }\end{array}$ \\
\hline
\end{tabular}

\section{Putnam 1988}

Methods Study design: RCT

Allocation procedure: Unclear if blind/secure

Protection against contamination: Yes

Outcome assessors blind?: Yes

Intention to treat analysis: Unclear

Potential for unit of analysis error for some outcomes?: Yes, but adjustments made

Participants Speciality: Internal medicine residents

Clinical setting: Medical walk-in clinic, USA

Types of patients: Adults consulting with various problems

Interventions Content of intervention:

Group sessions followed by individual sessions where the trainer reviewed audiotapes of the provider's recent encounter with a patient (focusing on the provider's listening skills and provider's explanations of the patient's illness or its treatment).

In group sessions, active listening and giving thorough information about illness and treatment was stressed and techniques discussed included:

- using respectful silence, verbal encouragements, occasional reflections;

- avoidance of asking too many questions (especially closed) during first five minutes of interviews;

- avoidance of using evaluative words to acknowledge patient communication;

- the importance of spending time giving patients information; and

- the importance of giving information in non-technical terms.

Providers participated in an active listening exercise during this group session

Each provider was given a short manual that described and gave examples of patient exposition and provider explanation

Duration and timing: One or two group sessions followed by five or six individual sessions. Total average training time $=3.7$ hours, of which 2.3 hours was spent in individual sessions

Numbers of providers receiving intervention: 11

Numbers of patients followed up in IG: 156

Review authors' score for intensity of the patient centredness of the intervention: $4 / 10$

Review authors' score for intensity of the teaching strategies: $5 / 10$

Interventions for providers to promote a patient-centred approach in clinical consultations (Review) 


\section{Putnam 1988 (Continued)}

Control group received no training

Numbers of providers in CG: 8

Numbers of patients followed up in CG: 112

Outcomes Consultation/practice process measures: Provider and patient use of various patient centred communication behaviours (for full list see Additional Table 1)

Patient satisfaction with care:

Affective satisfaction (provider warmth and patient feelings of trust, confidence, freedom to express herself, eg. 'the doctor seemed interested in me as a person');

Cognitive satisfaction (provider information-giving and patient understanding of the diagnosis, etiology, prognosis, and treatment of the illness, eg. 'After talking with the doctor, I know just how serious my illness is').

Health care behaviours: Behavioural; medication; and appointment adherence

Health status and well being: Symptom improvement

\section{Notes $\quad$ Measures used:}

For all consultation/practice process outcomes:

Type: Analysis of audiotapes

Index: Coded using a general-purpose conceptually-based taxonomy of verbal response modes (Stiles 1978)

For patient satisfaction (affective and cognitive):

Type: Medical Interview Satisfaction Scale (MISS)

Index: 28 item with 7 point scale ranging from 'very strongly agree' to 'very strongly disagree' (Wolf 1978; Wolf 1980; Wolf 1981)

For behavioural and medication adherence:

Type: Structured telephone interviews

For appointment adherence:

Type: Outpatient appointment books checked

For symptom improvement:

Type: patient questionnaire

Index: 3x5 point scales (Mushlin 1978)

\section{Robbins 1979}

Methods Study design: RCT

Allocation procedure: Unclear if blind/secure

Protection against contamination: Unclear

Outcome assessors blind?: Yes

Intention to treat analysis: Done

Potential for unit of analysis error for some outcomes?: No

Participants Speciality: Internal medicine residents

Clinical setting: Hospital department of Internal Medicine, USA

Types of patients: Adults consulting with various problems 
Robbins 1979 (Continued)

Interventions Content of intervention:

Training involved critically reviewing videotapes of consultations and discussion of the following issues:

1. responding effectively to patients in four response modes (exploring, listening, affective reacting, and honest labelling);

2. dealing with patients who arouse affect in the physician;

3. dealing with older patients;

4. learning what it means to be a 'good doctor';

5. dealing with common patient fears;

6. incorporating specific interviewing tools into the provider's individual interpersonal style.

For the remainder of the two month rotation, providers reviewed one or two of their own patient interviews per week with a trained faculty member. There were also weekly meetings during which the learned skills were practiced and defined

Upon completion of the programme, the provider should be able to perform a medical interview that effectively demonstrates the use of facilitating responses, attention to psychosocial aspects of illness, and expression of empathy.

Duration and timing: $8 \times 1-2$ hours training (over a two month period)

Numbers of providers receiving intervention: 26

Numbers of patients followed up in IG: Not stated (no patient numbers given)

Review authors' score for intensity of the patient centredness of the intervention: 2/10

Review authors' score for intensity of the teaching strategies: 9/10

Control group received no training

Numbers of providers in CG: 25

Numbers of patients followed up in CG: Not stated (no patient numbers given)

Outcomes Consultation/practice process measures: Provider empathy scores; various provider interview behaviours (for full list see Additional Table 1)

Patient satisfaction with care: N/A

Health care behaviours: N/A

Health status and well being: N/A

Notes $\quad$ Measures used:

For rating the level of empathy:

Type: analysis of videotapes

Index: The Carkhuff rating scale was used (Truax 1967)

For various provider interview behaviours:

Type Analysis of videotapes

Index: The Kagan rating scale was used to rate specific interview skills taught (Kagan 1975) and the Brockway scale was used to rate use of appropriate medical interviewing skills (Brockway 1978) 
Methods Study design: RCT

Allocation procedure: Unclear if blind/secure

Protection against contamination: Not done

Outcome assessors blind?: Yes

Intention to treat analysis: Not done

Potential for unit of analysis error for some outcomes?: Yes, but adjustments made

Participants Speciality: Primary care physicians

Clinical setting: Internal medicine and family practice, USA

Types of patients:

Adults consulting with various problems

Interventions Content of Intervention:

Emotion-Handling skills intervention group $(\mathrm{EH})$

The sessions involved lectures, discussion and role play.

The first two hours of the first session consisted of:

1) 20 minute presentation on rationale for the CME programme, including the epidemiology of psychologic problems

in primary care and the relation between communication skills and positive patient outcomes;

2) 40 minute informal round-table discussion on prevalence and types of psychosocial problems typically encountered

in their practices;

3) 40 minute interactive presentation on common DSM-III defined disorders, modes of presentation of these disorders in primary care. Participants were given a syllabus that included a bibliography and case examples; operational definitions of the communication skills to be taught; and $3 \times 5$ cards that summarised targeted skills

The last two hours of the first session and all of the second session consisted of small group work focusing on practice of targeted skills (with preceptor and a simulated patient). Skills were displayed on a flip chart

Homework assignment given between the two sessions. Providers given a portable tape-recorder to tape themselves practicing skills on one or two patients. Tapes brought to second session for discussion.

Emotion-Handling Skills included:

Signaling receptivity by

1) asking patients about their feelings

2) listening more, talking less

3) following up signs of patients' emotional distress

Showing positive regard by

4) complimenting patient efforts

5) making statements of legitimation (explicitly stating that patients' feelings/views are normal or understandable)

Expressing mutuality by

6) expressing empathy (accurately acknowledging an emotion expressed by the patient)

7) making explicit statements of partnership or support

8) providing appropriate reassurance

Problem-defining skills intervention group (PD)

Identical in all aspects to group 1a, except in skills trained

The sessions involved lectures, discussion and role play.

The first two hours of the first session consisted of:

1. 20 minute presentation on rationale for the CME programme, including the epidemiology of psychologic problems in primary care and the relation between communication skills and positive patient outcomes.

2. 40 minute informal round-table discussion on prevalence and types of psychosocial problems typically encountered in their practices

3. 40 minute interactive presentation on common DSM-III defined disorders, modes of presentation of these disorders in primary care. Participants were given a syllabus that included a bibliography and case examples;

Interventions for providers to promote a patient-centred approach in clinical consultations (Review) 


\section{Roter 1995 (Continued)}

operational definitions of the communication skills to be taught; and 3x5 cards that summarised targeted skills. The last two hours of the first session and all of the second session consisted of small group work focusing on practice of targeted skills (with preceptor and a simulated patient). Skills were displayed on a flip chart

Homework assignment given between the two sessions. Providers were given a portable tape-recorder to tape themselves practicing skills on one or two patients. Tapes brought to second session for discussion

Problem-defining skills included:

Eliciting the full spectrum of patient concerns by

1) resisting immediate follow-up of the patient's first expressed concern

2) asking the patient explicitly about other problems or concerns ('anything else'), including problems of daily living and stressors

3) prioritising with patients (negotiating use of time)

Delineating the patient's problem by:

4) starting with open-ended questions

5) using facilitative statements to help patients' tell their story in their own words

6) Assessing the effect of the patient's problem on psychosocial functioning

Understanding the patient's perspective by:

7) Probing explicitly for patients' understanding and expressing concern about their problem(s)

8) Clarifying patient expectations for the visit

Duration and timing: Both intervention groups attended $2 \times 4$ hour sessions given one week apart in the evening

Numbers of providers receiving intervention: $\mathrm{EH}=22 ; \mathrm{PD}=23$

Numbers of patients followed up in IG: Not stated (311 patients overall)

Review authors' score for intensity of the patient centredness of the intervention: $\mathrm{EH}=3 / 10 ; \mathrm{PD}=8 / 10$

Review authors' score for intensity of the teaching strategies used: $E H=6 / 10 ; P D=6 / 10$

Control group received no training

Numbers of providers in CG: 24

Numbers of patients followed up in CG: Not stated (311 patients overall)

Outcomes Consultation/practice process measures: Provider use of various patient centred communication skills (EH and PD); provider recognition of emotional problems/distress; provider management of emotional problems; clinical proficiency in identifying distress

Patient satisfaction with care: N/A

Healthcare behaviours: Utilisation of health care by GHQ positive patients

Health status and well being: GHQ status of patients who were GHQ positive at baseline

Notes $\quad$ Measures used:

For provider use of communication skills:

Type: analysis of audiotapes

Index: a study-specific method of coding was designed (no reference given)

For provider recognition of emotional problems/distress and provider management of emotional problems:

Type: provider self report

Index: no reference given

For clinical proficiency in identifying distress:

Type: analysis of audiotapes and consultation letters

For healthcare utilisation:

Type: telephone interview, where patients were asked about number of visits to provider 


\section{Roter 1995 (Continued)}

For GHQ status of patients who were GHQ positive at baseline:

Type: Patient General Health Questionnaire

Index: 28 items (Goldberg 1988)

Roter 1998

Methods

Study design: CBA

Allocation procedure: Doctors were not randomised (those who did not attend the training were allocated to control)

Protection against contamination: Not done (some doctors drawn from the same clinics)

Outcome assessors blind?: Yes

Intention to treat analysis: Not done

Potential for unit of analysis error for some outcomes?: Yes, but adjustments made

Participants Speciality: Primary care physicians (trained in internal medicine or family practice)

Clinical setting: Ministry of Health $(\mathrm{MOH})$ clinics, Trinidad and Tobago

Types of patients: Adults with a chronic disease

Interventions Content of intervention:

The first day was divided into three parts:

1) An overview of the literature and rationale for the CME describing basic research regarding links between interpersonal communication and patient and doctor outcomes;

2) Presentation of the results of the baseline study conducted in the $15 \mathrm{MOH}$ clinics prior to training;

3) The last two hours of the first session and all of the second day's session were devoted to role play and practice of specific communication skills

Skills emphasised were informativeness, emotional responsiveness, and partnership building.

Informative elements emphasised in the training were increased information giving in both the biomedical and psychosocial realms. Also included in this domain was an emphasis on increasing providers' use of open-ended questions.

In the affective domain, emotional responsiveness was emphasised, including statements of concern, empathy, and reassurance, as well as positive exchanges.

As a method of enhancing patient involvement in the process of care, and thereby building a stronger therapeutic partnership, providers were encouraged to use facilitations, which include paraphrase, interpretations, and signals of interest.

Participants were provided with a detailed and annotated manual defining the target skills, transcripts of sample $\mathrm{MOH}$ medical visits, an overview of patient and doctor questionnaire results, and selected readings and bibliography

Duration and timing: $2 \mathrm{x} 4 \mathrm{hr}$ sessions given over two day period

Numbers of providers receiving intervention: 10 (3 for one day of training only)

Numbers patients followed up in IG:43

Review authors' score for intensity of the patient centredness of the intervention: $6 / 10$

Review authors' score for intensity of the teaching strategies used: 6/10

Control group received no training

Numbers of providers in CG: 8

Numbers of patients followed up in CG: 28

Outcomes

Consultation/practice process measures: Provider talk and emotional tone during visits; patient talk and emotional tone during visits; verbal dominance: ratio of all doctor to patient statements; (for full list see Additional Table 1)

Patient satisfaction with care: Pre/post satisfaction change scores 


\section{Roter 1998 (Continued)}

Healthcare behaviours: N/A

Health status and well being: N/A

Notes Measures used:

For all consultation process outcomes:

Type: Analysis of audiotapes

Index: Roter Interactional Analysis System (RIAS) (Roter 1997)

For patient satisfaction:

Type: patient questionnaire

Index: 9 item on a 2 point scale (no reference given)

Smith 1995

Methods Study design: RCT

Allocation procedure: Unclear if blind/secure

Protection against contamination: Not done

Outcome assessors blind?: Yes

Intention to treat analysis: Done

Potential for unit of analysis error for some outcomes? Yes, but adjustments made

Participants Speciality: Internal medicine and family residents

Clinical setting: Primary care outpatients clinics

Types of patients: Adults consulting with various problems

Interventions Content of intervention:

A psychosocial training program presented as a four week block rotation.

The training was experiential and skills oriented and was guided by competency-based objectives that were both learner and teacher centred. General teacher centred objectives (for which there were explicit learning models) fell into four categories: interviewing, somatisation, patient education, and self-awareness

The teaching had three components:

- core learning experiences (which included background discussion; demonstration; modelling; and role play);

- interviewing (emphasising psychosocial aspects of the patient);

- patient management rounds (emphasising skills to address the newly identified psychosocial issues)

NB: same training intervention as in Smith 1998

Duration and timing: No specific details provided (training sessions over four week period)

Numbers of providers receiving intervention: 15

Numbers of patients followed up in the IG: Not stated (approximately 78 overall)

Review authors' score for intensity of the patient centredness of the intervention: $3 / 10$

Review authors' score for intensity of the teaching strategies used: 10/10

Control group received no training

Numbers of providers in CG: 14

Numbers of patients followed up in the CG: Not stated (approximately 78 overall)

Outcomes

Consultation/practice process measures: N/A

Patient satisfaction with care: patients' assessments of their opportunity to disclose things to the provider; provider

Interventions for providers to promote a patient-centred approach in clinical consultations (Review)

Copyright $\Subset 2012$ The Cochrane Collaboration. Published by John Wiley \& Sons, Ltd. 


\section{Smith 1995 (Continued)}

empathy; their confidence in provider abilities; general satisfaction with medical appointments; and comparison of the provider with other providers

Healthcare behaviours: N/A

Health status and well being: N/A

Notes $\quad$ Measures used:

For patient satisfaction:

Type: patient questionnaire

Index: 29 items with a 5 point scale where $1=$ highly dissatisfied to $5=$ highly satisfied and (for comparison of provider with others) a 7 point scale where $1=$ poor in comparison to $7=$ excellent in comparison (no reference given, developed by authors)

Smith 1998

Methods Study design: RCT

Allocation procedure: Unclear if blind/secure

Protection against contamination: Unclear

Outcome assessors blind?: Yes

Intention to treat analysis: Unclear

Potential for unit of analysis error for some outcomes?: Yes, but adjustments made

Participants Speciality: Medical/family residents in postgraduate year 1

Clinical setting: Primary care outpatient clinics, USA

Types of patients: Adults consulting with various problems

Interventions Content of intervention:

The training was experiential and skills oriented and was guided by competency-based objectives that were both learner and teacher centred. The focus of the training was efficient data gathering, emotion handling, patient education, and the management of psychosocial and psychiatric problems in primary care settings

Four interviewing models were used to enhance learning:

1. basic patient-centred interviewing and provider-patient relationship model. This focused on placing the patient's needs and the provider-patient relationship first. This basic model was developed to include other skill areas such as:

2. interacting with patients who had chronic somatization using cognitive-behavioural principles;

3. informing and motivating patients to take a new course of action; and

4. giving patients bad news.

Non-interviewing training objectives included helping providers develop self-awareness of potentially harmful personal reactions.

During training, a brief discussion of each interviewing model (or other objective) was followed by demonstration of and repeated practice with the model through role playing.

Providers were given a syllabus of required readings and other materials

Duration and timing: $12 \mathrm{x}$ seminar sessions and $20 \mathrm{x}$ supervisory sessions. Training took place in a four week full time teaching (residency) block

Numbers of providers receiving intervention: 31

Numers of patients followed up in IG: Not stated

Review authors' score for intensity of the patient centredness of the intervention: $2 / 10$

Review authors' score for intensity of the teaching strategies used: 10/10

Control group received no training

Interventions for providers to promote a patient-centred approach in clinical consultations (Review) 


\section{Smith 1998 (Continued)}

Numbers of providers in CG: 32

Numers of patients followed up in CG: Not stated

Outcomes Consultation/practice process measures: Provider use of various data gathering skills with actual patient; provider use of various data gathering skills with simulated patient; provider use of various informing and motivating skills with simulated patient (for full list see Additional Table 1)

Patient satisfaction with care: Patient satisfaction with; opportunity to discuss concerns; provider empathy; confidence in provider's abilities; visit overall

Healthcare behaviours: N/A

Health status and well being: Patients' physical and psychosocial well being

Notes $\quad$ Measures used:

For all consultation/practice process measures:

Type: Analysis of audio and videotapes of consultations

Measure: No reference given

For patient satisfaction:

Type: Patient questionnaire

Index: 29 item, 5 point scale (Smith 1995)

For patients' physical and psychosocial well being:

Type: General Health Questionnaire and Functional Health Questionnaire

Index: Not stated (Goldberg 1979; Greenfield 1985)

\section{Thom 1999}

\section{Methods Study design: RCT}

Allocation procedure: Unclear if blind/secure

Protection against contamination: Unclear

Outcome assessors blind?: Unclear

Intention to treat analysis: Unclear

Potential for unit of analysis error for some outcomes: Yes, but acknowledged and adjusted for

Participants Speciality: Community- based family physicians

Clinical setting: Community- based family practices, USA

Types of patients: Adults consulting with various problems

Interventions Content of intervention

Workshop designed to teach skills that build and maintain patient-provider trust. It addressed:

- models of patient-provider relationship;

- goals for the office visit; barriers to achieving these goals; and techniques for overcoming these barriers;

- an adapted version of the 'Bayer Communication Workshop' ;

- patients' experiences with patient-provider trust (as described in prior focus groups)

Specific behaviours related to developing trust were targeted:

- greetings to demonstrate respect and connect with patient as person;

- eliciting/ acknowledging patients' goals for visit;

- demonstrating thoroughness in history taking and examination; 
- negotiating a mutually agreeable treatment plan;

- answering questions/ explaining;

- arranging follow-up/access.

Problem-based learning techniques were used. The workshop included brief didactic presentations, group discussion, viewing of videotaped encounters with patients, and role-playing

Duration and timing: Seven hours (one day workshop)

Numbers of providers receiving intervention: 10

Numbers of patients followed up in IG: Not stated (343 patients overall)

Review authors' score for intensity of the patient centredness of the intervention: 5/10

Review authors' score for intensity of the patient centredness of the teaching strategies used: 5/10

Control group received no training

Numbers of providers in CG: 10

Numbers of patients followed up in CG: Not stated (343 patients overall)

Outcomes Consultation/practice process measures: Provider's humaneness during visit

Patient satisfaction with care: Patient's satisfaction with visit; patient's trust in the provider

Healthcare behaviours: Continuity with study provider; adherence to advice or prescribed medication; number of referrals made; number of diagnostic tests ordered

Health status and well being: N/A

Notes

Measures used:

For provider's humaneness during visit:

Type:Patient questionnaire (Physician Humanistic Behaviours Questionnaire)

Index: 19 items (Weaver 1993)

For patient satisfaction with visit:

Type: patient questionnaire

Index: not stated (Davis 1991)

For patient trust in the provider:

Type: patient questionnaire (Trust in the Physician scale)

Index: not stated (Anderson 1990)

For continuity with study provider and adherence to advice or prescribed medication:

Type: Patient questionnaire

Index: 2 questions (no reference given)

For numbers of referrals made and number of diagnostic tests ordered:

Type: Data from patients' charts 
Characteristics of excluded studies [ordered by study ID]

\begin{tabular}{|c|c|}
\hline Study & Reason for exclusion \\
\hline Alroy 1984 & Intervention did not meet patient centred criteria. \\
\hline Baile 1997 & Ineligible study design. No relevant outcomes assessed. \\
\hline Baile 1999 & $\begin{array}{l}\text { Intervention did not meet patient centred criteria. } \\
\text { Ineligible study design. No relevant outcomes assessed. }\end{array}$ \\
\hline Beckman 1990 & Intervention did not meet patient centred criteria. Ineligible study design \\
\hline Bensing 1985 & Ineligible study design. \\
\hline Berg 1983 & Intervention did not meet patient centred criteria. Ineligible study design. No relevant outcomes assessed \\
\hline Blaasvaer 1998 & Intervention not directed at health care providers. \\
\hline Bohme 1998 & Patients are receiving psychotherapeutic treatment. \\
\hline Breunlin 1990 & No relevant outcomes assessed. \\
\hline Calhoun 1985 & Intervention did not meet patient centred criteria. Ineligible study design \\
\hline Caris-Verhallen 2000 & Not focused on clinical consultation. \\
\hline Covinsky 1998 & Intervention not directed at health care providers. \\
\hline Cox 1981 & Ineligible study design. Intervention not directed at health care providers \\
\hline Cummings 1989 & Intervention did not meet patient centred criteria. \\
\hline Dick 1997 & Intervention not directed at health care providers. \\
\hline Dougherty 1998 & Intervention did not meet patient centred criteria. \\
\hline Douglas 1996 & Intervention not directed at health care providers. \\
\hline Edberg 1996 & Intervention did not meet patient centred criteria. \\
\hline Eijkman 1977 & No numerical data available (contacted authors). \\
\hline Ericson 1997 & Ineligible study design. \\
\hline Evans 1987 & Intervention did not meet patient centred criteria. \\
\hline Evans 1991 & Intervention did not meet patient centred criteria. \\
\hline
\end{tabular}


(Continued)

\begin{tabular}{|c|c|}
\hline Evans 1992 & Intervention did not meet patient centred criteria. \\
\hline Evans 1993 & Ineligible study design. \\
\hline Fallowfield 1998 & Intervention did not meet patient centred criteria. Ineligible study design. No relevant outcomes assessed \\
\hline Family Heart Study & Intervention did not meet patient centred criteria. \\
\hline Farhall 1998 & Ineligible study design. \\
\hline Farsad 1978 & Intervention did not meet patient centred criteria. \\
\hline Fine 1977 & No relevant outcomes assessed. \\
\hline Finnema 2000 & Not focused on clinical consultation. \\
\hline Foley 1997 & Intervention did not meet patient centred criteria. \\
\hline Fox 1997 & Intervention not directed at health care providers. \\
\hline Goldberg 1980 & Intervention did not meet patient centred criteria. \\
\hline Greenberg 1999 & Intervention did not meet patient centred criteria. Ineligible study design \\
\hline Greenfield 1988 & Intervention not directed at health care providers. \\
\hline Guillory-Dunbar 1994 & Intervention did not meet patient centred criteria. Ineligible study design. No relevant outcomes assessed \\
\hline Haisch 1996 & Intervention not directed at health care providers. \\
\hline Handmaker 1999 & Intervention not directed at health care providers. \\
\hline Hebert 1992 & Follow up data to Ockene 1991. \\
\hline Hunsdon 1984 & Ineligible study design. No relevant oucomes assessed. \\
\hline Inui 1976 & Intervention did not meet patient centred criteria. \\
\hline Jacob 1988 & No relevant outcomes assessed (contacted authors). \\
\hline Johnson 1996 & Intervention did not meet patient centred criteria. \\
\hline Kauss 1980 & Ineligible study design. \\
\hline Kihlgren 1990 & Intervention was outwith clinical consultation. \\
\hline Kihlgren 1992 & Intervention was outwith clinical consultation. \\
\hline
\end{tabular}


(Continued)

\begin{tabular}{|c|c|}
\hline Kihlgren 1993 & Intervention was outwith clinical consultation. \\
\hline Kosower 1996 & Ineligible study design. \\
\hline Kramer 1987 & Intervention did not meet patient centred criteria. \\
\hline Ladyshewsky 1997 & Intervention did not meet patient centred criteria. Ineligible study design \\
\hline Landefeld 1995 & Intervention did not meet patient centred criteria. Intervention not directed at health care providers \\
\hline Llewellyn-Jones 1999 & Intervention did not meet patient centred criteria. \\
\hline Maguire 1977 & Intervention did not meet patient centred criteria. \\
\hline Maguire 1986 & Intervention did not meet patient centred criteria. \\
\hline Maiman 1988 & Intervention did not meet patient centred criteria. \\
\hline Maisiak 1996 & Intervention not directed at health providers. Intervention was outwith clinical consultation \\
\hline Martin 1998 & Intervention not directed at health care providers. \\
\hline Mayer 1998 & Ineligible study design. \\
\hline McCourt 1998 & Intervention did not meet patient centred criteria. Intervention not directed at health care providers \\
\hline McManus 1993 & Ineligible study design. \\
\hline Meland 1996 & Intervention did not meet patient centred criteria. \\
\hline Miller 1993 & Not directed at health care providers (All health care providers received patient centred care intervention) \\
\hline Morgan 1996 & Ineligible study design. \\
\hline Myers 1991 & Ineligible study design. No relevent outcomes assessed. \\
\hline Nathan 1991 & Ineligible study design. \\
\hline Novack 1992 & Ineligible study design. \\
\hline Ockene 1988 & Ineligible study design. \\
\hline Ockene 1991 & $\begin{array}{l}\text { Not directed at health care providers (All health care providers received patient centred care intervention) } \\
\text {. Authors contacted }\end{array}$ \\
\hline Ockene 1994 & Not directed at health care providers (All health care providers received patient centred care intervention) \\
\hline
\end{tabular}


(Continued)

\begin{tabular}{|c|c|}
\hline Ockene 1995 & For outcome of interest, ineligible study design. \\
\hline Ockene 1997 & For outcome of interest, ineligible study design. \\
\hline Ockene 1999 & Ineligible intervention (secondary, additional health-provider initiated component of the consultation) \\
\hline Ockene $1999 \mathrm{~b}$ & Ineligible intervention (secondary, additional health-provider initiated component of the consultation) \\
\hline Ogden 1997 & No relevant outcomes assessed. \\
\hline Olson 1987 & Intervention did not meet patient centred criteria. Ineligible study design \\
\hline OXCHECK study group & Intervention not directed at health care providers. \\
\hline Perkonigg 1995 & No relevant outcomes assessed (contacted authors). \\
\hline Phillips 1997 & Ineligible study design. \\
\hline Poole 1979 & Intervention did not meet patient centred criteria. \\
\hline Quirk 1993 & Not directed at health care providers (All health care providers received patient centred care intervention) \\
\hline Rabinowitz 1994 & Intervention did not meet patient centred criteria. Ineligible study design. No relevant outcomes assessed \\
\hline Razavi 1988 & Does not meet our criteria for patient centred care intervention. No relevant outcomes assessed \\
\hline Robins 1989 & No relevant outcomes assessed. \\
\hline Roche 1996 & Intervention did not meet patient centred criteria. \\
\hline Rollnick 1997 & Ineligible study design. \\
\hline Roter 1990 & Intervention did not meet patient centred criteria. \\
\hline Saltmarche 1998 & Ineligible study design. \\
\hline Sanson-Fisher 1978 & Intervention did not meet patient centred criteria. \\
\hline Scheidt 1986 & Intervention did not meet patient centred criteria. \\
\hline Schubert 1989 & Intervention was outwith the clinical consultation. \\
\hline Seim 1995 & Ineligible study design. \\
\hline Sidorov 1997 & Ineligible study design. Intervention did not meet patient centred criteria \\
\hline Simek-Downing 1985 & Intervention did not meet patient centred criteria. Ineligible study design \\
\hline
\end{tabular}


(Continued)

\begin{tabular}{|c|c|}
\hline Simkin-Silverman 1997 & Intervention did not meet patient centred criteria. \\
\hline Smith 1991 & No relevant outcomes assessed. \\
\hline Snoek 1986 & Intervention did not meet patient centred criteria. Ineligible study design \\
\hline Stein 1999 & Ineligible study design. \\
\hline Steyn 1997 & Ineligible study design. \\
\hline Stillman 1977 & Intervention did not meet patient centred criteria. \\
\hline Szekely 1986 & Ineligible study design. Intervention did not meet patient centred criteria \\
\hline Ter Horst 1980 & Ineligible study design. \\
\hline Ter Horst 1984 & Intervention did not meet patient centred criteria. No relevant outcomes assessed \\
\hline Teusch 1997 & Intervention did not meet patient centred criteria. Intervention not directed at health care providers \\
\hline Thompson 1982 & Ineligible study design. \\
\hline Thompson 1990 & Intervention not directed at health care providers. \\
\hline Utting 2000 & Ineligible study design. \\
\hline Vaidya 1999 & Intervention did not meet patient centred criteria. Ineligible study design \\
\hline Vail 1996 & Ineligible study design. No relevant outcomes assessed. \\
\hline Verhaak 1988 & Ineligible study design. \\
\hline Ward 1975 & Ineligible study design. \\
\hline Ward 1996 & Intervention did not meet patient centred criteria. \\
\hline White 1999 & Ineligible study design. \\
\hline Wilkinson 1998 & Ineligible study design. \\
\hline Willetts 1997 & Ineligible study design. \\
\hline Wist 1993 & Intervention did not meet patient centred criteria. Ineligible study design. No relevant outcomes assessed \\
\hline
\end{tabular}




\section{DATA ANDANALYSES}

This review has no analyses.

\section{A D DITIONAL TABLES}

Table 1. Patient centred training for providers versus control: Consultation processes

\section{Study ID}

Howe 1996

Within 3 months of intervention, IG providers detected a significantly greater amount of psychological distress in patients who had previously been identified as having high emotional distress scores. At baseline, the mean proportion of cases detected by the IG $=43 \%$ and the $\mathrm{CG}=45 \%$. After the intervention, the mean proportion of cases detected by the IG increased to $52 \%$ (range 35 to $66 \%, 95 \%$ CI 0.21 to 083 ), while the rating of the CG deteriorated slightly to $44 \%$ (95\%CI 0.21 to 0.77 ). Comparing the proportion of cases detected in the second data collection to the first, there was a statistically significant difference between IG and CG $(\mathrm{P}<0.05)$

At approximately 10 months post intervention, there were statistically significant between group differences post intervention (favouring IG) for the following items (scores for specific behaviour or quality aspects $0=$ does not occur; $1=$ bad performance, to $5=$ very good performance. For script-specific items, raters provided a mark whenever the information was mentioned during an interview): Acknowledging initial complaints $(\mathrm{CG}=2.89 \pm 0.68, \mathrm{IG}=$ $3.60 \pm 0.98 ; \mathrm{P}<0.005)$; take up emotions $(\mathrm{CG}=2.30 \pm 0.79, \mathrm{IG}=3.34 \pm 0.91 ; \mathrm{P}<0.001)$ ;Use of checking $(\mathrm{CG}=1.08 \pm 0.87 ; \mathrm{IG}=4.00 \pm 1.12 ; \mathrm{P}<0.001)$; Clarify consultation reasons $(\mathrm{CG}=3.08 \pm 0.72, \mathrm{IG}=4.00 \pm 0.74 ; \mathrm{P}<0.001)$; sum score of medical facts $(\mathrm{CG}=6.10 \pm 1$. $07, \mathrm{IG}=6.89 \pm 1.14 ; \mathrm{P}<0.02)$; communicate about treatment options $(\mathrm{CG}=2.86 \pm 1.51$, $\mathrm{IG}=4.23 \pm 1.59 ; \mathrm{P}<0.009)$; communicate about feasibility of treatment $(\mathrm{CG}=2.80 \pm 2.29$, $\mathrm{IG}=4.84 \pm 2.04 ; \mathrm{P}<0.004)$; communicate about future prospects $(\mathrm{CG}=3.82 \pm 1.65$, IG $=5.39 \pm 2.35 ; \mathrm{P}<0.02)$; explicit announcement of history-taking phase $(\mathrm{CG}=1.30 \pm 1.58$, $\mathrm{IG}=3.79 \pm 1.61 ; \mathrm{P}<0.001)$; generally structuring the conversation $(\mathrm{CG}=2.55 \pm 0.61, \mathrm{IG}=$ $3.81 \pm 0.73 ; \mathrm{P}<0.001)$; shared assessment of the consultation $(\mathrm{CG}=1.79 \pm 1.73$, IG $3.61 \pm$ 0.77 ; $\mathrm{P}<0.001)$; global evaluation of consultation structure $(\mathrm{CG}=2.55 \pm 0.61, \mathrm{IG}=3.87 \pm$ 0.77 ; $\mathrm{P}<0.001)$; patient-centred communication style $(\mathrm{CG}=3.14 \pm 0.85, \mathrm{IG}=3.92 \pm 0.74$; $\mathrm{P}<0.002)$; involvement of patients in decision making $(\mathrm{CG}=2.89 \pm 0.98, \mathrm{IG}=4.01 \pm 0.74$; $\mathrm{P}<0.001$ ). There were no statistically significant between group differences reported for the following items: empathy in greeting behaviour; characterise complaints; finding information about time course of complaints, etiological factors, impact on daily life, previous treatment, family history, personal history, addiction, drugs, system history, sum score of psychological facts; convey information about results, preliminary diagnosis, etiology of symptoms, and prognosis

One month post intervention, there were no statistically significant between group differences post intervention for the following provider behaviours: positive talk; biomedical information giving; closed ended questions; open ended questions; psychosocial talk; and in the following patient behaviours: biomedical information giving; psychosocial talk. There was also no statistically significant between group differences for provider/patient positive or negative emotional tone rating during visit 
Table 1. Patient centred training for providers versus control: Consultation processes (Continued)

Putnam 1988

Robbins 1979
Immediately post intervention, there were statistically significant differences between interviews before and after training in the IG for the following behaviours: frequency of patient exposition in history segment $($ pre $=66.5$, post $=95.1, \mathrm{SE}$ of difference $=10.6, \mathrm{P}<0.05$ ) ; percentage of patient exposition in history segment (pre $=64.8$, post $=73.0$, SE of difference $=1.4, \mathrm{P}<0.001)$; percentage of patient yes $/$ no responses $($ pre $=23.6$, post $=15.0, \mathrm{SE}$ of difference 2.2, $\mathrm{P}<0.01$ ); percentage of provider acknowledgements in history segment (pre $=24.7$, post $=33.9, \mathrm{SE}$ of difference $=2.2, \mathrm{P}<0.05$ ); frequency of provider reflection in history segment ( pre $=5.6$, post $=3.1, \mathrm{SE}$ of difference $=0.8, \mathrm{P}<0.05$ ); percentage of provider reflection in history segment (pre $=6.3$, post $=3.9, \mathrm{SE}$ of difference $=0.5, \mathrm{P}<0$. 001 ); frequency of provider explanation in conclusion segment (pre $=22.2$, post $=29.1$, SE of difference 3.1, P < 0.05). No statistically significant within IG differences were reported for the following: frequency of patient yes/no responses in history segment; frequency of provider acknowledgement in history segment; frequency or percentage of provider question asking or use of truncators; percentage of provider explanations and in the total number of provider and patient utterences throughout the interview. There were statistically significant within control group differences reported for the following behaviours: percentage of patient exposition in history segment (pre $=63.9$, post $=69.3$, SE of difference $=2.1, \mathrm{P}<0.05$ ); percentage of patient yes/no responses (pre $=24.8$, post $=18.5$, SE of difference 2.2, $\mathrm{P}<0.05$ ); percentage of provider reflections in history segment (pre $=8.4$, post $=5.2, \mathrm{SE}$ of difference $1.0, \mathrm{P}<0.05$ ). There were no statistically significant within control group differences for frequency of patient exposition and yes/no responses; frequency of provider acknowledgements, question asking, use of truncators, reflections and explanations; percentage of provider acknowledgements, question asking, use of truncators, reflections or explanations. There was also no statistically significant within control group differences for total number of provider/patient utterances throughout the interview mean levels of provider empathy (pre $=2.34$, post $=2.68, \mathrm{P}<0.05$ ); mean number of provider empathic responses (pre $=2.00$, post $=4.10, \mathrm{P}<0.05$ ); percentage of provider medical responses (pre $=83.7 \%$, post $=66.8 \% \mathrm{P}<0.05$ ); percentage of provider psychosocial responses (pre $=5.5$, post $=17.8, \mathrm{P}<0.05$ ) and percentage of provider affective responses (pre $=0.9$, post $=4.1, \mathrm{P}<0.05$ ) . No statistically significant within IG differences were reported for percentage of provider exploratory, listening, honest labeling, yes/no or semi-exploratory responses. There were no statistically significant within CG differences for levels of empathy and other types of provider responses

There were statistically significant between group differences post intervention (favouring emotion handling skills IG) for mean frequencies of targeted emotion handling behaviours used with actual patients $(\mathrm{IG}(\mathrm{EH})=1.09, \mathrm{CG}=0.47, \mathrm{P}<0.05$, and with simulated patients IG $(\mathrm{EH})=3.23, \mathrm{CG}=1.35, \mathrm{P}<0.001)$ and for mean frequencies of targeted emotion handling and problem defining behaviours used with actual patients $(\mathrm{IG}(\mathrm{EH})=1.87, \mathrm{CG}=1.06$, and with simulated patients $\mathrm{IG}(\mathrm{EH})=6.00, \mathrm{CG}=3.52, \mathrm{P}<0.01)$. There was statistically significant between group differences post intervention (favouring problem defining skills training group) for mean frequencies of targeted problem defining skills used with actual patients (IG $(P D)=$ $1.16, \mathrm{CG}=0.59, \mathrm{P}<0.05$, and with simulated patients $\mathrm{IG}(\mathrm{PD})=4.43, \mathrm{CG}=2.17, \mathrm{P}<0.001$ ) and for mean frequencies of targeted emotion handling and problem defining skills with actual patients $(\mathrm{IG}(\mathrm{PD})=1.90, \mathrm{CG}=1.06, \mathrm{P}<0.05)$ but not with simulated patients. Providers trained in problem defining skills recognised a significantly greater amount of emotional problems and distress than the CG in patients previously identified as having high emotional 
Table 1. Patient centred training for providers versus control: Consultation processes (Continued)

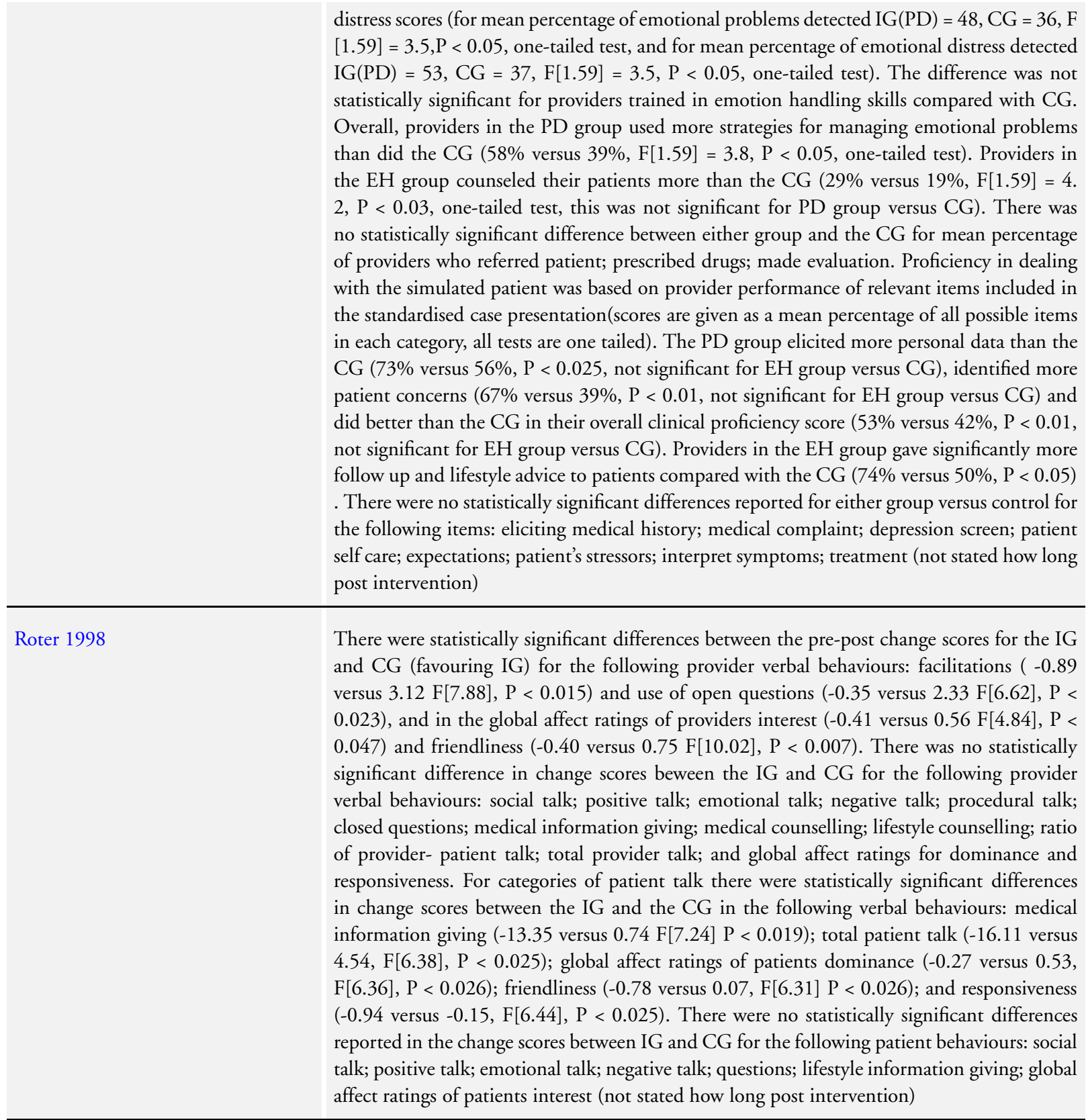

Smith 1998
At approximately one month post intervention, for ratings of providers' data gathering skills in interviews with actual patients, there were statistically significant differences between the post test means of the IG and CG for the following provider behaviours: responds to emotions (IG $=4.0, \mathrm{CG}=6.3$, difference, 2.33 points on an 11 point scale [95\%CI, 1.01 to 3.64$]$ ); pursues psychosocial data $(\mathrm{IG}=2.6, \mathrm{CG}=4.6$ difference, 1.94 on an 11 point scale $[95 \% \mathrm{CI}$, 0.54 to 3.34]); uses patient centred approach ( $\mathrm{IG}=5.0, \mathrm{CG}=6.1, \mathrm{P}<0.009$ difference, 1 . 16 [95\%CI, 0.30 to 2.03$]$ ); and in overall rating ( $\mathrm{IG}=4.2, \mathrm{CG}=5.6, \mathrm{P}<0.011$ difference, 
Table 1. Patient centred training for providers versus control: Consultation processes (Continued)

1.39 [ $95 \%$ CI, 0.32 to 2.45$]$ ). There were no statistically significant differences between the two groups for the following behaviours with actual patients: encourages responses; allows talking; pursues biomedical data; dominates interview; builds rapport; tracks patient; manages interview. For ratings of data gathering skills with simulated patients there were statistically significant differences reported for the post test means of the IG and CG (favouring IG) for the following provider behaviours: encourages responses (6.0 versus $8.5, \mathrm{P}<0.001$ difference $2.53[\mathrm{CI}, 1.92$ to 3.17$]$ ); allows talking (6.6 versus $8.3, \mathrm{P}<0.001$ difference $1.72[\mathrm{CI}, 0.94$ to $2.50]$ ); responds to emotions ( 4.5 versus $7.9, \mathrm{P}<0.001$, difference 3.35 [CI, 2.31 to 4.38$]$ ) ; pursues psychosocial data ( 4.5 versus $7.8, \mathrm{P}<0.001$, difference 3.37 [CI, 1.97 to 4.76]); dominates interview (5.3 versus $4.5, \mathrm{P}<0.001$, difference -0.88 [CI, -1.33 to -0.42 ]; builds rapport (6.2 versus $7.4, \mathrm{P}<0.001$, difference 1.17 [CI, 0.63 to 1.71$])$; tracks patient $(6.3$ versus $8.2, \mathrm{P}<0.001$, difference $1.93[\mathrm{CI}, 1.07$ to 2.79$]$ ); manages interview (6.4 versus 7 . $9, \mathrm{P}<0.001$, difference 1.47 [CI 0.71 to 2.22 ]; uses patient centred approach (5.6 versus 8 . $2, \mathrm{P}<0.001$, difference 2.60 [CI, 1.75 to 3.45$]$ ); overall rating $(5.2$ versus $7.8, \mathrm{P}<0.001$, difference 2.67 [CI, 1.77 to 3.56]. No statistically significant differences between the groups were found for amount of biomedical data pursued with simulated patients. For ratings of providers' informing and motivating skills, there were statistically significant differences in the post test means between the IG and CG for the following provider behaviours with simulated patients(favouring IG): encourages responses (5.7 versus $6.7 \mathrm{P}<0.045$, difference, 1.00 [CI, 0.03 to 1.98$]$ ); dominates interview (5.9 versus $5.2 \mathrm{P}<0.039$, difference -0.68 [CI, -0.04 to $-1.32]$ ); builds rapport (6.4 versus $7.1 \mathrm{P}<0.034$, difference 0.73 [CI, 0.06 to 1.39 ]); tracks patients ( 6.6 versus $7.6 \mathrm{P}<0.027$, difference 0.95 [CI 0.12 to 1.78 ]); overall rating ( 5.6 versus $7.3 \mathrm{P}<0.004$, difference 1.73 [CI 0.63 to 2.83 ]); informs patient $(5.9$ versus $7.5 \mathrm{P}<0.018$, difference 1.56 [CI, 0.30 to 2.82$]$ ); motivates patient $(5.0$ versus $7.7 \mathrm{P}<0.001$, difference 2.65 [CI, 1.17 to 4.13 ]); willing to help (5.1 versus $7.4 \mathrm{P}<0.002$, difference 2.35 [CI 0 . 94 to 3.76]) and no statistically significant differences between the post test means of the IG and the CG for the following: allows talking; responds to emotions; pursues biomedical data; pursues psychosocial data; manages interview; and uses patient centred approach. In rating providers' management of somatisation skills with simulated patients, there were statistically significant differences between the post test mean scores of the IG and the CG (favouring IG) for the following behaviours: encourages responses (6.2 versus $7.5, \mathrm{P}<0.007$, difference 1.29 [CI, 0.38 to 2.20$]$ ); allows talking (6.3 versus $7.4, \mathrm{P}<0.004$, difference 1.13 [CI, 0 . 40 to 1.86 ]); responds to emotions $(5.2$ versus $7.6, \mathrm{P}<0.001$, difference 2.42 , [CI 1.53 to $3.31])$; builds rapport (6.3 versus $7.5, \mathrm{P}<0.002$, difference 1.22 [CI,0.47 to 1.98$]$ ); tracks patient (6.2 versus 7.9, $\mathrm{P}<0.001$, difference 1.65 [CI 0.79 to 2.51 ]); manages interview (6. 0 versus $7.5, \mathrm{P}<0.005$, difference 1.59 [CI 0.53 to 2.64 ]); uses patient centred approach (6.1 versus $7.8, \mathrm{P}<0.003$, difference 1.69 [CI 0.64 to 2.74 ]); overall rating (5.0 versus 7 . $7, \mathrm{P}<0.001$, difference 2.75 , [CI 1.65 to 3.86 ]); manages somatisation (2.2 versus $6.0, \mathrm{P}<$ 0.001 , difference 3.80 [CI 1.80 to 5.81 ]). There were no statistically significant differences between the groups in this skill category for the following: pursues biomedical data; pursues psychosocial data; and dominates interview

Thom 1999

Approximately six months post intervention, there were no statistically significant differences in the pre-post change scores between the IG and the CG for levels of provider humaneness during consultation visit

Interventions for providers to promote a patient-centred approach in clinical consultations (Review) 
Table 2. Patient centred training for providers versus control: Patient satisfaction

\begin{tabular}{|c|c|}
\hline Study ID & \\
\hline Cope 1986 & $\begin{array}{l}\text { Immediately after post intervention medical visit, there was a statistically significant difference in the mean satis- } \\
\text { faction scores between the } \mathrm{IG} \text { and the } \mathrm{CG} \text { post intervention for subscales of 'art of care' }(\mathrm{IG}=4.75 \mathrm{SD}=0.15 \text {, } \\
\mathrm{CG}=4.43 \mathrm{SD}=0.14, \mathrm{P}<0.001) \text {; technical quality }(\mathrm{IG}=4.70 \mathrm{SD}=0.19, \mathrm{CG}=4.33 \mathrm{SD}=0.17, \mathrm{P}<0.001) \text { and } \\
\text { the total satisfaction scales }(\mathrm{IG}=4.74 \mathrm{SD}=0.15, \mathrm{CG}=4.40 \mathrm{SD}=0.14, \mathrm{P}<0.001)\end{array}$ \\
\hline Langewitz 1998 & $\begin{array}{l}\text { Immediately after post intervention medical visit, there were no statistically significant between group differences } \\
\text { reported for any item of a } 14 \text { item questionnaire or in the total score (for simulated patients). There was a significant } \\
\text { increase in the proportion of simulated patients who answered 'yes' to the question: 'Would you recommend this } \\
\text { doctor to a close friend or a relative?' (from } 23 \text { of } 38 \text { interviews to } 31 \text { of } 38 \text { interviews in the IG, and remained } \\
\text { stable with } 21 \text { of } 46 \text { interviews to } 24 \text { of } 46 \text { interviews in the CG). Whereas the } 95 \% \text { CI for the odds ratio of 'yes' } \\
\text { and 'no' answers includes } 1 \text { before the intervention, CIs are } 1.36 \text { to } 13.0 \text { for the observed odds ratio of } 4.06 \text { after } \\
\text { the intervention }\end{array}$ \\
\hline Putnam 1988 & $\begin{array}{l}\text { Immediately after post intervention medical visit, there were no statistically significant before and after results } \\
\text { reported for either the IG or the CG for subscales of 'affective satisfaction' (provider warmth and patient feelings } \\
\text { of trust, confidence, freedom to express oneself etc) and in 'cognitive satisfaction' (provider information giving } \\
\text { and patient understanding of the diagnosis, etiology, prognosis, and treatment of the illness) }\end{array}$ \\
\hline Roter 1998 & $\begin{array}{l}\text { Immediately after post intervention medical visit, there were no statistically significant before and after results } \\
\text { reported for either the IG or the CG in pre/post satisfaction change scores }\end{array}$ \\
\hline Smith 1995 & $\begin{array}{l}\text { Immediately after post intervention medical visit, there was a statistically significant between group difference } \\
\text { (favouring IG) in the post test means for the following aspects of satisfaction: patient confidence in provider (IG = }\end{array}$ \\
\hline
\end{tabular}

Table 3. Patient centred training for providers versus control: Healthcare behaviours

\section{Study ID}

Putnam 1988 One week post intervention, there were no statistically significant before and after results reported for either the IG or the CG for behavioural, medication or appointment adherence

Roter 1995 There were no statistically significant differences between either of the two intervention groups (EH or PD) and control for percentage of emotionally distressed patients revisiting providers at two weeks, three months and six months after initial medical visit

Thom 1999 Approximately six months after post intervention medical visit, there were no statistically significant between group results reported for continuity with the study provider, self reported adherence to treatment, number of referrals or number of diagnostic tests 
Table 4. Patient centred training for providers versus control: Health status \& well being

\section{Study ID}

Putnam 1988 At one week after post intervention medical visit, there were no statistically significant before and after results in either the IG or the CG for patient self reported symptom improvement

Roter 1995 There was a statistically significant difference between the problem defining (PD) IG and the CG for reduction in emotional distress (at three time points) among patients previously identified as having high emotional distress scores. Results were calculated as a change score from baseline to two weeks, three months, six months (at two weeks; $\mathrm{IG}=-6.81, \mathrm{CG}=-5.21, \mathrm{P}<0.05$; at three months; $\mathrm{IG}=-8.63, \mathrm{CG}=-6.18, \mathrm{P}<0.05$; at six months; $\mathrm{IG}=-8.43$, $\mathrm{CG}=-6.41, \mathrm{P}<0.05)$

Table 5. PCT for providers+PC materials for patients vs control: Consultation processes

\section{Study ID}

Joos 1996 There was a statistically significant difference between the IG and the CG (favouring IG) in the mean proportion of visits in which all concerns were elicited (increase from $35 \%$ to $60 \%$ in IG and decrease from $52 \%$ to $44 \%$ in $\mathrm{CG}, \mathrm{F}(1$, $40)=5.013, \mathrm{P}<0.032$, (not stated how long post intervention)), and in patients' perceptions of amount of information given by provider about disease conditions (increase in IG from 3.93 to 3.96, decrease in CG from 3.92 to 3.79, F $(1,40)=4.30, \mathrm{P}<0.04$, assessed immediately after post intervention medical visit) $)$ but differences between the two groups were not significant for patients perceptions of amount of information given by provider about medications and side effects

Lewis 1991 There was a statistically significant difference between the IG and the CG (favouring IG) in the percentage of provider recommendations addressed to child or child and parent $(\mathrm{IG}=50 \% \mathrm{SD}=43 \%, \mathrm{CG}=29 \% \mathrm{SD}=41 \%, \mathrm{P}<0.05$ ) and in percentage of medication recommendations recalled by child $(\mathrm{IG}=77 \% \mathrm{SD}=35 \%, \mathrm{CG}=47 \% \mathrm{SD}=50 \%$, $\mathrm{P}<0.01)$. Differences between the two groups were not significant for number of child substantive initiations and responses, percentage of provider recommendations recalled by child, and in the total number of statements during the consultation (not stated how long post intervention)

Pill 1998 Approximately eight or nine months post intervention, there was a statistically significant difference between the IG and the CG (favouring IG) in the percentage of patients who affirmed their current behaviour (IG $=100 \%, \mathrm{CG}=81 \%$ $\mathrm{P}<0.006)$ and initiated discussion of change ( $\mathrm{IG}=50 \%, \mathrm{CG}=25 \%, \mathrm{P}<0.03$ ). There were no significant between group differences for percentage of patients who decided topic to discuss; percentage of consultations in which any target was set; percentage of patients actually setting a target; and percentage of patients taking lead in target setting

Table 6. PCT for providers+PC material for patients vs control: Patient satisfaction

\section{Study ID}

Joos 1996 Immediately after the post intervention medical visit, there were no statistically significant differences between the IG and the CG post intervention for satisfaction scores

Lewis 1991 Immediately after the post intervention medical visit, there was a statistically significant difference between the IG and the CG post intervention (favouring IG) for child satisfaction with consultation visit (on a four point scale, $I G=3.30$ $\mathrm{SD}=0.52, \mathrm{CG}=3.10 \mathrm{SD}=0.51, \mathrm{P}<0.05)$. There were no statistically significant differences between groups post 
Table 6. PCT for providers+PC material for patients vs control: Patient satisfaction (Continued)

intervention for parent's satisfaction with consultation visit

Pill 1998 There was a statistically significant before and after result for the CG post intervention for satisfaction with recent consultations and treatment received (before $=12.50, \mathrm{SD}=2.13$; after $=13.03, \mathrm{SD}=1.76, \mathrm{P}<0.02$ ). There was no statistically significant change in the intervention group (before $=13.14, \mathrm{SD}=1.12$; after $=13.03, \mathrm{SD}=1.49$, data was collected at recruitment and nine and 18 months post intervention)

Table 7. PCT for providers+PC material for patients vs control: Healthcare behaviours

\section{Study ID}

Joos 1996 At three months after post intervention medical visit, there were no statistically significant differences between the IG and the CG for mean proportion of patients who adhered to their medications or at 12 months for the mean proportion of patients who failed to report for one or more scheduled general medicine clinic visit in the one-year intervals before and after the intervention

Pill 1998 At 18 months after post intervention medical visit, there were no statistically significant differences between the IG and the CG for attendance rates at practice over a 12 month period

Table 8. PCT for providers+PC materials for patients vs control: Health status \& well being

\section{Study ID}

Lewis 1991 There were no statistically significant differences between the IG and the CG for mean levels of reported anxiety (not stated how long after post intervention visit)

Pill 1998 Of the eight sub-scales comprising the SF-36, at nine and 18 months after post intervention medical visit, there was one statistically significant difference between the IG and the CG (favouring the CG) for physical functioning, as measured by self-reports of limitations to everyday activities $(\mathrm{P}<0.02)$. There were no statistically significant differences reported between the two groups 18 months after recruitment for glyco-Hb readings, BMI, weight in KG, diastolic and systolic $\mathrm{BP}$, and in the number of complications experienced

Table 9. PCT for providers+condition specific training for both: Consultation processes

\section{Study ID}

Clark 1998 On average two months after post intervention medical visit, parents of the children in the IG were significantly more likely than the CG to report that the pediatrician was reassuring and encouraging (IG $=4.63 \mathrm{CG}=4.42, \mathrm{P}<0.006$ ) ; described how child should be fully active ( $\mathrm{IG}=71 \% \mathrm{CG}=59 \%, \mathrm{P}<0.007$ ), and; and gave information to relieve specific worries $(\mathrm{IG}=4.1 \mathrm{CG}=3.9, \mathrm{P}<0.007$ ). There were no statistically significant differences between the groups in the percentage of parents who reported that pediatricians described at least one of three goals: child should sleep through the night; have no symptoms when active; be fully active. There were also no statistically significant differences between IG and CG parents in terms of feeling they knew how to make decisions about managing asthma at home. Parents of children in the IG were significantly more likely than the CG to report that the pediatrician had prescribed inhaled anti-inflammatory medicine for the child ( $\mathrm{IG}=82.7 \% \mathrm{CG}=70.3 \%, \mathrm{P}<0.018$ ) and also that the pediatrician 
Table 9. PCT for providers+condition specific training for both: Consultation processes (Continued)

had given the family a written plan for adjusting the doses of the medicine at home when symptoms change (IG = $26 \% \mathrm{CG}=16 \%$ odds ratio $=1.74, \mathrm{P}<0.03)$. There were no statistically significant differences between the groups in terms of parents reporting that the pediatrician had asked the child to demonstrate how to use a metered-dose inhaler. Other provider behaviours were assessed by provider self report. We decided to exclude the self-report measures as they may reflect intention rather than practice

Table 10. PCT for providers+condition specific training for both: Healthcare behaviours

Study ID

Clark 1998 According to parent self report (on average two months after post intervention medical visit), children in the IG compared with children in the CG made significantly fewer nonemergency physician office visits for asthma in the follow up period (on average within two months of first visit; $\mathrm{IG}=1.24 \mathrm{CG}=2.25, \mathrm{P}<0.005$ ); and fewer visits to follow up an episode of symptoms ( $\mathrm{IG}=0.94 \mathrm{CG}=1.61, \mathrm{P}<0.005)$. There was no statistically significant difference between the groups for number of $\mathrm{ED}$ visits or in number of hospitalisations

Meland 1997 According to patient self report, (12 months after post intervention medical visit) there were no statistically significant differences between the IG and the CG for weekly duration of exercise and global self-evaluated level of physical activity. 12 months after the intervention there was no significant difference between the groups for the mean numbers of cigarettes smoked per day

Table 11. PCT for providers+condition specific training for both: Health status \& well being

\section{Study ID}

Clark 1998 For children not using inhaled antiinflammatory medication at baseline and using it at follow up (on average two months after post intervention medical visit), children in the IG were significantly more likely to have a lower average number of days per month with asthma symptoms during the spring and summer months (in spring, $\mathrm{IG}=9.6 \mathrm{CG}=$ $21.5 \mathrm{P}<0.01$; in summer, $\mathrm{IG}=7.2 \mathrm{CG}=20.1 \mathrm{P}<0.005$ ). Differences between the two groups were not significant for the autumn and winter months

Meland 1997 There were no statistically significant differences at 12 months after post intervention medical visit, between the IG and the CG for mean systolic and diastolic blood pressure; mean total serum cholesterol (mmol/1); total/HDLcholesterol ratio: and mean log infarction score

Table 12. PCT for providers,PC materials for patients+condition specific material for both

Study ID Patient satisfaction

Kinmonth 1998 At one year post intervention, there was a statistically significant difference between the IG and the CG for the percentage of patients reporting high satisfaction (high satisfaction defined as above the overall median score) with treatment $(\mathrm{IG}=47.1 \% \mathrm{CG}=39.8 \% \mathrm{P}<0.05)$. There was not a statistically significant difference between the two groups for mean satisfaction with sty

Interventions for providers to promote a patient-centred approach in clinical consultations (Review) 
Table 13. PCT for providers,PC materials for patients+condition specific material for both

\begin{tabular}{ll}
\hline Study ID & Patient satisfaction \\
\hline Kinmonth 1998 & $\begin{array}{l}\text { At one year post intervention, there was a statistically significant difference between the IG and the CG for the } \\
\text { percentage of patients reporting high satisfaction (high satisfaction defined as above the overall median score) with } \\
\text { treatment (IG }=47.1 \% \mathrm{CG}=39.8 \% \mathrm{P}<0.05) . \text { There was not a statistically significant difference between the } \\
\text { two groups for mean satisfaction with style of car }\end{array}$ \\
\hline
\end{tabular}

Table 14. PCT for providers,PC material for patients+condition specific material for both

\begin{tabular}{l|l}
\hline Study ID & Healthcare behaviours \\
\hline Kinmonth 1998 & $\begin{array}{l}\text { There was no statistically significant difference between the IG and the CG for the proportion of patients smoking } \\
\text { at one year post intervention and in diet and exercise scores }\end{array}$ \\
\hline
\end{tabular}

Table 15. PCT for providers,PC material for patients+condition specific material for both

\begin{tabular}{|c|c|}
\hline Study ID & Health status and wellbeing \\
\hline Kinmonth 1998 & $\begin{array}{l}\text { One year after the intervention, average blood triglyceride concentrations were significantly higher in the IG than } \\
\text { the } \mathrm{CG}(\mathrm{IG}=2.62 \text { range }=0.60-13.5, \mathrm{CG}=2.23 \text { range }=0.60-11.6, \mathrm{P}<0.02) \text { and average body mass index was } \\
\text { also significantly higher in the IG compared with the control }(\mathrm{IG}=31.3 \text { range }=19.8-51.9, \mathrm{CG}=29.5 \text { range }= \\
19.1-48.5, \mathrm{P}<0.03) . \text { Overall wellbeing scores were significantly higher in the IG compared with the } \mathrm{CG}(\mathrm{IG}= \\
48.0 \text { range }=15.0-66.0, \mathrm{CG}=45.9 \text { range }=3.0-66.0, \mathrm{P}<0.03) \text {. There were no statistically significant differences } \\
\text { between the } \mathrm{IG} \text { and the } \mathrm{CG} \text { (one year after intervention) for mean percentage of haemoglobin A1c; mean total } \\
\text { cholesterol mmol } / 1 \text {; and for mean stystolic and diastolic } \mathrm{BP}(\mathrm{mm} \mathrm{Hg}) \text {. There were also no statistically significant } \\
\text { differences between the groups reported for mean scores on diabetes specific quality of life and depressed wellbeing } \\
\text { questionnaires and on various subscales of a generic wellbeing questionnaire (depression, anxiety, and energy } \\
\text { subscales) }\end{array}$ \\
\hline
\end{tabular}

\section{A P P E N DICES}

\section{Appendix I. MEDLINE search strategy}

1 randomized controlled trial.pt.

2 controlled clinical trial.pt.

3 randomized controlled trials.sh.

4 random allocation.sh.

5 double blind method.sh.

6 single-blind method.sh.

71 or 2 or 3 or 4 or 5 or 6

8 (animal not human).sh.

97 not 8

10 clinical trial.pt.

Interventions for providers to promote a patient-centred approach in clinical consultations (Review)

Copyright @ 2012 The Cochrane Collaboration. Published by John Wiley \& Sons, Ltd. 
11 exp clinical trials/

12 (clin\$ adj25 trial\$).ti,ab.

13 ((singl\$ or doubl\$ or trebl\$ or tripl\$) adj25 (blind $\$$ or mask $\$)$ ).ti,ab.

14 placebos.sh.

15 placebo\$.ti,ab.

16 random $\$ . t i, a b$.

17 research design.sh.

1810 or 11 or 12 or 13 or 14 or 15 or 16 or 17

1918 not 8

2019 not 9

21 comparative study.sh.

22 exp evaluation studies/

23 follow up studies.sh.

24 prospective studies.sh.

25 (control\$ or prospectiv\$ or volunteer\$).ti,ab.

2621 or 22 or 23 or 24 or 25

2726 not 8

2826 not $(9$ or 20$)$

299 or 20 or 28

30 patient-centered care/

31 patient-centered.tw.

32 patient-centred.tw.

33 person-centred.tw.

34 person-centered.tw.

35 patient-oriented.tw.

36 person-oriented.tw.

37 patient-focused.tw.

38 person-focused.tw.

39 client-focused.tw.

40 client-oriented.tw.

41 client-centred.tw.

42 client-centered.tw.

43 exp professional-patient relations/

44 professional-family relations/

45 patient participation/

46 patient care planning/

47 decision making/

48 exp education, professional/

49 inservice training/

50 (43 or 44$)$ and ( 45 or 46 or 47 or 48 or 49 )

5130 or 31 or 32 or 33 or 34 or 35 or 36 or 37 or 38 or 39 or 40 or 41 or 42 or 50

5229 and 51

Interventions for providers to promote a patient-centred approach in clinical consultations (Review) 


\section{WHAT'S NEW}

Last assessed as up-to-date: 29 December 1999.

\begin{tabular}{l|l|l}
\hline Date & Event & Description \\
\hline 6 March 2012 & Amended & Additional tables linked to text. \\
\hline
\end{tabular}

\section{H I S T O R Y}

Protocol first published: Issue 4, 2001

Review first published: Issue 4, 2001

\begin{tabular}{l|l|l}
\hline Date & Event & Description \\
\hline 10 September 2008 & Amended & Converted to new review format. \\
\hline
\end{tabular}

\section{CONTRIBUTIONS OFAUTHORS}

SL, ZCS, VE, MZ and JD applied the inclusion criteria, assessed the quality, extracted the data for the included studies and conducted the qualitative analysis. SL and ZCS drafted and revised the manuscript with input from the other review authors.

\section{DECLARATIONSOF INTEREST}

None

\section{SOURCES OF SUPPORT}

\section{Internal sources}

- Medical Research Council, South Africa.

\section{External sources}

- Health in Partnership initiative, Department of Health, UK.

- Department for International Development, UK.

- Nuffield Commonwealth Programme, UK.

- Chief Scientist Office of the Scottish Executive Health Department, UK. 


\section{INDEX TERMS}

\section{Medical Subject Headings (MeSH)}

Clinical Trials as Topic; Health Personnel [*education]; Intervention Studies; Patient Participation; Patient-Centered Care [ ${ }^{*}$ methods]; Physician-Patient Relations

\section{MeSH check words}

Humans 